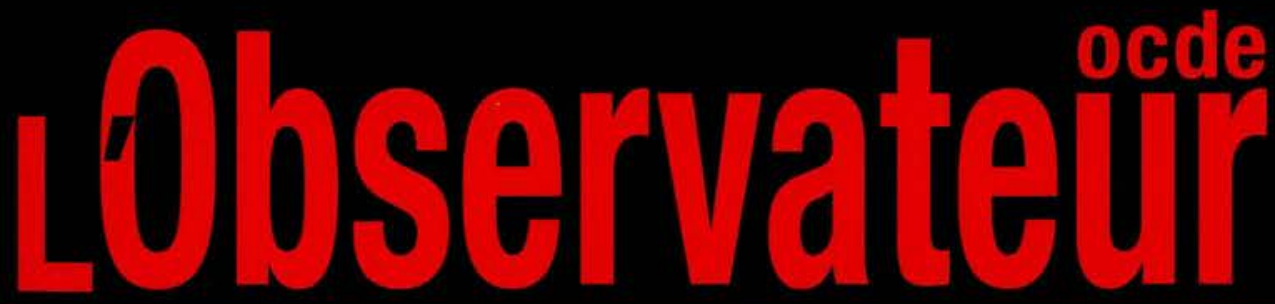

№ 269 Octobre 2008

Le Modèle de convention fiscale a $\mathbf{5 0}$ ans

Multinationales, bons salaires?

Forte pression fiscale

Palmarès universitaires

en question

Pour une aide plus efficace

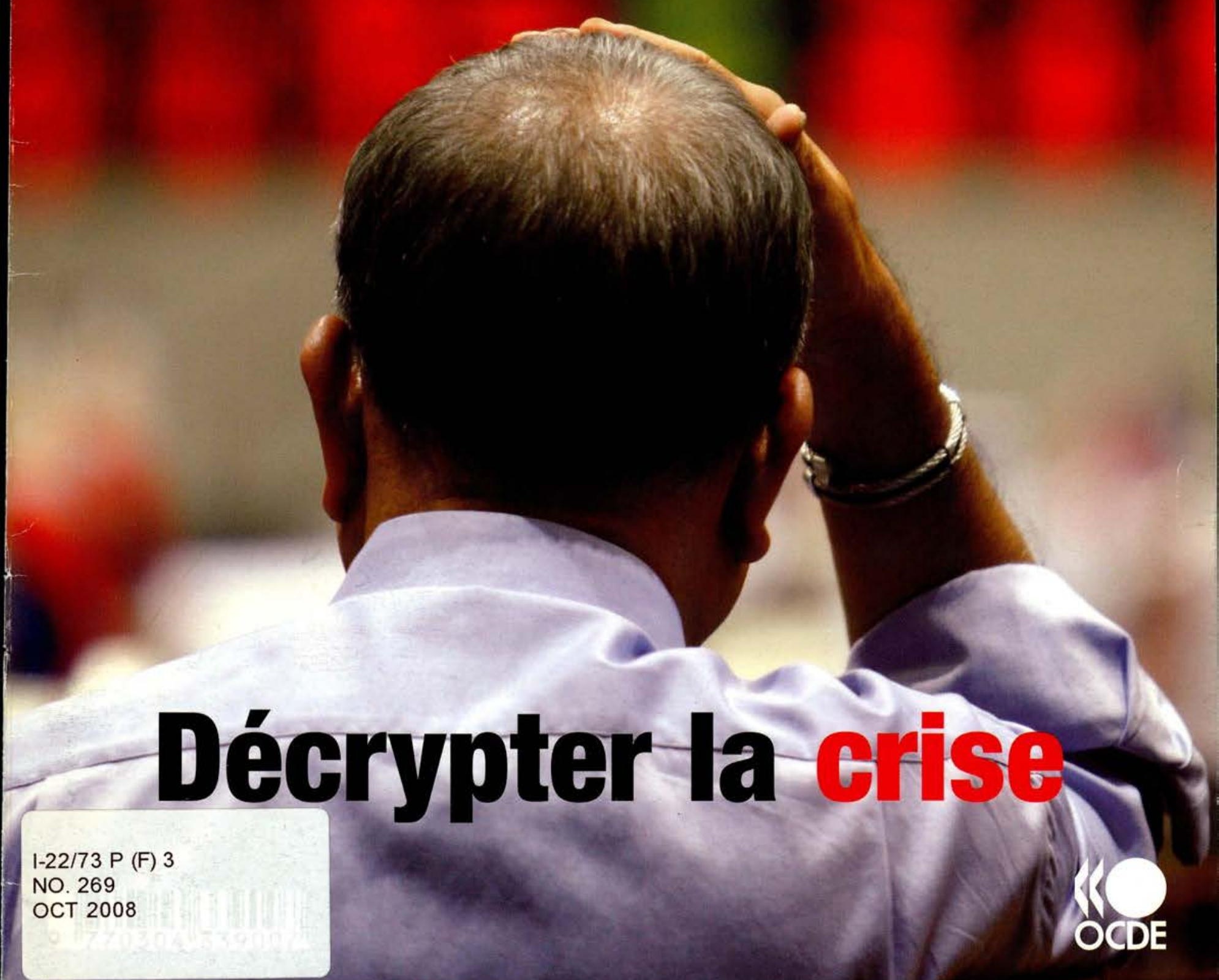




\section{Plus vert.}

L'Airbus A380 a été conçu pour être globalement plus vert. Cette volonté d'agir pourl'environnement ne se retrouve pas uniquement dans son design extrêmement performant et sa nouvelle génération de moteurs. Elle est beaucoup plus globale, elle vient d'un engagement fort pris par Airbus pour réduire l'impact de son avion sur l'environnement. Airbus est le seul avionneur de toute l'industrie aéronautique à avoir reçu, pour tous ses sites de production et tous ses produits, la certification environnementale ISO 14001, une des plus strictes au monde. L'A380 est donc un avion plus vert, à toutes les étapes de son cycle de vie, de son assemblage jusqu'à son démontage. Airbus A380. See the bigger picture.*

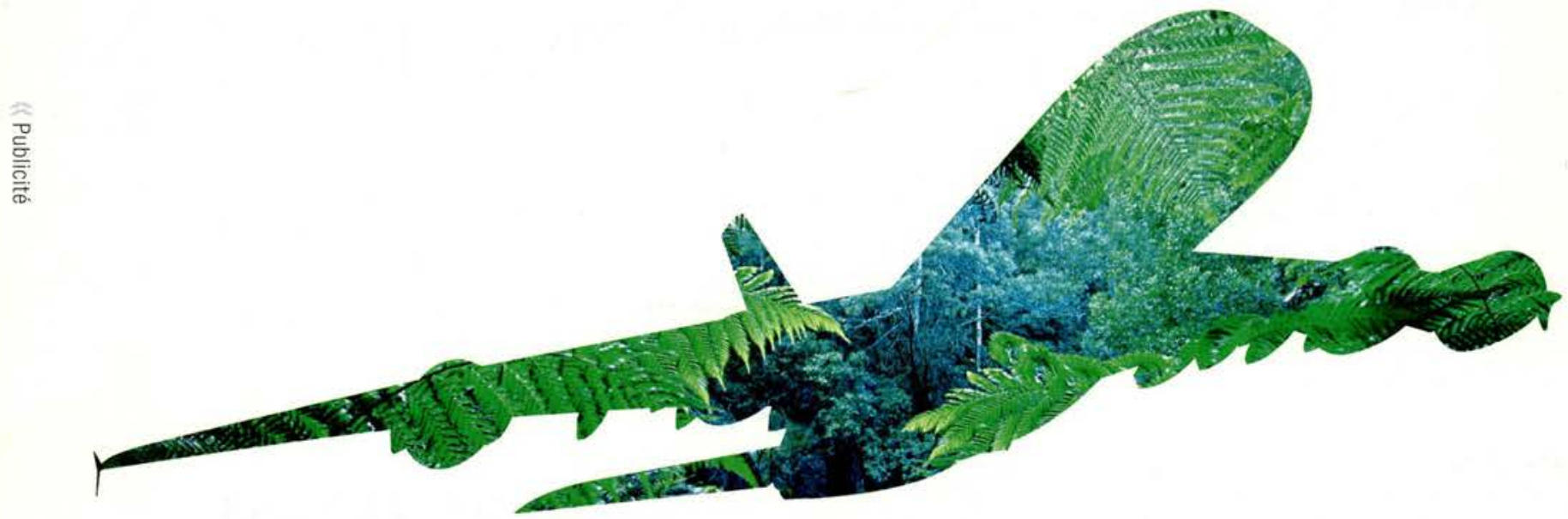




\section{COURRIER DES LECTEURS}

2 Investir contre la faim ; Une vérité fiscale

\section{ÉDITORIAL}

3 De la crise financière à la récession économique - Le grand défi : restaurer la croissance Angel Gurria

\section{EN BREF}

4-5 Royaume-Uni : améliorer les lois anti-corruption ; Égalité à conquérir ; Économie ; Best of ; Plus de transparence ; Verbatim ; Brèves

\section{ÉCONOMIE}

7 La crise financière et l'économie Entretien avec Klaus Schmidt-Hebbel

9 Protéger l'épargne

10 Le Modèle de convention fiscale de l'OCDE : les raisons d'un succès Jeffrey Owens et Mary Bennett

12 Un modèle à célébrer

Peter A. Barnes, General Electric

\section{SOCIÉTÉ}

15 Les multinationales favorisent-elles les salaires et les conditions de travail ?

Alexander Hijzen et Paul Swaim

18 Sortir du rang

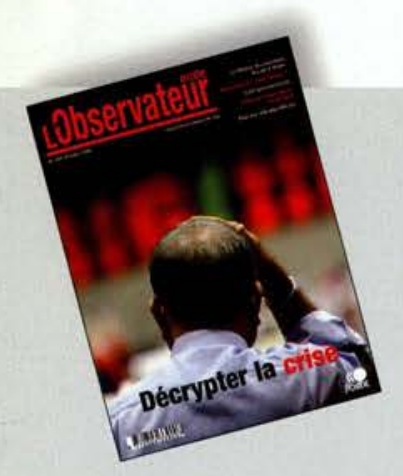

En couverture Décrypter la crise LObservateur de l'OCDE Photo : Darren Whiteside/Reuters

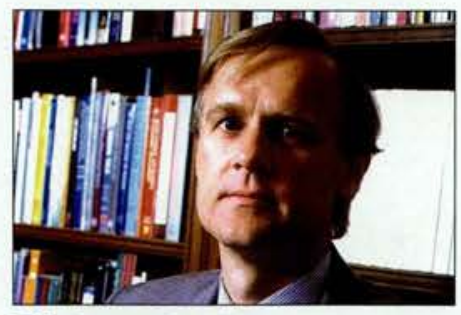

Réflexions sur la crise, page 7

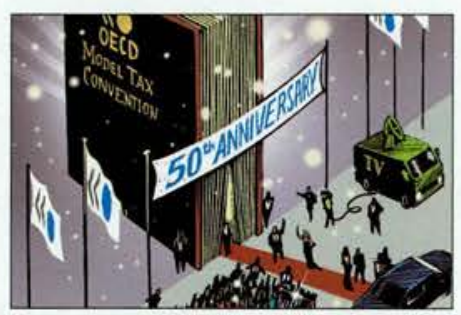

Les 50 ans du Modèle de convention fiscale, page 10

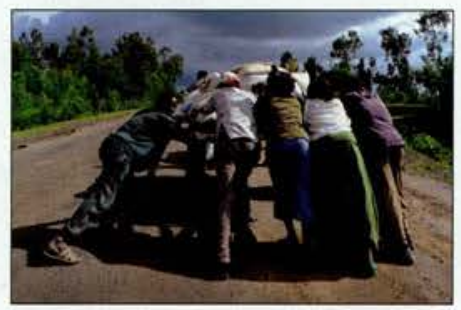

Pour une aide plus efficace, page 22

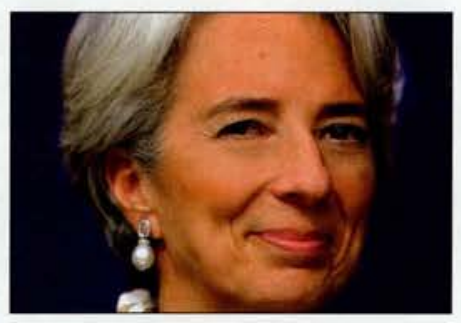

Réunion ministérielle, page 29

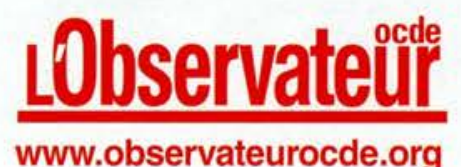

\section{DÉVELOPPEMENT}

$\begin{array}{ll}22 & \text { Pour une aide plus efficace } \\ 25 & \begin{array}{l}\text { Rééquilibrer la richesse des États } \\ \text { Javier Santiso }\end{array}\end{array}$

\section{OCDE.ORG}

29 Réunion du Conseil au niveau des ministres: Ouverture, réformes et économie du changement climatique

30 Visite du président des États-Unis ; Forum de l'OCDE : N'oublions pas la planète !; Internet stratégique

31 Thomas Bata ; Discours récent d'Angel Gurría ; Nouveaux ambassadeurs

32 Calendrier ; Frankie.org

\section{LIVRES}

33 Lécole de demain ; Recrutement éthique

34 SourceOCDE : Nouvelles publications

37 Sélection sur la fiscalité

38 Nemo-technique BON DE COMMANDE

\section{BANQUE DE DONNÉES}

$41 \quad \begin{aligned} & \text { Santé économique? ; Hausse des } \\ & \text { prix }\end{aligned}$
$42 \quad$ Indicateurs économiques
$44 \quad \begin{aligned} & \text { Retour du pic fiscal ? ; } \\ & \text { Demande de migrants peu qualifiés }\end{aligned}$




\section{LObservateulf}

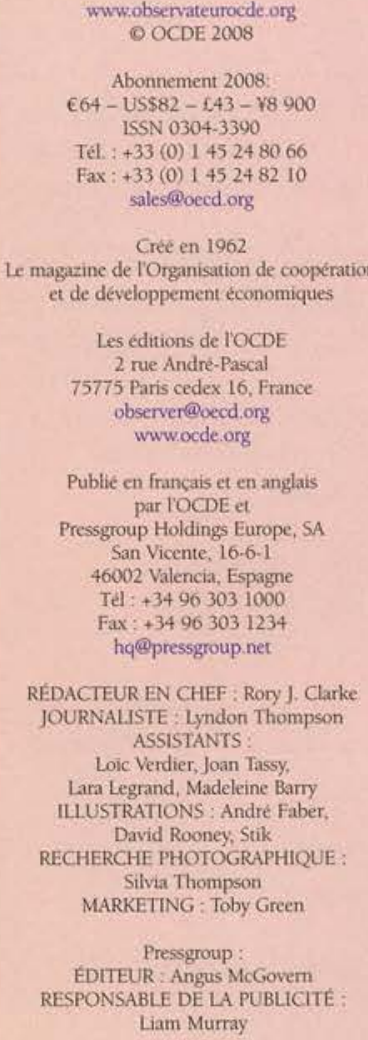

Les demandes de reproduction ou de traduction totales ou partielles des articles de VObservateur de TOCDE doivent érte adressees au chef des editions de IOCDE: 2 rue Andre-Pascal,

75775 Paris, cedex 16, Erance.

Les articles signés expriment Popinion de leurs auteurs et non pas nécessairement celle de TOCDE

Les articles reproduits ou traduits doivent étre accompagnés de la mention - Reproduit (ou Imaduit) de l'Obienateur de l'OCDE = et de

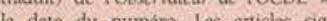
la date du numero. Les articles signés ne peuvent être reproduits ou traduits qu'avec leur signature. Deux exemplaires significatifs doivent etre envoyés au rédacteur en chef. Toute correspondance doit etre adressée au rédacteur en chef. La redaction n'est pas tenue de rendre les manuscrits non sollicites.

\section{Votre fenêtre sur l'OCDE}
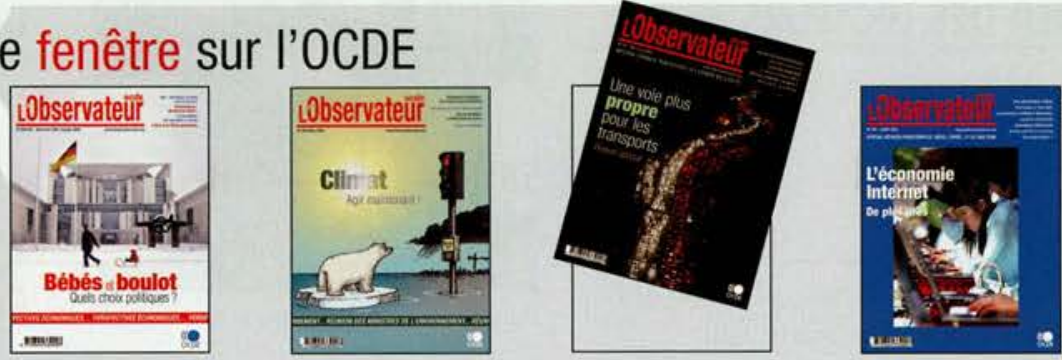

Abonnez-vous aujourd'hui au magazine primé* de l'OCDE sur www.observateurocde.org, ou utilisez le bon de commande page 38. En supplément gratuit, recevez L'OCDE en chiffres, un recueil de données original et pratique.

*Recommandé par le jury au Prix 2002 de * the Association of Learned and Professional Society Publishers », Royaume-Uni.

\section{Investir contre la faim}

Comme l'indique votre article "Prix alimentaires: grains de vérité ", la réponse à la crise alimentaire devrait associer des stratégies de court et de long terme, y compris par des politiques encourageant la croissance et le développement et améliorant la productivité agricole (n² 267, mai-juin 2008).

Une plus forte croissance agricole est essentielle pour la croissance économique globale, et pour atteindre le premier Objectif du millénaire pour le développement réduire la pauvreté et la sousnutrition de moitié d'ici à 2015.

Dans une étude récente, l'Institut de recherche international sur la politique alimentaire montre que linvestissement public supplémentaire requis pour atteindre le premier Objectif serait de 14 milliards de dollars par an pour l'ensemble des pays en développement. Pour la seule Afrique sub-saharienne, ce montant varie entre 3,8 et 4,8 milliards de dollars par an. La croissance et les ressources financières nécessaires dans chaque pays dépendent des progrès effectivement réalisés dans la réduction de la pauvreté, et de la place de l'agriculture dans l'économie.

En l'état actuel des choses, il sera très difficile d'atteindre le premier Objectif de développement. Mais si les gouvernements nationaux et les divers acteurs du développement investissent intelligemment dans lagriculture, nous pouvons surmonter la crise alimentaire mondiale et réduire la pauvreté chronique et la faim à long terme.

Shenggen Fan et Mark Rosegrant Institut de recherche international sur la politique alimentaire, Washington, D.C.

\section{Une vérité fiscale}

Votre article sur les pratiques fiscales dommageables soulève certaines questions sur les impératifs commerciaux des centres financiers internationaux ( ${ }^{\circ} 267$, mai-juin 2008). Si la surveillance de l'OCDE a pu, à l'origine, être mal accueillie, sa discipline a joué un rôle déterminant dans une période sans précédent d'innovation et de créativité. Gouvernements, régulateurs des marchés financiers et fournisseurs de biens et services ont dû collaborer plus étroitement pour élaborer des solutions compatibles avec les standards internationaux.

Les plus brillants cervaux de la finance ont creé de nouveaux régimes de fonds, le régime fiscal du zéro-dix pour les sociétés, de nouvelles structures de fiducie ainsi que des cadres de conformité plus simples et plus efficaces. La concurrence est devenue encore plus rude. Certains centres ont fermé, incapables d'assumer les couts d'adaptation. Mais de nouveaux centres sont apparus. Le meilleur exemple est le Centre financier international de Dubaï, qui est rapidement devenu un acteur mondial majeur.

Il a bénéficié du développement de la finance islamique. Cela a contribué à donner un nouveau souffle à Libuan, au Sultanat de Brunéi et à Bahrain. Mais quatre centres des Caraibes émergent également - Trinité-et-Tobago, la Jamaique, la Barbade et la République dominicaine.

Pour la réputation de ces centres, il est crucial que des organismes indépendants vérifient leurs standards de gouvernance.

Laffaire du Liechtenstein a mis en évidence l'éternelle bataille du secret bancaire. Elle n'est pas près de s'arrêter. Rares sont ceux qui sortent grandis de cette affaire. Ainsi, les autorités fiscales qui ont versé des sommes considérables pour obtenir des informations volées ont créé un regrettable précédent. De même, les deux autres centres financiers figurant sur la liste noire de l'OCDE (Andorre et Monaco) doivent réfléchir à leur avenir.

Dans le contexte commercial actuel, une capacité de régulation innovante et pertinente est une arme puissante pour assurer un climat d'affaires optimal à long terme.

Bob Reynolds

BusinessIFC.com info@businessifc.com 


\section{De la crise financière à la récession économique Le grand défi : restaurer la croissance}

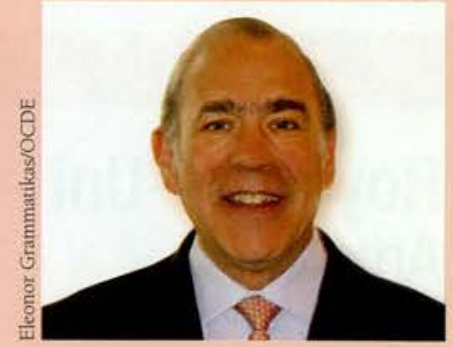

Angel Gurría, Secrétaire général de l'OCDE

$\mathrm{L}$ a crise financière qui balaie les marchés mondiaux est la plus grave depuis la Grande Dépression. À l'heure où cette crise s'étend à

l'économie réelle, le constat est douloureux. Comment les responsables politiques peuvent-ils aller de l'avant, avec des marges de manœuvre amoindries ?

L'ampleur et la durée de la crise restent incertaines, mais les coûts sont énormes : pertes liées aux crédits immobiliers à risque, effondrement des actions, plans de sauvetage, entre autres.

D'emblée, l'OCDE a salué les plans de sauvetage systémiques aux États-Unis et en Europe. L'injection de liquidités, l'octroi de garanties, le rachat d'actifs compromis et la recapitalisation du système bancaire devraient aider à relancer le crédit bancaire et à remettre l'économie sur les rails.

Les cycles d'expansion et de ralentissement ne sont pas nouveaux, mais les circonstances actuelles sont exceptionnelles. Cette fois, le système financier - cette machine qui fait tourner l'économie - s'est enrayé. Les États n'ont eu d'autre choix que d'intervenir.

Il faut désormais s'attaquer aux causes profondes. Alors que les marchés restent très nerveux, la crise a ébranlé la confiance envers les banques et les services financiers, et même envers l'économie de marché. Comment les États peuvent-ils restaurer la confiance et redresser les marchés ?

Comprendre les causes est un préalable à toute action efficace, car si l'on ne s'attaque pas à la racine du mal, les bulles et les crises reviendront. Chacun s'accorde à reconnaître que les marchés doivent être mieux contrôlés et réglementés, et que le gouvernement d'entreprise doit être renforcé. La main invisible du marché s'était tout simplement égarée. Dans une période de faibles taux d'intérêt, les banques ont prêté a tout va, alimentant une demande insatiable de produits financiers à haut risque, avec l'aval d'agences de notation pas assez rigoureuses. Le marché, déjà fort complexe, est devenu illisible. Et la chute des prix des actifs a révélé un marché contaminé par des emprunts « toxiques *.

La réaction a été soudaine et l'inversion de l'effet de levier brutale, mais si nul n'avait annoncé cette crise, elle n'était pas non plus totalement inattendue. Cette année, certains membres de l'OCDE se sont inquiétés de la multiplication des produits financiers à fort effet de levier et très peu régulés. Il y a plusieurs mois, nous avons mis en garde contre les lacunes des normes comptables et réglementaires, et souligné les carences du gouvernement d'entreprise.

Sans doute ignorait-on le véritable montant des dettes et la nature des acteurs exposés, mais il est clair que les structures réglementaires étaient incapables de contrôler des instruments tels que les titres adossés à des créances hypothécaires, les produits dérivés ou les contrats d'échange sur risque de défaillance.

Aujourd'hui, nous devons faire en sorte que les plans de sauvetage fonctionnent pour relancer le crédit et garantir les systèmes de paiement. Pour ce faire, les marchés doivent retrouver une certaine normalité, et réduire leur volatilité.
Nous devons aussi réfléchir au long terme, et l'OCDE s'emploie, aux côtés des gouvernements, des banques centrales et des organisations internationales, à promouvoir les nécessaires réformes des normes réglementaires et comptables, des pratiques de crédit et du gouvernement d'entreprise. Nous devons aussi entendre lappel des dirigeants politiques à repenser l'infrastructure de gouvernance économique mondiale, afin d'accroître son efficacité et sa légitimité.

Dans l'ensemble, il faut adopter une approche plus holistique de la gestion des risques, des questions de rémunération et de la gestion responsable et éthique. Le tout doit s'appuyer sur des structures réglementaires plus solides et une mise en œeuvre plus poussée de normes reconnues, telles que les Principes de gouvernement d'entreprise de IOCDE, ainsi que sur l'éducation financière et la sensibilisation au risque de tous les utilisateurs des marchés financiers. Les politiques doivent s'étendre au-delà du seul secteur bancaire, par exemple au logement, afin que les ménages à faibles revenus ne soient pas injustement victimes de prêts immobiliers risqués.

Ce qui compte, c'est le bien-être économique des citoyens et la protection de leur logement, de leur entreprise et de leur emploi. Notre objectif ultime est d'éviter une récession mondiale durable et généralisée, de rétablir les conditions de la croissance et d'empêcher que cette crise ne se reproduise. Dès avant la crise, l'OCDE avait prévu un ralentissement dans certains pays, et à l'heure où nous préparons le prochain numéro des Perspectives économiques de l'OCDE prévu pour fin novembre, le tableau semble plus sombre encore. On ne sait pas encore dans quelle mesure l'intervention des pouvoirs publics creusera les déficits budgétaires et pèsera sur la demande globale, mais il est clair qu'une gestion budgétaire avisée sera nécessaire. De même, le ralentissement de l'inflation devrait permettre d'assouplir la politique monétaire, mais jusqu'à quel point ?

Des mesures visant à restaurer la croissance économique sont donc essentielles. Nous devons identifier les tendances de fond et les leviers d'action qui permettront de relancer la productivité et la croissance. Mais pour y parvenir, nous devons aussi traiter d'autres dossiers comme la concurrence et l'éducation, et engager les bonnes réformes. Il faudra également renforcer les mesures sociales pour faire face à la hausse prévue du chômage. Enfin, nous ne devons pas négliger d'autres enjeux, comme les objectifs d'aide au développement et la lutte contre le changement climatique.

Ces circonstances exceptionnelles peuvent conduire à redéfinir les priorités et les cadres d'action dans plusieurs pays de l'OCDE. La crise assombrit l'horizon, mais des lueurs d'espoir existent, car la baisse des prix des matières premières offre de précieuses marges d'action et la vigueur des pays émergents rééquilibre quelque peu l'économie mondiale.

L'économie de marché est en crise et les États sont désormais aux commandes. Nos dirigeants doivent résoudre ensemble la crise financière. LOCDE, avec sa structure plurielle renouvelée et plus pertinente, est un pivot du dialogue sur les défis mondiaux et contribue à montrer la voie. En ces temps troublés, notre engagement sera indéfectible. 


\section{Royaume-Uni Améliorer les lois anti-corruption}

L e Groupe de travail de l'OCDE sur la corruption a vivement critiqué le Royaume-Uni pour son échec à conformer ses lois anticorruption à ses obligations internationales. Présidé par Mark Pieth (voir photo), le groupe préconise la mise en place d'une nouvelle législation pour corriger cela au plus vite, réitérant ainsi ses recommandations de 2003, 2005 et 2007.

Selon le groupe, la législation britannique actuelle rend très difficile les poursuites judiciaires pour corruption à l'encontre des entreprises. Bien que le Royaume-Uni ait ratifié la Convention anticorruption de l'OCDE il y a 10 ans - qui fait de la corruption des responsables étrangers un délit dans tous les États membres - aucune poursuite pour corruption à l'encontre d'une société n'y a encore abouti.

Le Groupe de travail, qui réunit les 37 pays signataires de la Convention anti-corruption, s'est dit * déçu et très préoccupé » par l'incapacité

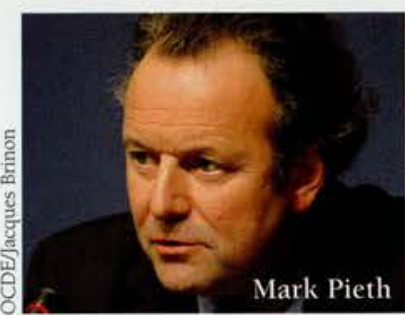

constante du Royaume-Uni à corriger les lacunes de sa législation sur la corruption d'agents publics étrangers et sur la responsabilité des entreprises pour corruption à l'étranger, réputées freiner les enquêtes.

Le groupe a reconnu des points positifs dans la lutte du RoyaumeUni contre la corruption à l'étranger, tel que la création d'une unité de police spéciale en la matière. Mais des affaires récentes ont mis en évidence la nécessité de sauvegarder l'indépendance du Bureau des fraudes graves et d'éliminer les obstacles superflus aux poursuites judiciaires. De plus, des réformes plus approfondies devraient être menées en priorité, notamment sur la responsabilité effective des entreprises, et sur la mise à l'écart de considérations d'intérêt économique national dans les décisions d'enquêtes et de poursuites.

Pour plus de détails sur le rapport sur l'application de la Convention anti-corruption de l'OCDE, voir www.oecd.org/daf/anticorruption

\section{Égalité à conquérir}

Les femmes ont $20 \%$ de chances de moins que les hommes d'avoir un emploi rémunéré, et ont un revenu inférieur de $17 \%$ en moyenne, selon la dernière édition des Perspectives pour l'emploi de l'OCDE. Au moins $30 \%$ de l'écart de revenus et $8 \%$ de l'écart dans le taux d'embauche résultent de pratiques discriminatoires sur le marché du travail. Des lois antidiscrimination sont en vigueur dans presque tous les États de l'OCDE, mais les gouvernements doivent davantage assurer leur application. Le rapport souligne les politiques contre les discriminations, et émet des recommandations, concernant l'éducation, la formation et les réformes pour inciter les chefs d'entreprise à abandonner les pratiques discriminatoires et à appliquer la législation existante. Le rapport examine également le marché de l'emploi pour les jeunes, le travail informel, la santé mentale au travail et le salaire multinational (voir article page 15).

Voir www.oecd.org/emploi

\section{Économie}

Les derniers indicateurs composites avancés (ICA) continuent de montrer une activité économique plus lente dans la zone OCDE, passant, après une baisse de 0,7 points en juillet 2008 , à 5,2 points de moins que l'année précédente. LIPC, qui reflète entre autres les carnets de commande, les permis de construire, les études d'opinion et les taux d'intérêt à long terme, laisse entrevoir un ralentissement économique dans tous les pays du G7 membres de l'OCDE. Il indique une expansion dynamique en Chine, au Brésil et en Russie, un peu moins en Inde.

L'inflation annuelle dans la zone OCDE a atteint $4,7 \%$ en aout 2008, une légère baisse, comparée aux $4,8 \%$ sur l'ensemble de l'année jusqu'à juillet. Sur une base mensuelle, les prix ont baissé de $0,1 \%$ en août, contre $0,4 \%$ en juillet. En août, les prix à la consommation énergétique ont augmenté de $20,9 \%$ sur l'année, avec une augmentation de $7,2 \%$ en juillet.

Malgré une relative reprise de la croissance des échanges commerciaux trimestriels en volume au premier semestre 2008
(2,5\% pour les exportations et $0,4 \%$ pour les importations), le volume annuel des importations des pays du G7continue de ralentir, avec $1 \%$ d'augmentation, le taux le plus bas depuis le premier trimestre 2006. Les exportations ont augmenté de 5,6 \% comparé à la même période en 2007. La croissance trimestrielle des exportations américaines a baissé de 0,2\% et les importations de $0,9 \%$

En mai 2008, le taux de chômage stagne à 5,7\% dans la zone OCDE, $0,1 \%$ de plus que le mois précédent et $0,1 \%$ de plus que l'année précédente. Il reste relativement stable dans la
Prix à la consommation Total OCDE

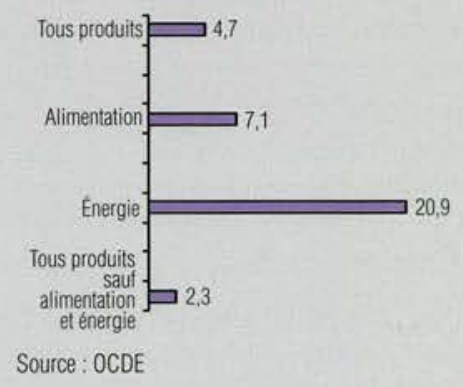

zone euro, aux États-Unis et au Japon, avec quelques baisses, comme en Allemagne où il était de $7,4 \%$, soit $1,1 \%$ de moins que l'année précédente.

Pour plus d'informations, voire www.oecd.org/statistiques

\section{Best of...}

* Un marché unifié des capitaux apparât sur lequel se font concurrence toutes sortes de financements et d'instruments d'épargne. (...) Pratiquement tous les pays de l'OCDE sont désomais partisans d'une libération des mouvements de capitaux et des services financiers et voient d'un ceil favorable les effets bénéfiques qu'elle peut avoir sur la répartition des ressources et la multiplication des produits proposés aux épargnants et des possibilités offertes aux investisseurs. ”

* Mouvements de capitaux : nouvelle libération *, n 159, aout-septembre 1989.

\section{LObservateculf}




\section{Plus de transparence}

L'Tle de Man et le Royaume-Uni ont conclu un accord bilatéral relatif à l'échange d'informations en matière fiscale. Annoncé fin septembre 2008, ce nouvel accord a été salué comme un progrès pour la transparence et l'équité dans les transactions financières transfrontalières. Depuis début 2007, les juridictions qui adhèrent aux principes de transparence et d'échange d'informations de l'OCDE ont signé 17 conventions bilatérales avec les États membres de l'OCDE. L'Allemagne et Jersey signaient la $16^{\text {ème }}$ convention en juillet.

Désormais, 35 juridictions se sont engagées à travailler avec des États membres de l'OCDE afin d'améliorer la transparence et d'établir un échange effectif d'informations en matière fiscale. Pourtant, selon un rapport publié le 29 septembre, malgré quelques avancées, les progrès de l'échange d'informations en matière fiscale sont limités. Des « restrictions significatives " dans l'accès aux informations bancaires pour raisons fiscales persistent dans trois pays de l'OCDE - l'Autriche, le Luxembourg et la Suisse - et dans plusieurs centres financiers, tels que le Lichtenstein, Panama ou Singapour. De plus, plusieurs centres similaires n'ont pas réellement mis en œuvre leurs engagements.

Coopération fiscale 2008 : Vers l'établissement de règles du jeu équitable est disponible sur www.oecd.org/ctp/pfd

\section{Verbatim}

" Voir le berceau des subprimes (...) retrouver aussi vite le chemin de la croissance alors que l'Europe, réputée vertueuse avec ses " fondamentaux sains ", glisse sur celui de la récession, ce n'est pas seulement un comble. C'est une humiliation, une de plus, pour les Européens. »

Pierre-Antoine Delhommais, Le Monde, 8 septembre 2008

« Investisseurs et créanciers faisaient confiance à n'importe qui, ils n'ont désormais plus confiance en personne. "

Martin Wolf, Financial Times, 7 octobre 2008

« Le défi politique le plus urgent (...) est

d'assurer la confiance dans les transactions. "

Le président coréen Lee Myung-bak, non pas sur la crise financière, mais sur l'économie Internet, cité par le Chosun Ilbo, 18 juin 2008. Voir aussi page 30.

\section{Brèves}

En 2006, les dépenses de santé ont augmenté d'un peu plus de $3 \%$ en moyenne dans la zone OCDE, le taux le plus bas depuis 1997. Mais les dépenses demeurent inchangées en proportion du PIB par rapport à 2005. L'édition en ligne Éco-Santé OCDE regroupe des données de l'OCDE, d'Eurostat et de l'OMS, et présente les dépenses par type de biens et de services, fournisseurs de soins médicaux et sources de financement. Ces données sont disponibles en anglais, français, allemand, italien, espagnol, japonais et russe.

Voir www.oecd.org/librairie et www.oecd.org/sante

Selon un récent rapport, la pollution des rivières, des lacs, et des zones aquifères dépasse les seuils recommandés pour l'eau potable dans les zones agricoles de nombreux pays membres de l'OCDE. D'après Performance environnementale de l'agriculture dans les pays de l'OCDE depuis 1990, des niveaux excessifs de nitrates, de phosphore ou de pesticides ont été trouvé dans plus d'un centre de contrôle sur 10 dans 13 pays membres de lOCDE. La contamination par les exploitations agricoles des eaux côtières pose également problème. Depuis 1990, l'utilisation de pesticides dans la zone OCDE a diminué mais la persistence de polluants, pourtant interdits, dans l'eau et les sols, demeure préoccupante. Ce rapport, qui examine également la diminution des ressources en eau, les subventions, les fermes biologiques et la gestion des exploitations, est disponible sur www.oecd.org/agriculture-fr et les données sur www.oecd.org/tad/env/indicateurs.

En matière d'éducation, avec l'augmentation du nombre d'étudiants à l'université, les gouvernements auront de difficiles décisions à prendre en termes de financement et de qualité. Selon Regards sur l'éducation 2008, les taux d'entrée à l'université ont presque doublé en moyenne dans la zone OCDE ces 10 dernières années. Or, dans de nombreux pays, le financement de l'enseignement supérieur est à peine maintenu, et chute parfois. Le financement de l'enseignement supérieur est toujours majoritairement public dans la plupart des pays de l'OCDE, mais les dépenses moyennes privées ont fortement augmenté ces dernières années. Voir www.oecd.org/education, et www.oecd.org/librairie pour commander Regards sur l'éducation.

D'après les Perspectives des migrations internationales 2008 , les pays développés devraient adapter leur politique de migration des travailleurs à la demande de main-d'œuvre de tous les secteurs économiques, et pas seulement à celle de travailleurs hautement qualifiés. Tandis que les pays de l'OCDE se concurrencent pour attirer les plus qualifiés, beaucoup sont réticents à accepter les immigrants moins qualifiés, alors qu'une forte demande existe. De fait, le rapport constate une demande continue de travailleurs peu qualifiés dans le secteur des soins à domicile, des métier liés à l'alimentation et de la construction. Le rapport montre également que les politiques qui poussent les migrants au retour n'ont qu'un impact limité. Environ 4 millions de personnes ont migré dans des pays membres de l'OCDE en 2006, sur une base de type permanent, une augmentation de $5 \%$ en 2005.

Voir page 44 et www.oecd.org/migrations

Selon un nouveau rapport, la Hongrie devrait investir plus dans la recherchedéveloppement pour stimuler son économie. Malgré ses progrès économiques, ses dépenses en R-D était inférieures de moitié à la moyenne de l'UE en 2006 : 0,48\% du PIB contre $1,1 \%$. Pour y remédier, l'OCDE recommande à la Hongrie d'améliorer son système scientifique et technologique et de mettre plus l'accent sur l'innovation dans les PME, y compris les services.

Voir Hongrie : Examens de l'OCDE des politiques d'innovation 2008 sur www.oecd.org/librairie

Le Pérou est devenu le $41^{\text {ème }}$ signataire de la Déclaration de l'OCDE sur l'investissement international et les entreprise multinationales. En y adhérant, le Pérou s'engage à traiter les investisseurs étrangers de la même façon que les investisseurs nationaux et à promouvoir des comportements commerciaux responsables. En contrepartie, le pays bénéfice des mêmes garanties pour ses investisseurs à l'étranger.

Voir www.oecd.org/daf/investissement 


\section{EDF et Toyota ont annoncé}

\section{un partenariat technologique en Europe relatif aux véhicules hybrides rechargeables}

EDF et Toyota ont récemment annoncé un partenariat technologique portant sur l'évaluation de véhicules hybrides rechargeables en Europe qui vise à développer des solutions pour la commercialisation future de véhicules hybrides rechargeables, aujourd'hui au stade du prototype. L'objectif est de réduire l'impact environnemental de l'automobile, particulièrement en milieu urbain.

Les véhicules hybrides rechargeables sont intégrés depuis le mois d'octobre dans la flotte d'EDF pour y être testés sur le réseau routier français, dans des conditions d'utilisation normales. Les tests routiers des véhicules hybrides rechargeables ont commencé en France à l'automne et pourront être étendus à l'avenir à d'autres pays européens. Équipés de la technologie hybride Toyota, les véhicules peuvent également être rechargés sur une prise électrique.
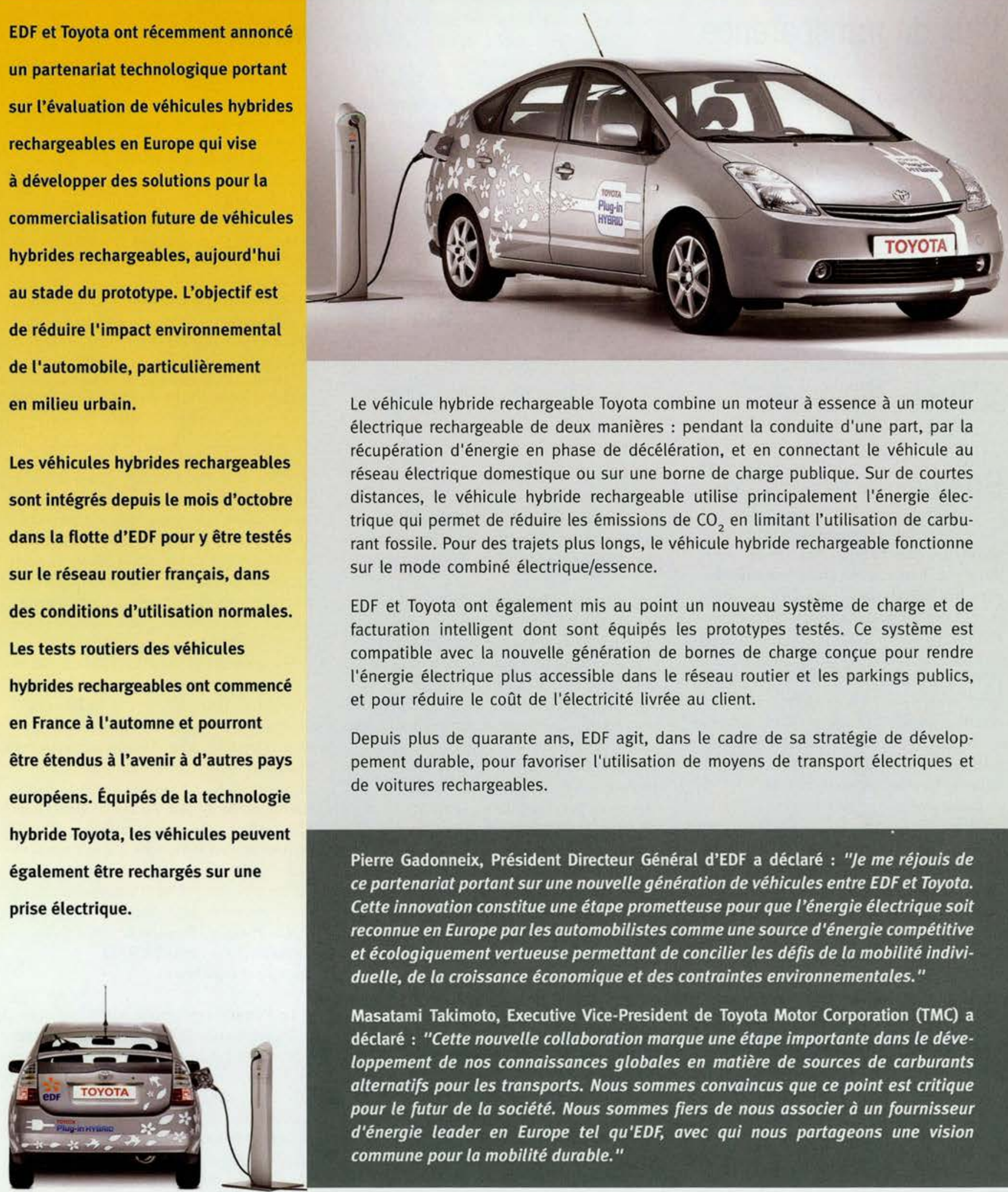

Le véhicule hybride rechargeable Toyota combine un moteur à essence à un moteur électrique rechargeable de deux manières : pendant la conduite d'une part, par la récupération d'énergie en phase de décélération, et en connectant le véhicule au réseau électrique domestique ou sur une borne de charge publique. Sur de courtes distances, le véhicule hybride rechargeable utilise principalement l'énergie électrique qui permet de réduire les émissions de $\mathrm{CO}_{2}$ en limitant l'utilisation de carburant fossile. Pour des trajets plus longs, le véhicule hybride rechargeable fonctionne sur le mode combiné électrique/essence.

EDF et Toyota ont également mis au point un nouveau système de charge et de facturation intelligent dont sont équipés les prototypes testés. Ce système est compatible avec la nouvelle génération de bornes de charge conçue pour rendre l'énergie électrique plus accessible dans le réseau routier et les parkings publics, et pour réduire le coût de l'électricité livrée au client.

Depuis plus de quarante ans, EDF agit, dans le cadre de sa stratégie de développement durable, pour favoriser l'utilisation de moyens de transport électriques et de voitures rechargeables.

Pierre Gadonneix, Président Directeur Général d'EDF a déclaré : "Je me réjouis de ce partenariat portant sur une nouvelle génération de véhicules entre EDF et Toyota. Cette innovation constitue une étape prometteuse pour que l'énergie électrique soit reconnue en Europe par les automobilistes comme une source d'énergie compétitive et écologiquement vertueuse permettant de concilier les défis de la mobilité individuelle, de la croissance économique et des contraintes environnementales."

Masatami Takimoto, Executive Vice-President de Toyota Motor Corporation (TMC) a déclaré : "Cette nouvelle collaboration marque une étape importante dans le développement de nos connaissances globales en matière de sources de carburants alternatifs pour les transports. Nous sommes convaincus que ce point est critique pour le futur de la société. Nous sommes fiers de nous associer à un fournisseur d'énergie leader en Europe tel qu'EDF, avec qui nous partageons une vision commune pour la mobilité durable." 


\section{La crise financière et l'économie}

\section{Entretien}

Quels sont les principaux effets de la crise financière sur l'économie réelle et quelles leçons en tirer pour l'avenir? Le prochain numéro des Perspectives économiques de l'OCDE, qui paraitra le 25 novembre, répondra en partie à ces questions. Klaus Schmidt-Hebbel, nouvel Économiste en chef de l'OCDE, nous a fait part de ses premières réflexions.

L'Observateur de l'OCDE : Dans sa mise à jour de septembre, l'OCDE brosse des perspectives économiques plutôt sombres pour le G7. Quelles sont selon vous les questions majeures au regard de la crise financière, et pouvez-vous nous livrer le fruit de vos réflexions avant la parution du prochain numéro des Perspectives économiques de l'OCDE?

Klaus Schmidt-Hebbel : Notre dernière évaluation de l'économie, en septembre, est parue juste avant que les turbulences financières ne se transforment en véritable crise. Elle portait néanmoins sur les effets de trois facteurs à l'œuvre depuis mi-2007: la hausse des prix des produits de base, la contraction du marché immobilier dans plusieurs pays de l'OCDE et, déjà, les turbulences financières. Mais ces turbulences ont déclenché une crise systémique des marchés financiers mondiaux, qui concentre toutes les attentions.

Depuis mi-septembre, la confiance entre les acteurs des marchés financiers s'est évaporée, accompagnant une chute des transactions financières à court terme dans les grandes économies de l'OCDE et un effondrement des marchés boursiers mondiaux. Lorsqu'on en arrive à un blocage du crédit interbancaire, du financement par billets de trésorerie et des opérations sur les marchés monétaires, il n'y a plus de crédit pour les entreprises et les ménages. Les dépenses, la production et l'emploi pourraient potentiellement s'effondrer.

Les gouvernements et les banques centrales sont parfaitement conscients de ces énormes risques pour l'économie mondiale, comme le montrent les mesures radicales qu'ils ont prises ces dernières semaines. Ces mesures visent à sauver le système financier mondial en rétablissant la confiance et en reconstituant les bilans des institutions financières. Elles sont sans précédent par leur ampleur, par les nouveaux instruments qu'elles mobilisent, et par la coordination internationale entre grands pays qui les accompagne.

ll reste à savoir si ces mesures auront un effet rapide et efficace.

Quelles peuvent être les conséquences pour l'économie?

Au département des Affaires économiques de l'OCDE, nous élaborons nos prévisions 2009-2010 pour 30 pays membres de l'OCDE et 10 pays non membres. Elles figureront dans nos Perspectives économiques le 25 novembre. Bien entendu, notre point de vue se fondera sur les données les plus récentes disponibles et sur notre vision du déploiement des effets de la crise financière.

Notre scénario de base repose sur l'hypothèse que le blocage actuel des marchés financiers à court terme prendra fin relativement vite, mais que le désendettement et la recapitalisation des banques, de même que le rétablissement de la confiance sur les marchés, prendront beaucoup plus de temps. D'où un prolongement de conditions financières restrictives, avec ses répercussions sur le crédit et, plus généralement, sur l'accès aux financements. Dans le même temps, la demande de crédit ralentit de toute façon, car la forte baisse des prix des actifs et le sentiment général d'incertitude poussent les ménages et les entreprises à restreindre leurs dépenses.

C'est pourquoi nous prévoyons un net ralentissement de l'économie mondiale, et une récession, tôt ou tard, pour de nombreux pays de l'OCDE.

La question est de savoir pour combien de temps. La reprise sera sans doute plus lente qu'après les récents ralentissements économiques, mais son rythme dépendra largement de celui de la reprise des opérations

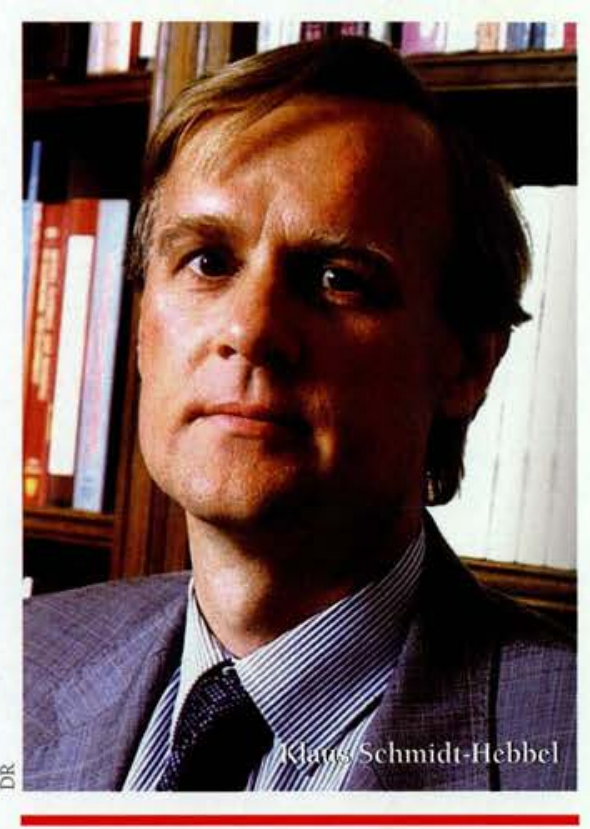

« Nous prévoyons un net ralentissement de l'économie mondiale, la question est de savoir pour combien de temps "

et du crédit sur les marchés financiers, même si le crédit reste relativement limité, au moins par rapport à la période 2002-2007.

Mais au-delà des interventions sur les marchés financiers, n'oublions pas que la politique macroéconomique doit également jouer un grand rôle pour atténuer l'impact récessif de la crise financière. Autrement dit, les économies s'affaiblissant rapidement et l'inflation refluant, certains pays de l'OCDE pourront se permettre de baisser les taux d'intérêt, et de stimuler l'activité par des mesures budgétaires ponctuelles, temporaires et ciblées.

Quels sont selon vous les principaux risques?

Il y a deux grands risques, liés entre eux. D'une part, le dégel des marchés financiers et du crédit pourrait être plus long que prévu, ce qui affecterait plus gravement les dépenses, la production et l'emploi. Cela aboutirait à une récession plus profonde et plus durable.

Lautre risque est lié au coût budgétaire encore inconnu des plans de sauvetage gouvernementaux. Une fois la crise 
financière et la récession passées, des ajustements budgétaires seront nécessaires pour préserver la confiance dans la dette publique et dans la monnaie, en particulier dans les pays qui auront secouru leurs banques au prix fort.

Mais un élément positif s'annonce également la baisse des prix du pétrole, des denrées alimentaires et des autres produits de base consécutifs au ralentissement économique mondial. Si celui-ci s'avère plus important que prévu, l'inflation diminuera davantage, les revenus réels des importateurs de produits de base augmenteront, et cela accroîtra la marge d'assouplissement des politiques monétaires.

\section{Doit-on craindre une dépression mondiale ?}

La dépression économique est un concept ambigu; on peut considérer qu'il s'agit d'une récession très profonde et très longue. Nous n'en sommes certainement pas là. Bien sûr, c'est la plus grave crise financière depuis des décennies, mais une réédition de la crise des années 1930 est hautement improbable, en partie grâce aux plans de sauvetage massifs désormais en place.

\section{Aviez-vous vu venir cette crise ?}

La plupart des économistes savent que les cycles économiques ont leur vie propre, et ils s'attendaient à ce que lextrême gonflement du crédit entre 2002 et 2007 et l'expansion économique se tassent à un moment ou à un autre. Mais il est impossible de prévoir avec précision le moment et l'intensité des récessions futures. Dans le cas présent, ni les économistes, ni les acteurs des marchés, ni même les gouvernements n'avaient prévu une crise financière de ce type et de cette ampleur. Leffondrement de la confiance et le gel du crédit après la faillite de Lehman Brothers ont constitué un choc non seulement pour le système, mais aussi pour la plupart des économistes et des acteurs du marché.

\section{Quelles leçons peut-on en tirer?}

Il est encore tôt pour le dire, mais je vois d'ores et déjà des leçons à tirer dans quatre domaines. Premièrement, tout a commencé par une crise des prêts immobiliers dits " subprimes " aux États-Unis, qui s'est progressivement étendue à d'autres marchés et à d'autres pays du fait de défaillances des marchés combinées à des faiblesses réglementaires. Les défaillances des marchés tenaient à une mauvaise gouvernance et à une structure d'incitation des dirigeants d'entreprises financières inadaptée à l'impératif de stabilité de ces entreprises ; elles tenaient aussi à l'opacité des instruments financiers et de leurs transactions, ainsi qu'à un manque d'information du public sur les bilans des institutions financières et sur leurs opérations hors bilan.

Dans le même temps, il y a eu de nombreuses omissions et carences réglementaires. Beaucoup de pays n'avaient pas de réglementation complète et unifiée des conglomérats financiers et de leurs instruments de marché, alors même que les ratios de fonds

\section{Notre tâche primordiale est de surmonter cette crise et de faire en sorte que les plus touchés en souffrent le moins possible}

propres et les règles comptables ont amplifié le mouvement conjoncturel d'endettement et de crédit bancaires. La faiblesse de la surveillance exercée par les agences de notation a également joué.

Les futures réformes réglementaires devront à lévidence viser à améliorer les modèles d'affaires, la transparence, l'information et la surveillance des institutions financières. En outre, les acteurs des marchés financiers ne doivent pas simaginer que le renflouement est la norme, et les réformes devront donc réduire au minimum le risque d'" aléa moral » dans les comportements futurs sur les marchés financiers. Enfin, sil est nécessaire de modifier profondément la régulation des marchés de capitaux et des marchés financiers, tant au niveau national qu'international, il faudra éviter le piège d'un excès de réglementation, car ceci peut aussi être très nocif, en entravant linnovation financière, l'intégration des marchés et la croissance. Plus que de nouvelles réglementations, nous réclamons une meilleure régulation.

La deuxième leçon est que nous devons faire plus d'efforts pour renforcer les composantes anticycliques des politiques budgétaires, monétaires et financières, à la fois pour atténuer lintensité des cycles futurs et pour réduire la probabilité d'une nouvelle crise mondiale.

Troisièmement, il faudra améliorer considérablement la planification d'urgence et la gestion de crise. En définitive, la crise actuelle a été gérée de façon assez aléatoire. Les gouvernements ont tardé à passer du renflouement d'urgence, ponctuel et sélectif, au sauvetage d'ensemble du système financier. Et c'est seulement très tard, après avoir privilégié lélimination des actifs toxiques, qu'ils ont opté pour une aide globale en faveur des différents postes des bilans, en garantissant les dépôts et les prêts interbancaires, en se portant acquéreurs de créances douteuses des établissements bancaires et non bancaires et en procédant à des injections de capitaux. C'est seulement à la dernière minute qu'une meilleure démarche a été adoptée.

Enfin et surtout, nous devons repenser l'architecture financière internationale. Cela nécessite une coopération internationale sur la réforme de la régulation des marchés de capitaux et des marchés financiers, des normes comptables internationales et du traitement des transactions financières internationales. Le but est de renforcer l'intégration et la stabilité des marchés mondiaux de capitaux. Nous devons aussi revoir la façon dont les institutions financières internationales peuvent aider les pays en situation critique pour leurs besoins en capitaux et leurs paiements extérieurs, comme actuellement l'Islande, la Hongrie et l'Ukraine.

Ce ne sont là que quelques leçons parmi d'autres. LOCDE peut jouer un rôle majeur pour les mettre en acte.

Vous venez de rejoindre l'OCDE après avoir passé plusieurs années à la banque centrale du Chili, pays candidat à l'adhésion à l'OCDE. En quoi votre expérience est-elle un plus pour ce nouveau poste?

C'est exact, j’ai passé les 12 dernières années de ma carrière à la banque centrale du Chili et les huit années précédentes à la Banque mondiale. J'ai la double citoyenneté allemande et chilienne, mes enfants sont nés aux États-Unis, ma femme est chiliennogermano-costaricaine, j'ai vécu une partie de mon adolescence au Brésil et j'adore la France. Je me sens véritablement plus citoyen du monde que ressortissant d'un pays, ce qui donne une forte motivation pour travailler à l'OCDE. Ma vie professionnelle associe une expérience universitaire - je suis professeur titulaire à I'Université catholique du Chili et professeur associé à l'Université du Chili et je viens juste de quitter la présidence de l'Association économique chilienne - à des activités de recherche et de conseil à la Banque mondiale et à la banque centrale du Chili. Jai aussi travaillé comme consultant auprès de 25 pays 
industrialisés et émergents et d'un grand nombre d'organisations internationales.

Je me suis spécialisé dans la croissance et les réformes structurelles, la macroéconomie et ses implications politiques, l'économie internationale et le développement, ainsi que les marchés financiers et les systèmes de retraite. Jai travaillé à la fois dans et sur les économies en développement, émergentes ou industrielles. Je n'ai donc pas seulement analysé les mutations de l'économie mondiale ; je comprends les pressions que subissent les pays, riches ou pauvres.

Je n'aurais pas pu rejoindre l'OCDE à un moment plus exigeant, aussi bien pour nos pays membres que pour moi-même. Mais c'est un défi intellectuel que je suis prêt à relever.

Selon moi, les enjeux sont énormes, mais ont le mérite d'être clairs. Notre tâche primordiale est de nous employer activement à surmonter cette crise, et à faire en sorte que les plus touchés en souffrent le moins possible. Nous devons aussi faire encore davantage pour évaluer les options politiques et recommander les réformes structurelles nécessaires à une croissance plus forte et plus stable dans les pays membres, et pour améliorer le bien-être de leur population. Enfin, puisque les économies émergentes auront de plus en plus de poids dans l'économie mondiale, il nous faudra travailler à lintégration de ces économies au niveau mondial et au resserrement de leurs liens avec nos pays membres. Cest pourquoi il faut soutenir pleinement la nouvelle orientation mondiale de l'OCDE menée par Angel Gurría.

Pour finir, je tiens à vous dire que je suis à la fois très heureux et très fier de rejoindre cette organisation exceptionnelle, avec ses équipes d'économistes et de spécialistes de très haut niveau. Nous avons tous à coeur de fournir le meilleur service possible à nos pays membres et de les aider à rétablir la bonne santé de nos économies et une solide croissance à long terme.

\section{Références}

- Les Perspectives économiques de l'OCDE n 84 seront publiées le 25 novembre 2008.

- Perspectives économiques de l'OCDE n 83 , juin 2007, Paris.

- OCDE (2008), Quelles perspectives économiques pour les pays de l'OCDE Évaluation intérimaire, septembre, Paris, voir www.oecd.org/dataoecd/0/51/41229145.pdf

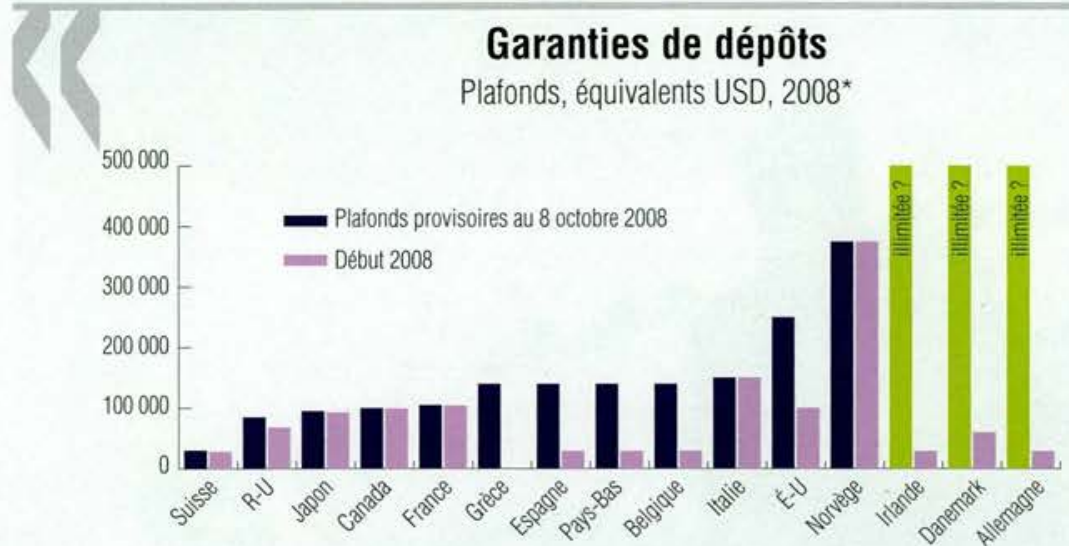

Source : Financial Market Trends No 94, vol. 2008/1, autres données de I'OCDE

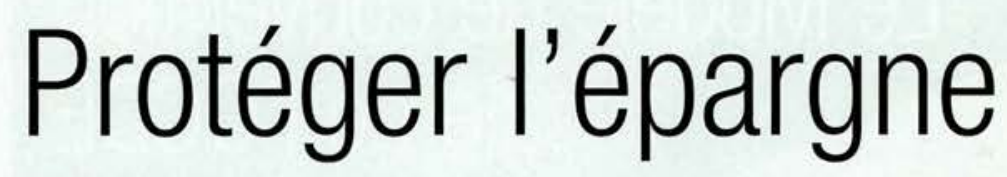

Ф ace à la plus grave crise financière depuis les années 1930, les dirigeants européens se sont engagés à protéger

l'épargne des particuliers. La plupart des pays de l'OCDE disposent déjà de mécanismes officiels et plafonnés de garantie des dépôts. Plusieurs pays ont choisi de relever provisoirement ces plafonds.

Jusqu'aux récentes déclarations suggérant linstauration de garanties illimitées, la Norvège, la France, l'Italie et le Mexique proposaient les couvertures les plus élevées. Aux États-Unis, le plafond garanti a été temporairement relevé de 100000 à 250000 dollar par compte. Le graphique montre les niveaux de garantie en vigueur début 2008 et leur situation au 8 octobre 2008 , sur la base des déclarations des gouvernements.

Pour qu'un mécanisme de garantie soit en mesure de prévenir les retraits massifs de dépôts en période de crise financière, les garanties doivent être fixées à des niveaux adéquats. Les épargnants doivent être informés de leur plafond. Or, les enquêtes auprès des consommateurs ont montré que peu d'épargnants connaissent les mécanismes existants. Dans une étude récente, l'OCDE a comparé les niveaux de garantie en vigueur en juin 2008 dans 33 pays (voir références).

Pour les partisans des mécanismes de garantie des dépôts, en rassurant les banques et les déposants, ces garanties permettent de maintenir les activités de prêt et de remboursement. Pour leurs détracteurs, ils encouragent une prise de risque excessive par les banques, protégées par un filet de sécurité public. Pour réduire cet " aléa moral ", il est essentiel de promouvoir une bonne gouvernance au sein des banques et de mettre en place un cadre de supervision solide.

Les mesures de protection financière s'articulent autour de trois composantes étroitement liées : réglementation prudentielle et supervision, prêteur en dernier ressort et garantie des dépôts. Un pays qui n'aurait développé que l'un ou deux de ces trois domaines pourrait avoir du mal à prévenir ou à résoudre des défaillances graves de son système bancaire. $\mathrm{SDB}$

* « Illimitée ? " est une interprétation des implications d'annonces ou de déclarations politiques sur le plafonnement des garanties, et du fait que les données présentées peuvent différer des plafonds en vigueur. Les données peuvent donc ne pas être strictement comparables d'un pays à l'autre.

OCDE (2008), "Financial turbulence: some lessons regarding deposit insurance", Financial Market Trends No. 94, Paris (disponible en anglais uniquement). Voir www.oecd.org/finance-fr 


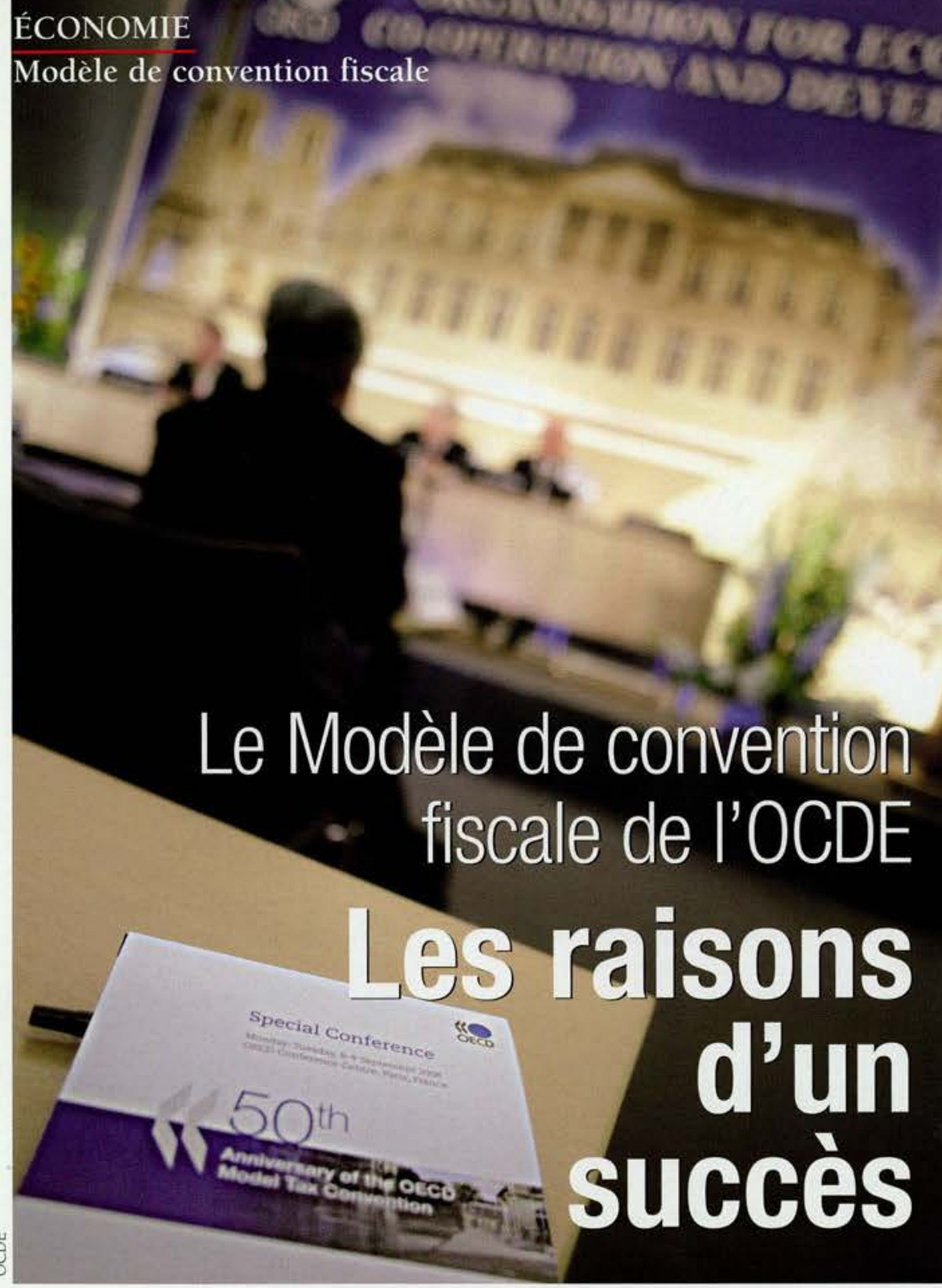

Jeffrey Owens et Mary Bennett

Centre de politique et d'administration fiscales de l'OCDE (CTP)*

\section{Le Modèle de convention fiscale de l'OCDE, qui vient de fêter} ses 50 ans, peut-il continuer à jouer son rôle : rendre la fiscalité internationale plus équitable et plus facile à maîtriser ? Probablement oui, mais ce n'est pas toujours simple.

I y a un demi-siècle, le Comité fiscal de l'Organisation européenne de coopération Léconomique (OECE), future OCDE, publia les grandes lignes d'un modèle de convention sur la fiscalité internationale. Dans le contexte d'une intégration croissante de l'économie mondiale, son objectif était d'aider entreprises et pouvoirs publics en évitant la double imposition et en empêchant la fraude fiscale. Le problème était clair : comment les États peuvent-ils fonctionnaires des services fiscaux européens qui, en 1956, décidèrent de rédiger des dispositions uniformes destinées aux conventions fiscales, sous l'égide de l'OECE. Comme tous les parents, ils ne savaient pas ce que leur enfant allait devenir.

À cette époque, le rythme de vie était plus tranquille. Les délégués se rendaient à Paris plusieurs fois par an pour des sessions de rédaction d'une semaine. Le mercredi, épuisés, ils passaient une journée à la campagne, puis reprenaient leurs travaux, ragaillardis

En 1963, un projet complet était prêt, mais il fallut attendre 1977 pour que le Modèle de convention de double imposition soit publié. Le texte de 1963 synthétisait essentiellement quatre versions antérieures, dont la première avait été publiée en 1958. C'est pourquoi le $1^{\text {er }}$ juillet 1958 est considéré comme la date de naissance du Modèle de l'OCDE.

Au départ, moins de 15 pays ont participé à la rédaction du premier texte ; en 1963 , l'OCDE s'était élargie à 20 pays. Ce sont principalement les pays membres de l'OCDE qui ont participé à la rédaction du Modèle, mais depuis 1996, le processus est ouvert aux pays non membres et aux entreprises et, chaque année, l'OCDE organise en septembre un forum mondial réunissant les hauts fonctionnaires qui travaillent sur les conventions fiscales. Nous avons également mis en place un réseau mondial de centres de formation fiscale permettant aux responsables de pays non membres d'acquérir les compétences nécessaires pour négocier et faire appliquer les conventions. Plus d'un millier d'agents fiscaux du monde entier ont suivi ces cours.

Aujourd'hui, plus de 3000 conventions fiscales dans le monde s'inspirent du Modèle de l'OCDE. Une trentaine de pays non membres ont donné leur avis sur le Modèle. Nous ne sommes pas toujours d'accord entre nous, mais au moins nous connaissons nos points de désaccord.

exercer leur droit régalien à imposer des entreprises internationales en plein essor, tout en s'assurant que celles-ci ne soient soumises à d'injustes surcroîts de fiscalité dans leurs pays d'implantation ?

Le Modèle de convention fiscale de l'OCDE était né. Les modèles dits de Londres et de Mexico de la Société des Nations figuraient dans son arbre généalogique. Mais ses parents directs étaient les hauts
Le Modèle de l'OCDE s'est imposé comme l'instrument permettant de résoudre les problèmes les plus fréquents en fiscalité internationale. En assurant une harmonisation des conventions de double imposition, il offre un cadre de référence pour les négociations bilatérales et pour le règlement des différends. 
Prenons la question de la double imposition. Si une entreprise américaine vend ses produits aux États-Unis et en tire un revenu, elle devra acquitter un impôt aux États-Unis. Si elle vend aussi ses produits en France, elle risque d'être assujettie à un impôt sur le même revenu dans les deux pays. Mais quel sera le montant de cet impôt et à quelle administration devra-t-elle le payer? On perçoit aisément les

\section{Aujourd'hui, plus de 3000 conventions fiscales dans le monde s'inspirent du Modèle de l'OCDE}

conséquences négatives d'une réponse inappropriée à cette question sur les échanges internationaux, l'investissement et la confiance. Entreprises et pouvoirs publics veulent éviter toute forme de perte financière, de découragement ou de discrimination. Les conventions de double imposition contribuent à dénouer ces questions délicates en établissant des règles communes d'imposition des revenus transnationaux, afin que l'entreprise ne soit pas imposée deux fois sur le même revenu.

Le Modèle de convention fiscale de l'OCDE contribue à résoudre ces problèmes, sans être juridiquement contraignant pour autant. LOCDE formule une recommandation basée sur la position commune de ses membres, lesquels s'engagent à appliquer le Modèle et ses Commentaires, en tenant compte des réserves qui y figurent, lorsqu'ils concluent ou révisent une convention fiscale bilatérale. Les Commentaires détaillés et régulièrement mis à jour qui accompagnent le Modèle donnent des orientations sur l'interprétation du texte principal et sont une référence très utile pour les contribuables, administrations fiscales et tribunaux, des pays membres ou non membres.

Pour que cette approche non contraignante puisse fonctionner, souplesse et transparence sont de mise. Les modifications du Modèle sont systématiquement publiées à l'avance sous forme de projet, et les pays membres ont le temps de les examiner et d'apporter des changements supplémentaires. Un dialogue permanent avec les entreprises et les économies non membres est indispensable pour définir des règles fiscales judicieuses, et le Modèle s'est toujours enrichi des contributions des administrations fiscales et de l'expérience des entreprises, qui évolue au fil des ans.

Depuis 1991, le Comité des affaires fiscales a effectué des mises à jour et des modifications (en 1992, 1994, 1995, 1997, 2000, 2003, 2005 et 2008), périodiques ou ponctuelles, sans attendre de révision complète.

Prenons la mise à jour de 2008, approuvée récemment, qui comporte plusieurs modifications intéressantes inspirées des rapports établis par l'OCDE ces deux dernières années. Elle comprend une clause d'arbitrage obligatoire pour résoudre, par la procédure dite amiable, les questions difficiles non réglées, avec des commentaires sur les modalités de cette procédure.

Nous avons clarifié les modalités d'attribution de bénéfices à un établissement stable (une succursale par exemple) par le biais duquel le résident d'un pays exerce des activités dans un autre pays - question qui intéresse tout particulièrement les entreprises du secteur financier.

Nous avons également précisé l'épineux concept de "siège de direction effective ", critère décisif pour régler les cas dans lesquels des sociétés ont une double résidence à des fins fiscales, et adopté une disposition alternative qui délaisse ce critère pour s'en remettre à la procédure amiable.

\section{Perspectives pour les 50 ans à venir}

Le Modèle de convention fiscale de l'OCDE est confronté à un dilemme : comment rester ferme tout en s'adaptant aux circonstances nouvelles, et toujours plus rapidement. Certes, nous avons su relever d'autres défis, par exemple en définissant les modalités d'imposition du commerce électronique transnational ; mais de nouvelles difficultés, comme la question des fonds souverains, apparaissent régulièrement alors que les attentes des pouvoirs publics, des multinationales et du public ne cessent de croître.

Le Modèle de convention fiscale de l'OCDE est-il encore en mesure de relever ces défis ? Oui, mais voici dix points susceptibles de faire la différence ces 50 prochaines années :

1. Systématiser les clauses d'arbitrage dans les conventions. Elles seraient probablement rarement appliquées, ce qui prouverait leur efficacité, les parties parvenant à un accord sans avoir recours à un arbitrage ayant force obligatoire.

2. Veiller à une application plus cohérente des conventions fiscales.

3. Commencer à élaborer un instrument multilatéral sur la taxe sur la valeur ajoutée (TVA). Bien que 141 pays aient une TVA, de nombreuses questions importantes sont en suspens, comme le lieu de consommation.

4. Trouver le moyen d'accélérer la mise à jour des conventions s'inspirant du Modèle.

5. Insister sur le fait que l'objectif des conventions n'est pas seulement d'éviter la double imposition, mais aussi de lutter contre la fraude fiscale.

6. Associer plus étroitement les hauts responsables politiques à l'élaboration des conventions. Les conventions sont trop importantes pour être confiées à des négociateurs peu expérimentés.

7. Renforcer la coordination entre les pays de l'OCDE vis-à-vis des nouveaux pays qui s'associent pour la première fois aux travaux relatifs aux conventions (par exemple Hong Kong, Chine).

8. Revoir la nature des réserves et observations figurant dans le Modèle et leurs liens avec les vues minoritaires exprimées dans les commentaires.

9. Associer plus étroitement aux travaux les pays non membres de l'OCDE et leur donner davantage voix au chapitre.

10. Enfin, rien de tout cela ne sera possible si les États n'allouent pas plus de ressources à leurs services de fiscalité internationale.

* Raffaele Russo, du CTP, a également participé à la rédaction de cet article.

\section{Références}

- OCDE (2008), Modele de convention fiscale concernant le revenu et la fortune, septième édition de la version abrégée, Paris.

- Pour plus d'informations sur les conventions fiscales, voir www.oecd.org/ctp/tt

- Voir également www.oecd.org/ctp

Note spéciale sur les prix de transfert Un projet de rapport sur les aspects relatifs aux prix de transfert des restructurations d'entreprises est désormais disponible en ligne pour examen sur www.oecd.org/ctp/tp/br. Les commentaires sont à adresser avant le 19 février 2009. 
Peter A. Barnes

Fiscaliste international, General Electric

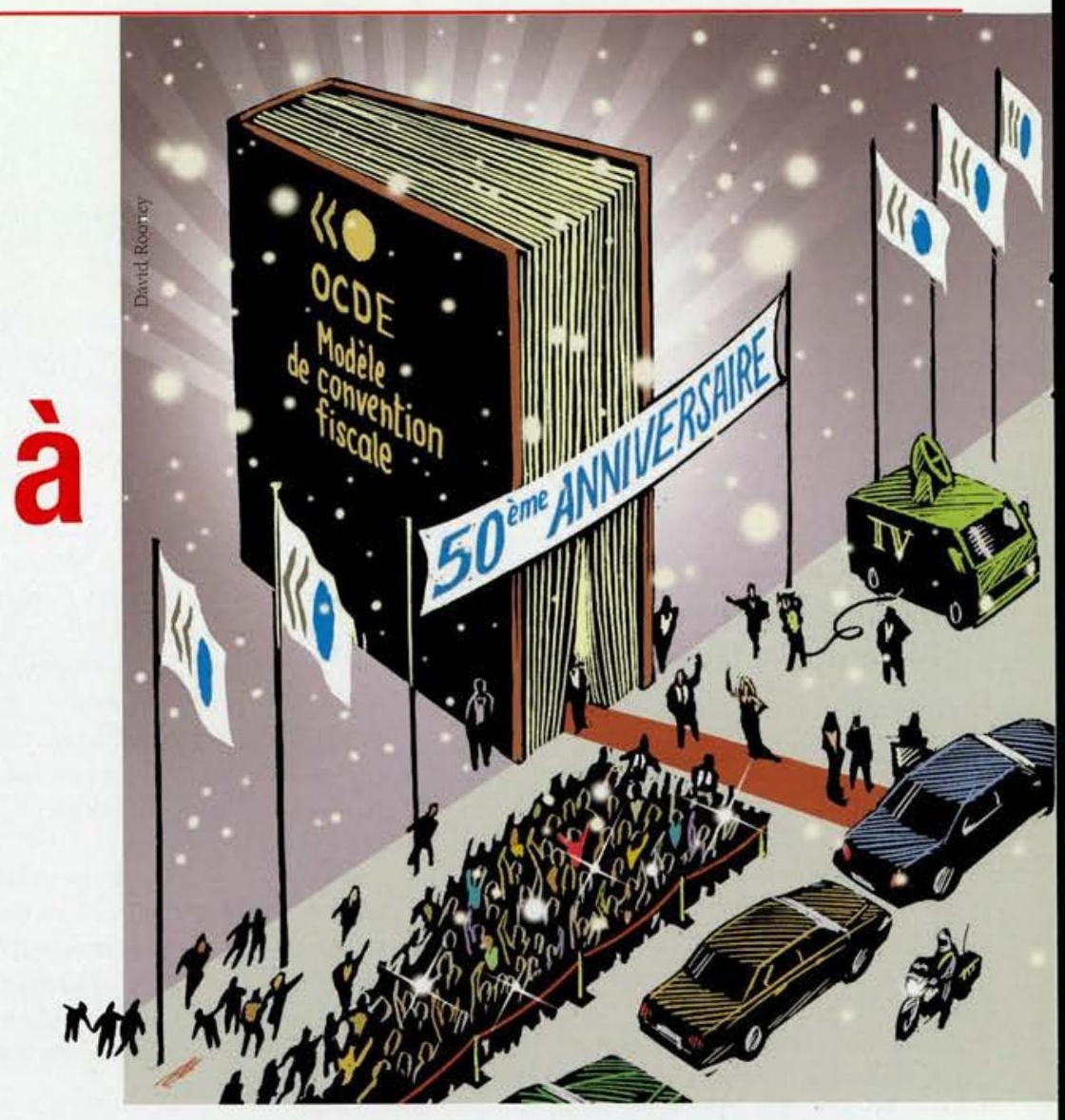

\section{En 50 ans, le Modèle de convention fiscale de l'OCDE est devenue une référence incontournable pour le monde des affaires. Voici pourquoi.}

$\mathrm{P}$ our les fiscalistes de 2008, l'époque où le commerce électronique allait révolutionner le monde du commerce - et de la fiscalité - peut paraître lointaine.

État de la source ; état de la résidence ; établissement stable ; attribution de revenus.. Nous redoutions que le commerce électronique ne bouleverse tous nos concepts fiscaux et n'oblige à une redéfinition complète de l'imposition des transactions internationales.

Or que s'est-il passé ? Le commerce électronique s'est développé à une vitesse exponentielle. Mais après la parution de centaines d'articles dans les revues fiscales, plusieurs rapports des autorités fiscales américaines et d'autres pays, et un examen approfondi par les cinq groupes techniques consultatifs de l'OCDE sur le commerce électronique, le consensus suivant s'est imposé : les concepts fiscaux existants, et le cadre fiscal international du Modèle de convention fiscale de l'OCDE fonctionnent très bien, merci. Une refonte radicale des principes fiscaux n'a pas été jugée nécessaire.

Et c'est pourquoi nous célébrons le 50 ème anniversaire de cet instrument : alors que le monde du commerce international ne cesse d'évoluer et de s'accroître, le Modèle de convention fiscale de l'OCDE a fait ses preuves, durant ces cinq dernières décennies, en tant que cadre de référence en matière d'imposition internationale, et semble en bonne voie de le rester dans les 50 années à venir.

Le Modèle de convention fiscale de l'OCDE n'est pas le premier du genre (cet honneur revient aux modèles de conventions fiscales élaborés par la Société des Nations au cours des années 1920); ce n'est non plus le seul modèle important aujourd'hui (celui des Nations unies, publié pour la première fois en 1980, fait encore autorité dans certains pays). Mais le Modèle de l'OCDE a réussi à devenir le cadre de référence pour la très grande majorité des négociations de conventions fiscales.
Récemment, une ancienne négociatrice de conventions fiscales internationales pour la Chine me parlait d'une importante négociation avec un grand pays en développement, à laquelle elle avait participé. Quel modèle d'accord avait servi de point de départ aux pourparlers ? Le Modèle de convention fiscale de l'OCDE, bien sûr, alors même qu'aucun des deux pays en question n'est membre de l'Organisation.

On peut voir le Modèle de convention fiscale de l'OCDE avec cynisme. Oui, l'OCDE représente les pays industrialisés et les besoins de leurs économies. Oui, les voix des économies en développement ne sont pas toujours suffisamment entendues, malgré le réel effort d'ouverture du Comité des affaires fiscales au cours des dix dernières années. Oui, le chemin pour atteindre un consensus sur la formulation des rapports et du modèle peut s'étendre péniblement en longueur.

Mais ne vous y trompez pas : l'OCDE est une organisation d'une importance vitale et le 
Modèle de convention fiscale de l'OCDE est un instrument indispensable pour faciliter les échanges transfrontaliers et le commerce mondial.

Les exemples abondent ; je me contenterai ici d'en citer deux. Premièrement, les écrits et analyses de l'OCDE au sujet des principes de fiscalité internationale sont la source la plus exhaustive en la matière. De fait, aucune instance faisant autorité ne rivalise avec l'OCDE dans ce domaine.

Si un fiscaliste - ou un haut fonctionnaire d'un pays émergent - n'avait dans sa bibliothèque que deux livres sur la fiscalité internationale, on pourrait deviner sans trop de peine lesquels : le Modèle de convention fiscale de l'OCDE avec ses Commentaires, et les Principes applicables en matière de prix de transfert de 1995 de l'OCDE. Pourquoi

\section{Aucune instance officielle ne rivalise avec l'OCDE en matière de fiscalité internationale}

est-ce important ? Parce que les principes formulés dans ces documents, tels que la distinction entre un bureau de représentation non imposable et une succursale ou activité imposable, le concept d'attribution de revenus, et les grands principes de fixation de prix de transfert de pleine concurrence, permettent de garantir l'existence d'un certain fair play en matière de fiscalité internationale.

Au début de ma carrière, j'ai eu le grand privilège de siéger aux côtés de Marcia Field et de Mordy Feinberg, principaux négociateurs américains de conventions fiscales pendant 20 ans - entre les années 70 et 90 - et de les voir dévoiler les subtilités de divers articles de conventions ; ces séances se déroulaient souvent en présence de négociateurs d'autres pays qui, comme moi, étaient moins au fait des implications de telle ou telle formulation. Le Modèle de convention fiscale de l'OCDE a tiré parti d'un siècle d'expérience en matière de fiscalité internationale pour en extraire les principes fondamentaux. Nous sommes nombreux à avoir été formés à cette discipline en étudiant le Modèle de convention et ses Commentaires.
Les firmes multinationales ouvrent de plus en plus souvent leurs propres bureaux sur les marchés émergents d'Afrique, du Moyen-Orient, d'Amérique du Sud et d'Asie, alors qu'elles s'appuyaient auparavant sur des distributeurs locaux. Ces nouvelles implantations ne sont possibles que parce que les principes fiscaux de base formulés et étayés par l'OCDE et son Modèle de convention fiscale sont généralement applicables. Ainsi, lorsqu'une multinationale s'implante pour la première fois au Kenya, au Sri Lanka ou en Uruguay, elle utilise le même langage fiscal que les autorités locales, ce qui facilite les discussions.

Si l'OCDE n'existait pas, nous n'en connaitrions pas moins les concepts d'" établissement stable », d'" imposition à la source " et bien d'autres piliers de la fiscalité internationale. Mais la manière de définir et d'appliquer ces principes fiscaux ne serait pas aussi homogène.

Pour mieux saisir, imaginez que l'on donne à des sportifs de différents pays un filet, un ballon et un terrain, et qu'on leur dise " à vous de jouer ». Sans doute seraient-ils ravis, mais il est certain que les sports ainsi créés seraient très différents les uns des autres. De même, imaginez que l'on donne à des fonctionnaires fiscaux quelques concepts - * compétence en matière fiscale ", "redevances ", "retenues à la source " - et qu'on leur dise d'imaginer un système d'imposition des non-résidents. Il en résulterait un véritable chaos.

Il reste encore beaucoup à faire. Comme l'a montré l'expérience du commerce électronique, et comme le montre aujourd'hui la mondialisation des services financiers, l'application des principes du Modèle de convention fiscale de l'OCDE à des méthodes commerciales spécifiques nécessite un travail important. De plus, former des fiscalistes expérimentés et de nouveaux fonctionnaires des impôts reste un défi, car les principes d'imposition internationale sont loin d'être faciles à comprendre. Cependant, l'accent mis en permanence par l'OCDE sur les questions nouvelles, comme l'imposition des rémunérations différées et des retraites des travailleurs étrangers, et sur la nécessité d'écouter les nouveaux intervenants, en particulier les pays en développement, permettent à toute la communauté fiscale internationale d'aller sans cesse de l'avant pour relever les nouveaux défis.

Deuxièmement, l'OCDE joue un rôle important en ce qu'elle permet de confronter diverses positions, puis de trancher. Ce ne sera pas toujours la bonne décision ( bonne », du moins, pour chacune des parties concernées !), et ce n'est certainement pas la seule possible. Mais une décision aura été prise. C'est ainsi qu'un projet de construction ne peut être considéré comme un établissement stable que s'il dure plus de 12 mois - et non pas trois, six ni neuf mois. Les bénéfices provenant de l'exploitation d'aéronefs en trafic international sont imposés sur la base de la résidence, et non de la source.

La Société des Nations n'a jamais eu la volonté ou l'autorité nécessaire pour élaborer un modèle unique. Elle a donc fini par en proposer quatre. LOCDE offre l'avantage de confronter différentes positions pour retenir finalement une seule proposition. Une fois la position de lOCDE exprimée, la " charge de persuasion " incombe à la partie qui a une position différente. A mesure que de nouveaux membres rejoindront l'OCDE et que le nombre des pays participant au commerce mondial s'accroîtra, il deviendra de plus en plus difficile d'exprimer une position tranchée - mais ce sera aussi de plus en plus indispensable.

Les défis à relever pour étendre les échanges internationaux au $21^{\text {ème }}$ siècle sont nombreux, comme l'a illustré l'échec du cycle de Doha pour un nouvel accord commercial mondial. Cependant, les échanges internationaux seraient encore plus compliqués si les différentes autorités fiscales déterminaient de leur propre chef - et aveuglément, pourrait-on dire - les règles fiscales applicables aux transactions internationales.

En tant que fiscalistes internationaux, nous prenons tous part aux réussites et aux difficultés de l'OCDE, ainsi qu'à ses travaux sur les conventions fiscales. Aujourd'hui, nous fêtons les progrès significatifs que nous avons réalisés ces 50 dernières années, et nous relèverons tout autant les défis des 50 ans à venir grâce au Modèle de convention fiscale et à une réelle volonté de coopération.

Cet article est une adaptation d'un article publié sur www.taxanalyst.com. 


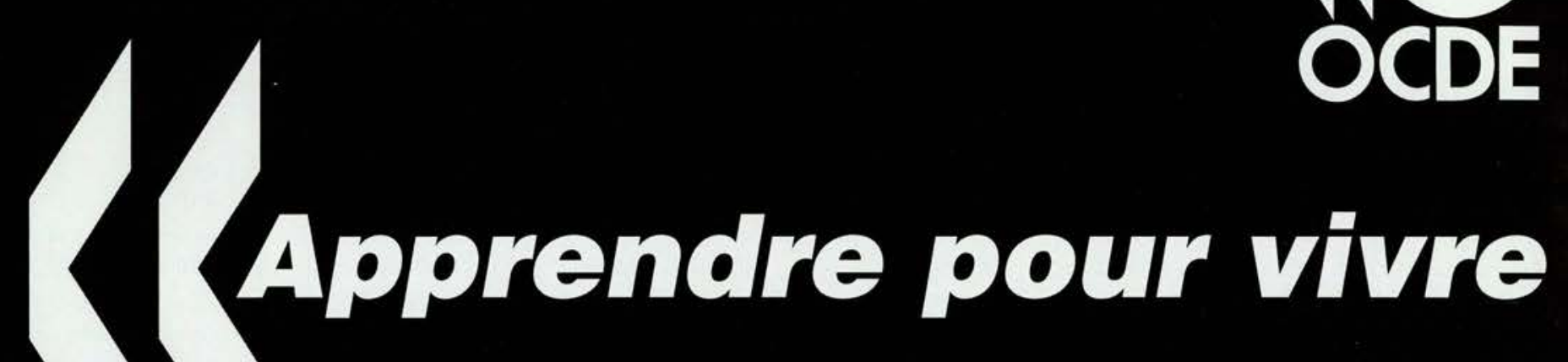

\section{LES ESSENTIELS DE L'OCDE}

BRIAN KEELEY

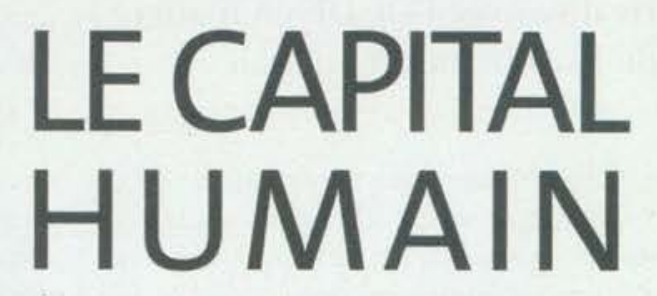

Comment le savoir détermine notre vie

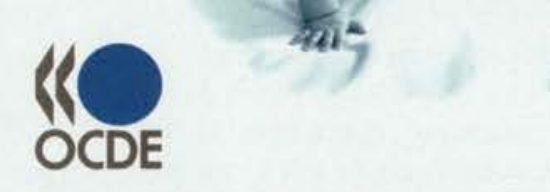

ISBN : 9789264029101 www.oecd.org/lesessentiels 


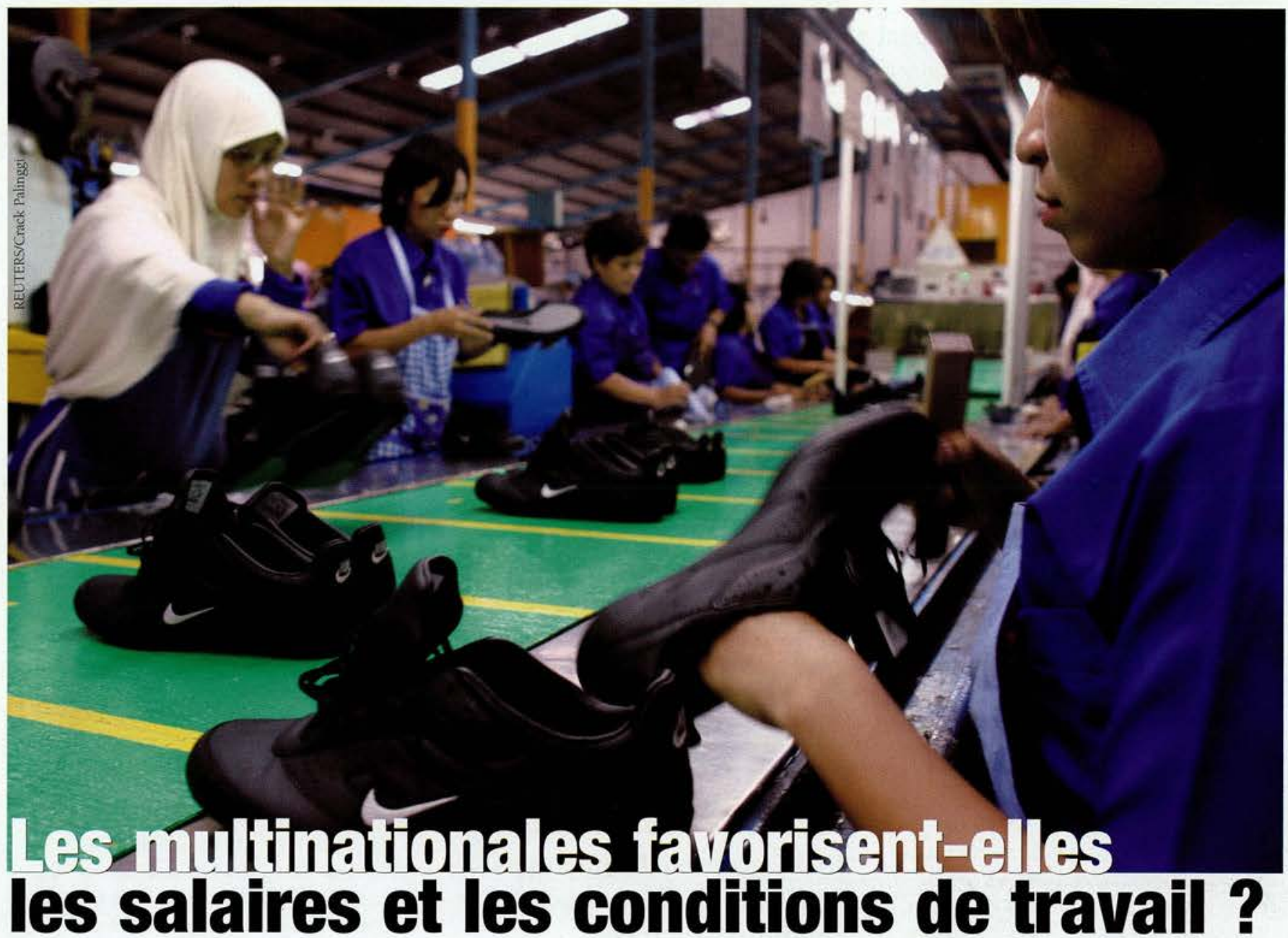

Alexander Hijzen et Paul Swaim, Direction de l'Emploi, du travail et des affaires sociales de l'OCDE

Les multinationales peuvent avoir des effets positifs sur les salaires et les conditions de travail, mais certaines exigences doivent être prises en compte, notamment par les responsables publics qui souhaitent attirer l'investissement direct étranger.

S

, il est une question qui oppose partisans et adversaires de la mondialisation, c'est bien le titre de cet article. Gages de progrès futurs et d'élévation du niveau de vie, insisteront ceux qui répondent par l'affirmative, vecteurs de sous-développement et d'exploitation occidentale, diront les autres.

Qui a raison? Avant d'esquisser une réponse, examinons la signification réelle de " multinationale ». Ce terme désigne communément les sociétés ayant leur siège dans un pays et leurs sociétés apparentées, leurs filiales ou les entreprises issues de fusions, dans un ou plusieurs autres. Elles s'implantent à l'étranger pour gagner des parts de marché ou tirer parti des ressources locales : matières premières, main-d'œuvre meilleur marché, etc. On peut citer de grandes marques comme Coca-Cola, Nike et Microsoft pour les États-Unis, le groupe énergétique EDF pour la France, ou le groupe minier anglo-australien Rio Tinto et la société japonaise Toyota.
Les multinationales jouent un rôle essentiel sur la scène mondiale depuis au moins un siècle. Certains voient leur origine dans la Compagnie

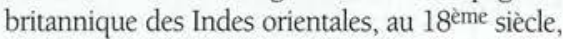
d'autres citent la Compagnie hollandaise des Indes orientales (Verenigde Oost Indische Compagnie, VOC), fondée au $17^{\text {ème }}$ siècle.

Il existe aujourd'hui des milliers d'entreprises multinationales, et toutes ne reflètent pas la domination économique occidentale. La liste 2008 du Financial Times qui recense les sociétés les plus valorisées sur les marchés comprend des 


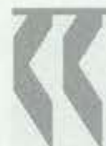

\section{Impact sur les salaires}

Effets des prises de contrôle transfrontières sur les salaires, variation en \%*

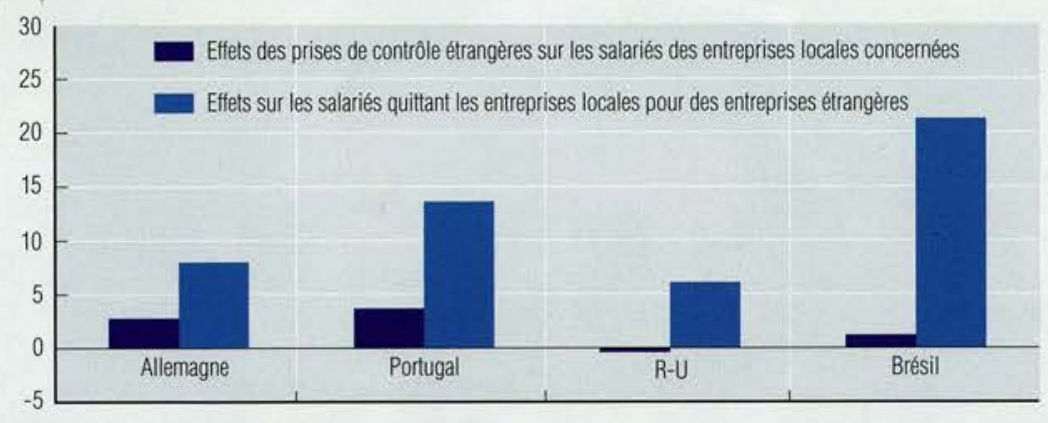

* Effets moyens lors des 3 premieres années après la prise de contrôle

Source : Perspectives de l'emploi de I'OCDE 2008, Paris

entreprises chinoises, russes, indiennes et brésiliennes.

En dépit des controverses, les entreprises multinationales vont probablement continuer à jouer un rôle croissant dans l'économie mondiale, les pouvoirs publics de tous les pays rivalisant d'efforts pour attirer l'investissement étranger. Déjà en 2006, l'investissement direct étranger (IDE), qui constitue un bon indicateur de l'internationalisation de la production, représentait près d'un quart du PIB mondial, contre moins de $10 \%$ en 1990 . Les filiales étrangères des multinationales sont à l'origine d'environ un tiers des exportations mondiales.

Mais les multinationales favorisent-elles vraiment l'emploi et les salaires dans les pays d'accueil, et y améliorent-elles les conditions et les pratiques, ou exercent-elles une emprise excessive sur sur les pays en développement, avec peu d'espoir de progrès ? Ces deux points de vue se défendent. Pour les optimistes, grâce à leur savoir-faire technique et à leurs méthodes de gestion modernes, les multinationales peuvent octroyer des salaires élevés. Les pessimistes doutent de leur volonté réelle de le faire, car elles sont généralement en position de force vis-à-vis des travailleurs locaux.

Le seul moyen de répondre sérieusement à cette question est de comparer les pratiques de travail des entreprises locales et celles des sociétés étrangères, comme l'ont fait les auteurs d'une récente étude intitulée « Les entreprises multinationales favorisent-elles l'amélioration des rémunérations et des conditions de travail ? " (voir les références). Ils comparent les pratiques en termes de salaires, de temps de travail, de formation, etc. et analysent les différences.

Cette étude de l'OCDE montre que, dans l'ensemble, les entreprises multinationales tendent à verser des salaires plus élevés que les entreprises locales, mais cet écart diminue sur des marchés similaires. En général, les salaires moyens des multinationales étrangères sont

\section{LIDE n'a probablement pas beaucoup d'effet sur les conditions de travail}

supérieurs de $40 \%$ à ceux des entreprises locales, et la différence est plus grande dans les pays à faible revenu d'Asie et d'Amérique latine. Cette politique de salaires plus élevés tient peutêtre à la volonté de réduire autant que possible la rotation des effectifs et de faire baisser les couts de suivi.

Outre les salaires plus élevés, les multinationales se distinguent des entreprises locales à bien des égards, comme leur taille beaucoup plus importante et leur meilleure productivité. Il se peut donc qu'elles proposent de meilleurs salaires uniquement parce qu'elles préferent investir dans des secteurs à forte intensité de capital et faire appel à des travailleurs très qualifiés. Si tel est réellement le cas, il ne faut pas penser pour autant qu'elles rémunèrent de la même façon les travailleurs ayant les mêmes qualifications que ceux qui effectuent des tâches analogues dans d'autres entreprises.
Selon les auteurs de l'étude, seules des comparaisons plus précises permettent de déterminer si les multinationales offrent effectivement des salaires plus élevés et de meilleures conditions de travail. Ils analysent donc les changements qui adviennent lorsqu'une société étrangère rachète une entreprise locale, ainsi que l'expérience des travailleurs qui quittent une entreprise locale pour une entreprise étrangère.

Lorsque l'on compare des entreprises analogues, il semble encore que les salaires offerts par les multinationales soient plus élevés, mais l'écart est plus limité. Pour effectuer des comparaisons plus fines, le rapport étudie trois pays de l'OCDE (Allemagne, Portugal et Royaume-Uni) et deux économies émergentes (Brésil et Indonésie). Il apparait que les prises de contrôle étrangères entraînent une augmentation des salaires moyens au niveau de l'entreprise, cet effet étant très faible en Allemagne et représentant $5 \%$ au Royaume-Uni, $8 \%$ au Portugal, $11 \%$ au Brésil et $19 \%$ en Indonésie. Étant donné que dans les pays en développement les multinationales ont généralement une avance technologique sur leurs concurrentes locales, il est logique que la hausse des salaires due à IIDE y soit plus forte que dans les économies développées.

En outre, les gains salariaux dus à des prises de contrôle étrangères sont susceptibles d'augmenter au fil du temps, avec le transfert de techniques de production modernes de la société-mère aux filiales et l'acquisition de nouvelles compétences par les salariés. Cette forme d'IDE étranger a entraîné en Indonésie une augmentation de $18 \%$ des salaires moyens dans un premier temps, puis de quatre autres points environ deux ans après le rachat. Le Brésil, le Portugal et, dans une moindre mesure, le Royaume-Uni, ont connu des évolutions comparables.

En somme, ces résultats tendent à montrer que l'opinion courante concernant le potentiel de création de richesses de l'IDE n'est pas fausse, en particulier pour les pays en développement. Mais elle est valable pour les salaires moyens versés dans les entreprises qui font l'objet d'un rachat.

L'examen des salaires individuels plutôt que des salaires moyens offre une vision plus précise. Lorsque l'on compare les travailleurs qui restent dans les entreprises rachetées à leurs homologues des entreprises locales, on constate que les prises de contrôle étrangères n'ont 
qu'un effet insignifiant, voire nul, sur les salaires individuels. Ceci indique que la hausse des salaires moyens tient en partie au changement de la structure des effectifs par qualification qui accompagne généralement les nouvelles prises de contrôle.

Mais qu'en est-il des travailleurs qui passent d'une entreprise locale à une société à capitaux étrangers? Selon les Perspectives de l'emploi de l'OCDE, les salariés nouvellement recrutés voient leur rémunération progresser assez fortement, de $6 \%$ au Royaume-Uni, $8 \%$ en Allemagne, $14 \%$ au Portugal et de $21 \%$ au Brésil. En revanche, chez les travailleurs ayant quitté une entreprise étrangère pour une entreprise locale, les salaires ont légèrement diminué ou sont restés inchangés.

Il est certain qu'au cours des premières années qui suivent une prise de contrôle par une entreprise étrangère, ce sont les travailleurs qui arrivent dans cette entreprise, et non ceux qui s'y trouvaient déjà avant le rachat, qui y gagnent en salaire. C'est donc par ce biais, selon les auteurs de l'étude, que l'IDE entraine dans un premier temps une augmentation des salaires dans les pays d'accueil. Avec le temps, une proportion croissante de travailleurs est susceptible d'en bénéficier.

Les salaires ne sont toutefois qu'une facette de la médaille : qu'en est-il des conditions de travail ? Les tenants de l'IDE font notamment valoir que les multinationales favorisent l'investissement socialement responsable, et plusieurs études corroborent ce point de vue. Cependant, l'analyse des acquisitions étrangères dans le rapport de l'OCDE indique que l'IDE n'a probablement pas beaucoup d'effet sur les conditions de travail.

Plusieurs études antérieures montrent également que les multinationales tendent à s'adapter aux pratiques locales plutôt qu'à imposer les leurs. Ainsi, les entreprises américaines implantées en Europe y exportent leurs méthodes de gestion, mais respectent les standards locaux quant à l'équilibre entre travail et vie personnelle. Cette attitude tient en partie à la nécessaire adaptation des entreprises aux règles et conventions sociales locales, mais elle peut aussi refléter le style de gestion propre aux entreprises américaines, et n'est sans doute pas représentative de toutes les multinationales.

LIDE et les multinationales ont aussi d'autres retombées positives et négatives, que les auteurs de l'étude examinent, comme l'augmentation de la productivité et des salaires chez les fournisseurs des entreprises à capitaux étrangers. Létude montre aussi que les entreprises locales qui recrutent des cadres ayant acquis une expérience dans des multinationales améliorent leur productivité. Les entreprises sans lien direct avec celles-ci ont moins tendance à bénéficier de retombées positives. De fait, l'IDE peut avoir pour effet de réduire l'offre de main-d'œunve pour les entreprises locales. Cela dit, les travailleurs qualifiés exerçant dans le même secteur qu'une multinationale ont des chances de voir leur salaire augmenter avec le temps.

Si les conditions de travail s'améliorent lentement chez les fournisseurs, ce n'est pas toujours faute d'efforts des multinationales. Prenons l'exemple de Nike, fabricant de vêtements de sport abondamment critiqué par le mouvement antimondialisation qui l'accusait d'exploiter et de sous-payer ses ouvriers. Lentreprise a élaboré son premier code de conduite en 1992. En 2004, elle a employé 80 cadres spécialisés dans la responsabilité sociale des entreprises pour veiller au respect de ce dernier. Les usines de chaussures étaient inspectées chaque jour et celles qui fabriquaient des vêtements et des équipements, toutes les

\section{Toute réduction délibérée des normes du travail pour attirer l'IDE serait vaine}

semaines. De plus, Nike avait chargé environ 1000 chefs de production de travailler en collaboration étroite avec ses fournisseurs du monde entier. Malgré ces efforts, Nike constate que chez près de $80 \%$ de ses fournisseurs, les conditions de travail ne se sont pas améliorées (et se sont peut-être même détériorées). Un examen plus attentif montre que les dispositifs de contrôle de la conformité au code de conduite qui s'appuient sur des partenariats de production à long terme donnent de meilleurs résultats que ceux qui reposent sur la seule surveillance des conditions de travail.

Les entreprises ne sont toutefois pas seules à faire des efforts. Les pouvoirs publics et les organisations internationales peuvent inciter les entreprises multinationales à adopter un comportement plus responsable, notamment dans leur rôle d'employeur. Ils peuvent collaborer avec les associations de consommateurs et d'autres parties prenantes pour améliorer les pratiques. Citons, par exemple, les Principes directeurs de l'OCDE à l'intention des entreprises multinationales, qui offrent aux pouvoirs publics des pistes utiles pour encourager les entreprises à se conduire de manière responsable, en particulier dans les relations de travail. Bien quadoptés sur une base volontaire, ces principes suggèrent aux gouvernements qui y adhèrent de proposer des services de médiation lorsque des multinationales sont présumées avoir violé l'un ou plusieurs d'entre eux. La majorité des cas où l'on a recouru à ces services de médiation ont en fait concerné le comportement des multinationales en tant qu'employeurs.

Il conviendrait aussi d'inciter les pays en développement à reconnaître et à faire respecter les normes du travail admises au niveau international. Car pour faire progresser ces standards, les règles et normes du pays hôte sont aussi importantes que laction des multinationales.

Selon les auteurs de l'étude, l'action gouvernementale devrait aussi viser à réduire les obstacles à l'IDE, comme le recommande le Cadre d'action de l'OCDE pour l'investissement, ainsi qu'à améliorer les conditions générales de linvestissement. Une stabilité économique et politique, un cadre légal d'exécution des contrats, des mesures anti-corruption et de bonnes infrastructures doivent constituer autant de priorités, mais une chose ressort clairement du rapport : le droit du travail doit peut-être être assoupli, mais toute réduction délibérée des normes du travail pour attirer l'IDE serait vaine. Laffaiblissement des règles fondamentales de protection des travailleurs risque au contraire de décourager l'investissement.

En définitive, la contribution des multinationales au développement dépend d'elles-mêmes, mais aussi de l'action des pouvoirs publics

\section{Références}

- OCDE (2003), Les Principes directeurs de l'OCDE a l'intention des entreprises multinationales, rẻvision 2000, Paris, disponible sur http://publications.oecd.org/ acrobatebook/2100201E.PDF

- OCDE (2006), Cadre d'action de l'OCDE pour linvestissement, Paris, disponible sur http://publications.oecd.org/ acrobatebook/2006051E.PDE.

- OCDE (2008), « Les entreprises multinationales favorisent-elles l'amélioration des rémunérations et des conditions de travail ? ", Perspectives de l'emploi de l'OCDE, Paris

- OCDE (2008), « Limpact social de linvestissement direct étranger », Synthèses de l'OCDE, juillet, disponible sur http://www.oecd.org/dataoecd/30/14/41069438.pdf. 
Les palmarès universitaires sont à la mode, mais n'offrent pas pour autant des mesures exactes de la qualité de l'enseignement. L'OCDE s'emploie à élaborer d'autres outils pour mesurer les performances, comme elle l'a indiqué dans une conférence récente réunissant responsables politiques et professionnels de l'éducation.

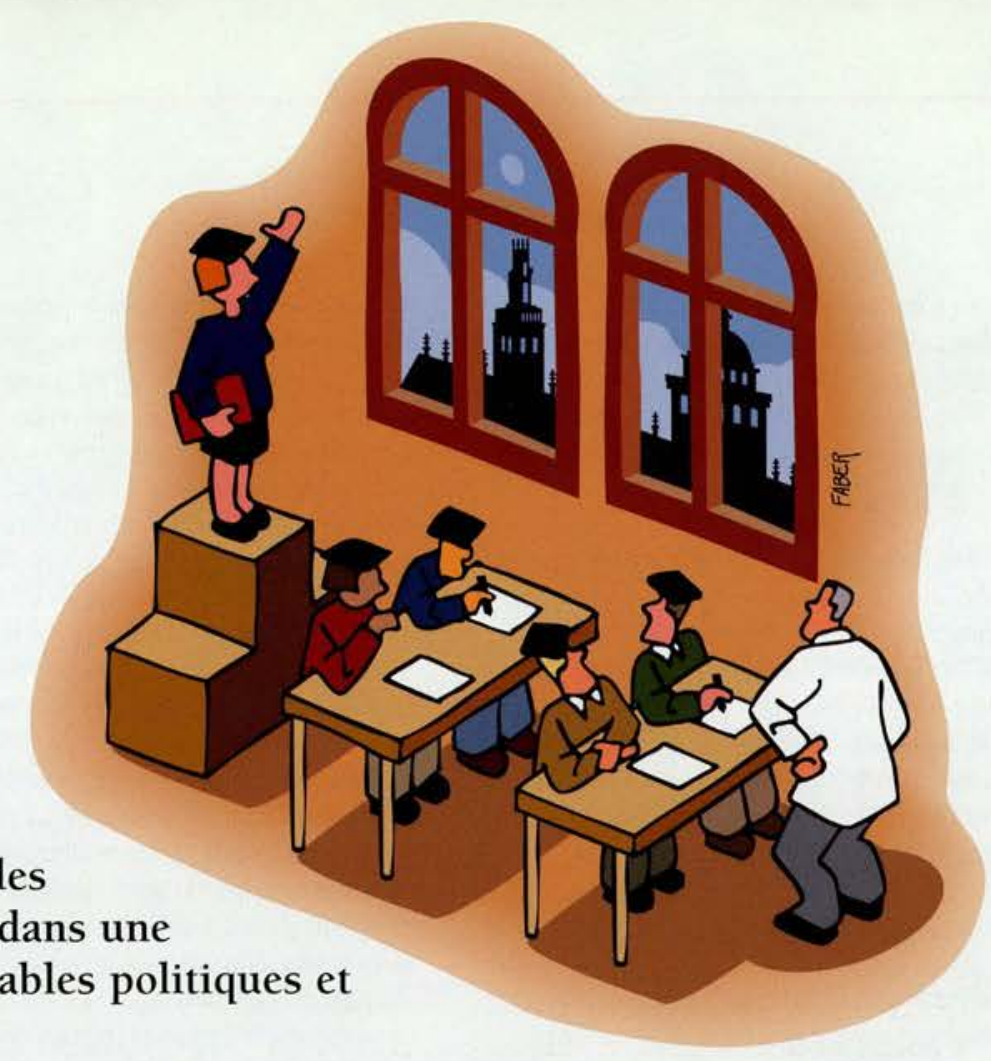

\section{$\mathrm{L}$} a rumeur veut que les plus grands amateurs de palmarès universitaires soient les recteurs d'universités et les mères de famille en Chine. Mais ces classements sont-ils fiables? Ou sont-ils simplistes et néfastes, comme le prétendent leurs détracteurs?

C'est l'excellence qui est recherchée. Or, l'excellence n'apparait que dans le haut des classements. Lors de la conférence « Enseignement supérieur : qualité, pertinence et impact », récemment organisée à l'OCDE à Paris (voir références), Franz Van Vught, du Centre européen pour la gestion stratégique des universités, résumait ainsi le problème : si $3 \%$ seulement des 17000 universités dans le monde sont considérées comme étant « de rang international ", cela ne signifie pas que les autres sont mauvaises.

Sommées d'acquérir une stature internationale, les universités se retrouvent sur un lit de Procuste d'indicateurs. Les présidents d'université réajustent fébrilement les programmes, redéfinissent la mission de leur établissement, gonflent leur nombre de candidats pour prouver leur sélectivité et cherchent à s'allier avec des établissements mieux classés - alors que les établissements d'élite, jaloux de leur réputation, répugnent à collaborer avec des universités moins prestigieuses. On va jusqu'à pratiquer des coupes sombres dans les départements de sciences humaines et de lettres, au profit des sciences de la nature et de la recherche. Lors de la conférence, Ellen Hazelkorn, de l'Institut technologique de Dublin, citait une personne interrogée lors d'une enquête internationale "Le moyen le plus simple de remonter dans le classement, c'est de se débarrasser des sciences humaines et des lettres ». Proposition irréaliste s'il en est, mais selon Mme Hazelkorn, une autre enquête indiquait que « la réputation est malheureusement toujours fondée sur la recherche, et la recherche attire les meilleurs éléments. "

La recherche est considérée comme le domaine le plus significatif des ressources intellectuelles d'un pays, de sa puissance économique et de sa compétitivité. Rien de surprenant, donc, à ce qu'elle soit un critère majeur de deux des palmarès mondiaux les plus reconnus, à côté de l'enseignement et des examens. Celui de l'Université Jia Tong de Shanghai (SJT) lui affecte un coefficient de $40 \%$, ce qui est considérable, et prend en compte le nombre de publications des enseignants et de leurs citations dans les revues scientifiques. Le classement Times Higher Education affecte $20 \%$ de coefficient à la recherche. Et celui de Shanghai attribue $40 \%$ supplémentaires en cas de prix Nobel ou de médaille Fields. Ceci fausse quelque peu la donne, car tous les établissements ne sont pas spécialisés en mathématiques ou en sciences, et le cas échéant, rien ne prouve que le fait d'avoir un lauréat du Nobel sur le campus, ou d'en avoir eu un il y a 50 ans ou plus, soit un atout pour mieux apprendre. Les auteurs du classement de Shanghai précisent bien que les tableaux ne doivent pas être utilisés comme une évaluation globale du niveau de performance d'une université. Mais c'est exactement ce que font le public et les médias.

À part recruter un prix Nobel, que peut faire une université pour remonter dans ces classements (à supposer qu'elle doive chercher à le faire)? Malheureusement, le meilleur moyen de gagner du prestige....est d'en avoir déjà.

Les établissements anciens comme Harvard et Oxford se retrouvent invariablement dans les 10 meilleurs. Leur aura attire les meilleurs étudiants et les meilleurs enseignants, et leur garantit de généreuses dotations. Leur réputation ne leur confere-t-elle pas un avantage injuste?

Pas forcément. D'autres universités anciennes, voire plus anciennes qu'Oxford, comme Fribourg en Allemagne, sont nettement plus bas dans le classement de Shanghai des 100 meilleures, et la plus ancienne de toutes, celle de Bologne en Italie, n'y figure même pas.

La réputation peut résulter en partie de préjugés. Dans son évaluation globale par les pairs, le Times Higher Education demande par email à quelque 200000 universitaires du monde entier quelles sont, selon eux, les 30 meilleures universités. Sachant que l'enquête 
n'utilise pas d'indicateurs clairs quant aux critères d'évaluation, qu'elle est publiée dans les pays anglophones, et que le taux moyen de réponse est de $1 \%$, il n'est guère surprenant que les établissements britanniques se retrouvent en tête. Tout dépend aussi de ce que l'on mesure : les palmarès de Shanghai et du Times ne notent pas très bien les universités françaises, mais dans le classement 2007 des écoles de commerce européennes du Financial Times, six des 10 meilleures sont françaises. Précisons que le FT publie toute une série de classements des écoles de commerce, notamment des MBA, certainement aussi pour en tirer des revenus publicitaires.

De même, ces classements semblent parfois quelque peu erratiques. Telle université très bien placée une année peut reculer brutalement de 40 places l'année suivante. Est-ce plausible? Si oui, qu'est-ce qui l'empêcherait de remonter de 50 places l'année d'après ? Par ailleurs, l'écart réel entre deux établissements éloignés

\section{Rien ne prouve que le fait d'avoir un lauréat du prix Nobel sur son campus améliore l'apprentissage des étudiants}

de 10 places peut être très faible, alors qu'un changement minime de certains facteurs peut avoir un impact marqué. Dès lors, doit-on tenir compte de ces classements? Dans l'enquête 2008 du Times Higher Education, publiée tout récemment, les établissements britanniques reculent fortement, ce qui accroit la morosité des gros titres sur l'état du pays.

Pour sortir de cette logique, certaines universités retournent les classements à leur avantage, utilisant leur position peu flatteuse comme argument marketing. La mobilité des étudiants n'a jamais été aussi forte. Dans la zone OCDE, les étudiants internationaux représentent près de $6,7 \%$ des effectifs; ;en Australie, la proportion est de $19,3 \%$, et jusqu'à $50 \%$ dans certaines universités.

Lun des plus gros défauts des classements ne tient pas tant à l'inexactitude des données qu'à la manière dont elles sont utilisées, et à qui elles s'appliquent. De plus, beaucoup d'aspects n'ont jamais été couverts, comme les progrès des étudiants, ou leur niveau par rapport à celui qu'ils avaient en entrant. Pour toutes ces raisons, il est difficile de dresser un tableau fidèle des performances des universités. Le plus problématique est que certaines données ne mesurent pas ce qui constitue pour beaucoup la finalité première des universités : l'enseignement.

Des indicateurs comme le " ratio enseignants/étudiants » sont trop faibles pour nous renseigner sur la qualité et l'impact de l'enseignement. Le Centre pour l'enseignement supérieur (CHE) en Allemagne publie des données à partir desquelles les étudiants peuvent établir leur propre classement en fonction de leurs besoins. Le CHE ne hiérarchise pas les établissements un par un, mais les classe par groupes: "bon ", " moyen " ou " mauvais " et par ordre alphabétique. Cette méthode permet d'atténuer l'impact démultiplicateur sur les classements de certains écarts en réalité insignifiants.

Les classements ne tiennent pas non plus compte de la valeur ajoutée des cursus. Évidemment, les meilleures universités recrutent d'excellents étudiants, qui deviennent d'excellents diplômés. Mais que dire des universités qui accueillent des étudiants simplement bons ou moyens et produisent de très bons diplômés ? En termes de valeur ajoutée, le deuxième programme obtiendrait une bien meilleure note.

Létude AHELO (Évaluation internationale des résultats de l'enseignement supérieur) de l'OCDE cherche à déterminer s'il est possible d'évaluer l'enseignement de manière pertinente, en examinant deux « axes " de compétences: les compétences liées à la discipline choisie, et les compétences génériques comme l'esprit critique ou la capacité à appliquer un savoir dans une situation concrète. Si elle fonctionne, cette méthode d'évaluation pourra être utilisée par les universités pour améliorer leurs performances, et par les étudiants pour trouver les établissements qui répondront le mieux à leurs besoins.

La question de la pertinence est fondamentale. Un programme diplômant est-il pertinent s'il ne prépare pas les étudiants au marché du travail, ou s'il ne démontre aucun impact social évident ? À notre époque inquiète face à la réduction des débouchés professionnels, entre autres, la pertinence des diplômes est cruciale. C'est pourquoi elle a êté longuement évoquée à la conférence de l'OCDE. Les sciences du vivant peuvent paraitre plus pertinentes à certains que les sciences humaines, elles sont néanmoins impuissantes à traiter certains grands enjeux des sociétés contemporaines - migrations, vieillissement, changement climatique, héritage du colonialisme ou extrémisme religieux -, comme le souligne Robert Berdahl, président de l'Association des universités américaines. On ne peut pas davantage laisser une génération juger seule des filières pertinentes pour l'avenir. Par exemple, lìndustrie nucléaire, dont la cote est aujourd'hui à la hausse en tant que source d'énergie, souffre d'une pénurie de spécialistes, car pendant longtemps les étudiants ont fui ce secteur. Et que dire de la crise boursière, qui redéfinit chaque jour les règles de l'orthodoxie économique?

Mais les classements ne vont pas disparaitre pour autant. Après tout, ils peuvent favoriser une certaine émulation : " Pourquoi ne sommes-nous pas dans le groupe de tête? ", "Comment conserver notre avance? ". Les gouvernements et les universités continueront à les utiliser, tandis que la concurrence poussera les établissements à se copier mutuellement, à moins que les pouvoirs publics ne prennent des mesures encourageant la diversité. La question de savoir si ces palmarès constituent un bon guide de l'enseignement supérieur est donc purement théorique.

Même pour leurs détracteurs, l'attrait des classements peut être irrésistible, comme l'illustre cette anecdote rapportée par une participante à la conférence IMHE. Le recteur d'une université bavaroise, à qui elle avait proposé d'inclure son établissement dans un palmarès, avait fermement décliné l'offre. Mais une fois assuré que son université ne figurerait pas dans le classement, il demanda où son établissement serait situé par rapport aux autres - simple curiosité... $\mid L T$

\section{Références}

- Les exposés présentés à la conférence de l'OCDE organisée par le Programme sur la gestion des établissements d'enseignement supérieur (IMHE) du 8 au 10 septembre « Enseignement supérieur : qualité, pertinence et impact » sont consultables sur: www.oecd.org/edu/imhegeneralconference 2008.

- Pour plus d'informations sur l'AHELO, voir www.oecd.org/edu/ahelo-fr. 


\section{Railteam}

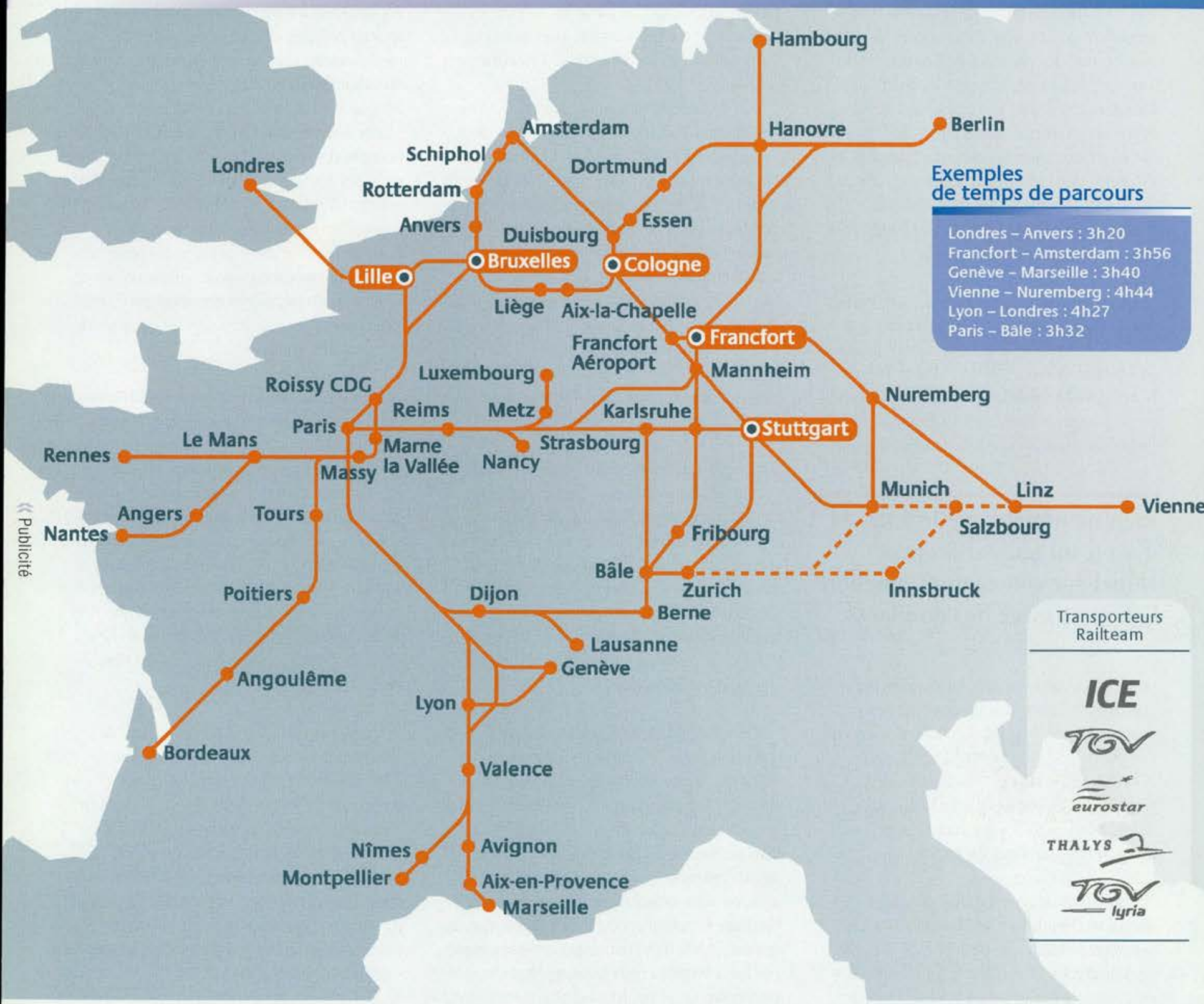

Le réseau Railteam :

Membres: DB BAHN

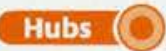

ro -n- Futures lignes Railteam

(B) $\underset{\text { eurostar }}{\approx}$
oHIspeed
Lignes Railteam

G SBB CFF FFS

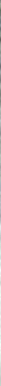




\title{
Avec Railteam,
}

\section{découvrez une autre manière de voyager en Europe}

\author{
Créée en juillet 2007, Railteam est une alliance entre sept compagnies ferroviaires ayant pour objectif \\ de faciliter les voyages à grande vitesse sur un réseau européen qui devrait tripler d'ici 2020. Les sept \\ compagnies membres sont aujourd'hui la SNCF (France), la DB (Allemagne), Eurostar UK Ltd \\ (Royaume-Uni), NS Highspeed (Pays-Bas), les ÖBB (Autriche), les CFF (Suisse) et la SNCB (Belgique).
}

Vous connaissez les avantages des voyages à grande vitesse avec ICE, TGV, Eurostar, Thalys et TGV Lyria : un service de centre-ville à centre-ville, extrêmement confortable et d'une grande fiabilité. Grâce à une coordination optimisée de leurs services, les compagnies membres de Railteam travaillent en étroite collaboration pour vous offrir un service aussi performant à l'échelle européenne, avec un soin particulier accordé à l'amélioration des correspondances et à l'information des clients tout au long de leur voyage.

\section{Les points d'information Railteam}

(1) i) Des points d'information Railteam sont d'ores et déjà à votre disposition dans les cinq hubs de notre réseau : Lille Europe, Francfort, Cologne, Bruxelles et Stuttgart et dans les principales gares de correspondance telles qu'Amsterdam et Munich.

Grâce à Railteam, plus de stress pour effectuer votre correspondance : les agents des points d'information Railteam sont à votre disposition pour toute question ou assistance, en anglais et dans la langue du pays.

\section{Service Hop on the next train}

Vous avez raté votre correspondance à cause d'un retard sur votre premier trajet Railteam Montez dans le train Railteam suivant, sans modifier votre billet."

Ce service vous est proposé dès maintenant dans les 5 hubs Railteam, dans le cadre d'une correspondance entre 2 trains Railteam. Le service 'Hop on the next train' sera très vite étendu à toutes les correspondances Railteam effectuées dans une même gare.

\section{Des avantages pour les Voyageurs Fréquents}

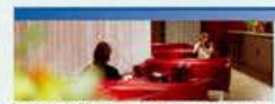

Grâce à l'alliance Railteam, les meilleurs clients de chaque compagnie membre bénéficient d'avantages étendus à l'ensemble du réseau. Ils ont ainsi accès, depuis juillet 2007, à tous les salons d'affaires du réseau Railteam. Ils bénéficient également de réductions sur les prix des locations de voiture dans les principales villes européennes. Et d'ici la fin 2008, les clients fréquents pourront utiliser leurs points de fidélité pour s'offrir des billets gratuits TGV, Eurostar, Thalys, ICE et TGV Lyria.

\section{Mobilité responsable}

Très faibles émissions de gaz à effet de serre, bon rendement énergétique, pollution atmosphérique réduite, haut niveau de sécurité, économie des surfaces occupées, le train est considéré à juste titre comme le mode de transport le moins consommateur d'énergie et le plus écologique.

Ainsi, sur un même trajet européen, un train à grande vitesse émet considérablement moins de $\mathrm{CO}_{2}$ qu'un avion. Une étude réalisée en Grande-Bretagne a révélé que les vols Londres-Paris et Londres-Bruxelles génèrent entre 8 et 11 fois plus d'émissions de $\mathrm{CO}_{2}$ qu'Eurostar sur les mêmes parcours.

D'après les chiffres donnés par l'EcoComparateur de voyages-sncf.com, un trajet Paris-Bruxelles génère en moyenne par voyageur environ $62 \mathrm{~kg}$ de $\mathrm{CO}_{2}$ s'il est effectué en voiture, $45 \mathrm{~kg}$ s'il est effectué en avion, et $10 \mathrm{~kg}$ seulement s'il est effectué avec Thalys.

Sur le trajet Paris-Francfort, en moyenne, l'émission en $\mathrm{CO}_{2}$ par voyageur est d'environ $116 \mathrm{~kg}$ en voiture, $67 \mathrm{~kg}$ en avion et $17 \mathrm{~kg}$ en ICE.

Railteam offre aux voyageurs européens un choix responsable en faveur de l'environnement. 


\section{Pour une aide plus efficace}

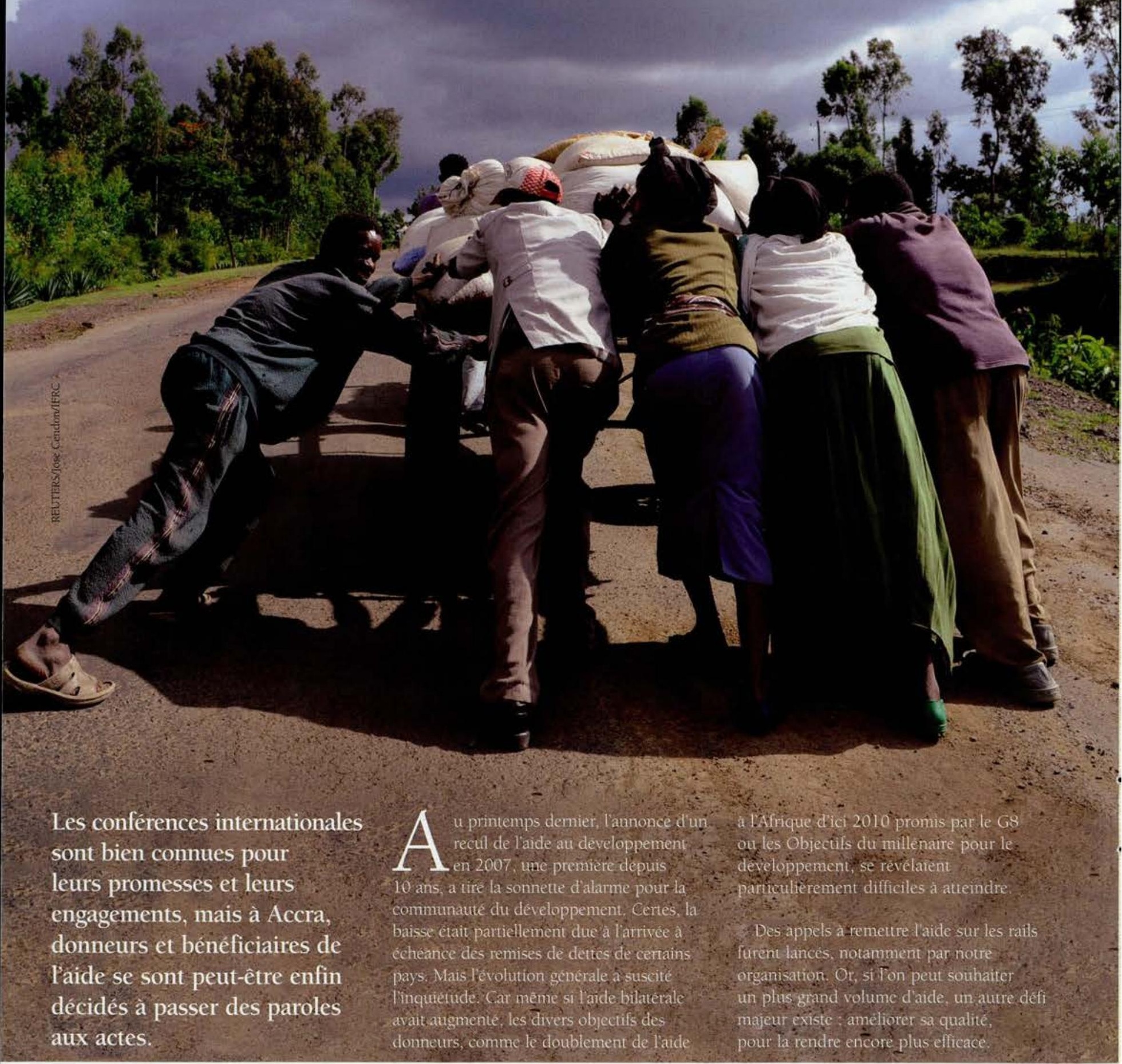


Bien entendu, la recommandation des Nations unies invitant les pays donneurs à consacrer $0,7 \%$ de leur revenu national à l'aide doit être un vrai critère de référence (et l'est d'ailleurs souvent). Pourtant, malgré certaines réussites exemplaires, le bilan de 40 années d'aide indique que pour certains pays la situation a empiré. Si le volume d'aide a généralement augmenté depuis le milieu des années 1990, l'incidence de la pauvreté aussi. Il faut donc veiller à ce que chaque dollar d'aide contribue réellement à réduire la pauvreté et à stimuler le développement. C'est l'esprit de la Déclaration de Paris sur l'efficacité de l'aide en 2005. À travers une série d'engagements, la déclaration fixe des objectifs pour 2010, aussi bien sur la prévisibilité de l'aide et l'utilisation des systèmes financiers internationaux - par opposition aux programmes et projets pilotés par les donneurs - que sur une coopération concertée et efficiente. Mais la singularité de cette déclaration réside avant tout dans le fait que les gouvernements ont accepté d'assurer un suivi de la réalisation de leurs engagements. Quel est le bilan?

Une enquête menée en 2008 auprès de 54 pays a montré que des progrès ont été réalisés, mais ils restent insuffisants pour atteindre les objectifs fixés pour 2010. Dans l'ensemble, il n'est pas plus fait appel qu'auparavant aux systèmes nationaux de gestion des finances publiques : depuis 2005, année de la première enquête, le montant des fonds acheminés via ces systèmes n'a crû que marginalement. Et les chiffres masquent d'importantes variations dans les pratiques observées entre les donneurs et dans les pays. Au Honduras, par exemple, 283 millions sur 331 millions de dollars passent par les systèmes nationaux d'exécution budgétaire, mais seulement 88 millions de dollars sont contrôlés par le système d'audit du pays. Ce qui signifie que des pays comme le Honduras n'ont pas une réelle maîtrise des fonds dont ils sont censés bénéficier. En d'autres termes, ils ne tiennent pas les rênes de leur propre développement.

Au Ghana, en septembre, les principes énoncés à Paris ont connu un nouvel élan une alliance sans précédent de partenaires du développement a prévu des mesures audacieuses pour améliorer l'efficacité de l'aide à l'égard de l'extrême pauvreté. Après des mois de négociations, les ministres présents au troisième Forum de haut niveau sur l'efficacité de l'aide (FHN), organisé sous les auspices du gouvernement du Ghana, de l'OCDE et de la Banque mondiale, ont entériné le Programme d'action d'Accra (PAA). Cette feuille de route marque un profond changement de comportement des donneurs comme des pays en développement. Elle vise à parachever le nouveau modèle de l'aide défini dans la Déclaration de Paris de 2005 et à produire des résultats tangibles, immédiats, là où ils sont le plus nécessaires.

Le PAA appelle à plus de transparence et de prévisibilité dans les transactions relatives à l'aide. Il exhorte les donneurs à limiter les conditions d'octroi de celle-ci et à la dissocier de l'obligation d'acheter biens et services au pays donneur. Il incite également les pays en développement à impliquer davantage parlementaires et citoyens, et les

\section{Il faut que chaque dollar d'aide donne plus de résultats}

donneurs à utiliser en premier ressort les systèmes nationaux de gestion des finances publiques des pays bénéficiaires lorsqu'ils octroient des aides. Enfin, le PAA multiplie la valeur de chaque dollar en enjoignant les donneurs de travailler ensemble, de se répartir les tâches et de veiller à ne pas toujours privilégier les mêmes secteurs.

Autre apport essentiel du PAA, il permet aux pays de gérer leur propre développement grâce à une plus grande prévisibilité de l'aide, les donneurs s'engageant à verser des fonds à moyen terme de sorte que les bénéficiaires puissent concevoir, budgétiser et exécuter leurs programmes sur la durée. Notre enquête de 2008 montre qu'en 2007, seuls $66 \%$ de l'aide ont été acheminés comme prévu. Prenons l'exemple du Bénin, l'un des pays africains les plus pauvres, qui devait recevoir 477 millions de dollars, mais n'en a finalement reçu que 151 millions. Cet écart par rapport aux prévisions pénalise durement des secteurs comme la santé, où il ne s'agit pas seulement de construire des hôpitaux, mais aussi de pouvoir compter sur des financements stables pour la distribution des médicaments et la rémunération du personnel des dispensaires.

Le PAA vise à remédier à d'autres insuffisances révélées par l'enquête, comme le fait que la décision des donneurs de recourir aux systèmes nationaux d'un pays ne semble pas dépendre de la qualité des systèmes en question. Limportant travail de réforme institutionnelle visant à renforcer et à rendre plus fiables les systèmes locaux restera sans effet si les donneurs ne jouent pas le jeu.

Il ne sera pas aisé de donner corps aux profonds changements prescrits par la Déclaration de Paris et renforcés par le Forum d'Accra. Les donneurs doivent pour cela accepter d'assouplir leur contrôle. L'enquête indique en effet qu'ils ont du mal à se modérer : en 2007 , 49 pays en développement ont accueilli 14054 " missions " de donneurs, soit près d'une par jour et par pays. Certains pays ont explicitement demandé des "périodes de calme " pour pouvoir s'occuper de leur travail substantiel, un vœu souvent resté lettre morte.

Cependant, si leur souhait de tenir davantage les rênes est légitime, les pays partenaires doivent en échange devenir plus actifs, par des politiques fermes, des capacités renforcées et une plus grande responsabilité envers leurs citoyens quant à leurs politiques de développement. L'enquête de l'OCDE montre que jusqu'ici seul un pays en développement sur cinq s'est doté de stratégies de développement opérationnelles conformes aux critères de la Banque mondiale, et moins de $10 \%$ appliquent des programmes axés sur les résultats.

Certes, un nombre croissant de pays en développement appliquent de véritables stratégies de réforme crédibles et ambitieuses. Et certains donneurs s'efforcent de renforcer les systèmes nationaux en les utilisant. En Zambie, on a pu constater une augmentation de $25 \%$ de l'utilisation des systèmes nationaux depuis 2006. De même, les donneurs commencent à réaliser que l'utilisation de ces systèmes peut contribuer à renforcer l'autorité de l'État dans les pays où elle est fragile. En outre, il y a moins d'aides liées qu'auparavant. Davantage de pays bénéficiaires utilisent l'aide pour s'approvisionner en biens et services sur les marchés locaux ou régionaux, et non plus nécessairement sur les marchés des pays donneurs. Selon l'OCDE, $60 \%$ des contrats sont conclus avec des sociétés situées hors du pays donneur, dont $40 \%$ se trouvent dans des pays en développement. 
Au forum d'Accra, les donneurs ont décidé de délier encore davantage leur aide par des offres plus variées et vers plus de pays. En 2001, les donneurs du Comité d'aide au développement (CAD), pourvoyeurs d'aide publique au développement (APD), avaient décidé d'accorder l'essentiel de leur aide aux pays les moins avancés. Aujourd'hui, grâce au PAA, ils la libéreront au profit des pays pauvres et très endettés (PPTE). Ainsi, l'essentiel de l'aide consentie aux 60 pays les plus pauvres n'est plus conditionnée.

Huit pays du CAD, l'Australie, la Belgique, l'Irlande, le Luxembourg, la Norvège, les Pays-Bas, le Royaume-Uni et la Suède, ont intégralement délié leur aide bilatérale. Quatre autres, l'Allemagne, le Danemark, la France et la Suisse, en ont délié la majeure partie. Laide provenant de la Millenium Challenge Corporation aux États-Unis (qui représente certes une part seulement de l'aide américaine) n'est pas liée, tandis que la Communauté européenne délègue la responsabilité de l'acheminement de son aide à d'autres donneurs selon des relations de réciprocité.

En conséquence, la part d'aide non liée est passée de $43 \%$ en 2002 à $53 \%$ en 2006. Laide liée a quant à elle reculé, passant de 7 à $3 \%$. Chiffres à l'appui, le PAA invite les autres donneurs, notamment l'Autriche, le Canada, l'Espagne, les États-Unis, la Grèce, l'Italie, le Japon et le Portugal, à suivre cette tendance.

LOCDE suivra les progrès réalisés, et demandera des comptes aux membres si les résultats ne sont pas au rendez-vous.

Quelle est la prochaine étape ? Le PAA requiert des résultats. Or, les défis à relever sont de taille, et la montée des prix alimentaires et pétroliers ainsi que les turbulences économiques mondiales compliquent la donne.

Cela dit, tout comme l'amélioration de l'aide favorise les échanges, des succès en termes de développement amélioreront le

\section{Du chemin à parcourir}

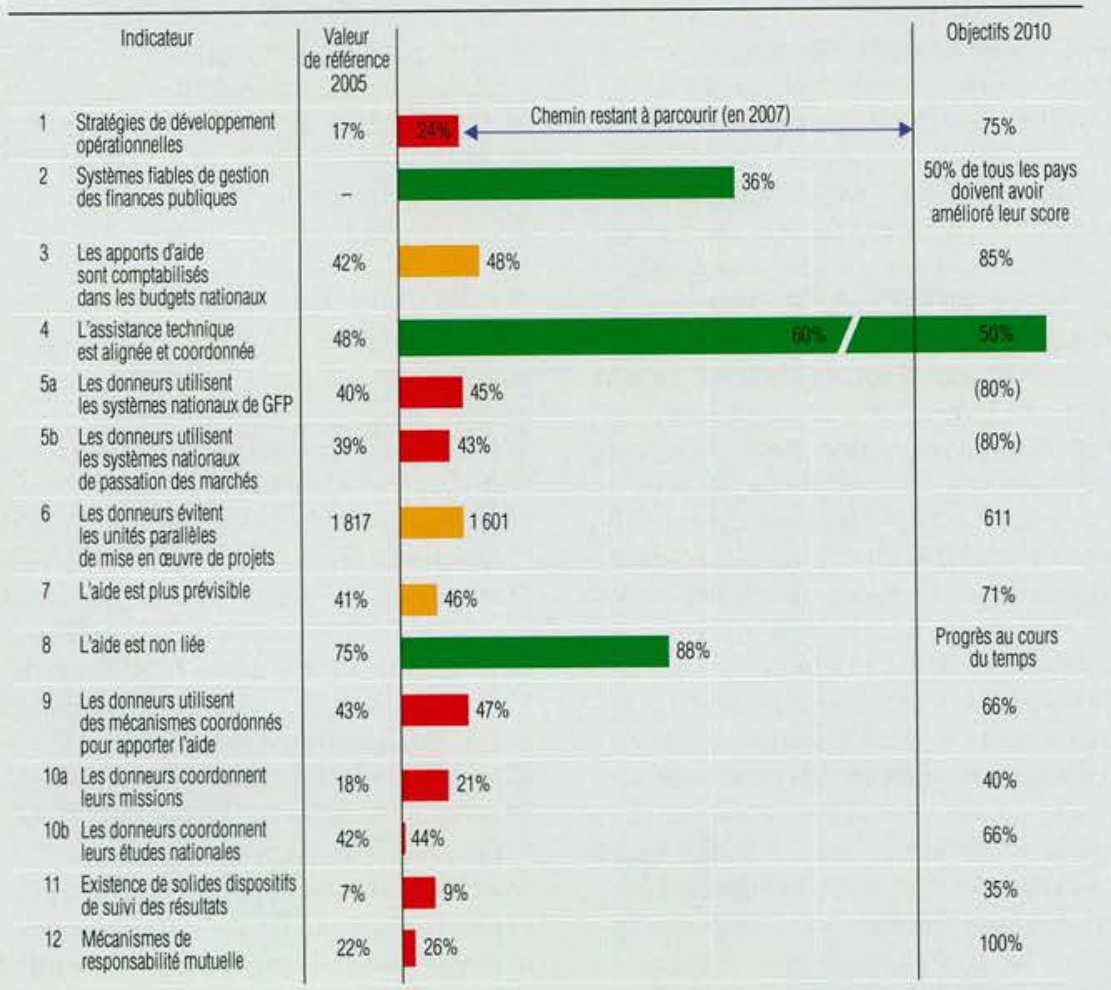

Source : OCDE (2008), Enquête 2008 de suivi de la mise en @euvre de la Déclaration de Paris : Rendre laide plus efficace dici 2010, Paris

financement. De nombreux donneurs se sont engagés à accroître leurs aides dans les prochaines années, encore faut-il qu'ils précisent quand. Car la prévisibilité de l'aide est une condition de l'amélioration des résultats.

La Déclaration de Paris et ses objectifs sont des projets politiques. Leur mise en œuvre soulèvera des questions de pouvoir et d'économie, c'est pourquoi l'engagement de l'ensemble des parties prenantes est crucial. À mesure que le PAA sera mis en acte, la société civile appellera les ministres à rendre compte des progrès réalisés, des pratiques observées et des programmes mis en cuvre.

Le dernier paragraphe du Programme d'action d'Accra adresse un message fort : "Aujourd'hui plus que jamais, nous sommes déterminés à cuvrer ensemble pour aider les pays du monde entier à construire cet avenir prometteur que nous appelons de tous nos vœux, un avenir bâti sur une volonté commune de surmonter la pauvreté, un avenir dans lequel plus aucun pays ne dépendra de l'aide. " Pour le moment, nous en sommes encore au stade des mots. Pour donner aux 1,4 milliard de personnes qui vivent encore dans l'extrême pauvreté la possibilité de mener une existence meilleure, les gouvernements et les autres participants au Forum devront prouver qu'ils savent vraiment passer des paroles aux actes.

LOCDE s'attelle à la tâche. Le Programme d'action d'Accra contribuera à changer les modalités de l'aide, pour permettre aux pays en développement de s'en affranchir définitivement. C'est là le but de l'aide au développement. CG

\section{Références}

- OCDE (2008), Enquête 2008 de suivi de la mise en auvre de la Déclaration de Paris : Rendre l'aide plus efficace d'ici 2010, Paris.

- Voir www.oecd.org/dac/hlfsurvey

- Voir www.accrahilf.net pour plus de détails sur le Programme d'action d'Accra.

- Pour plus d'informations, veuillez contacter Brenda.Killen@oecd.org ou Christine.Graves@oecd.org

- Voir « Report on the Use of Country Systems in Public Financial Management ", www.oecd.org/dataoecd/29/20/41085468.pdf 


\section{Rééquilibrer la richesse des Etats}

Javier Santiso, Directeur et Chef économiste du développement, Centre de Développement de l'OCDE

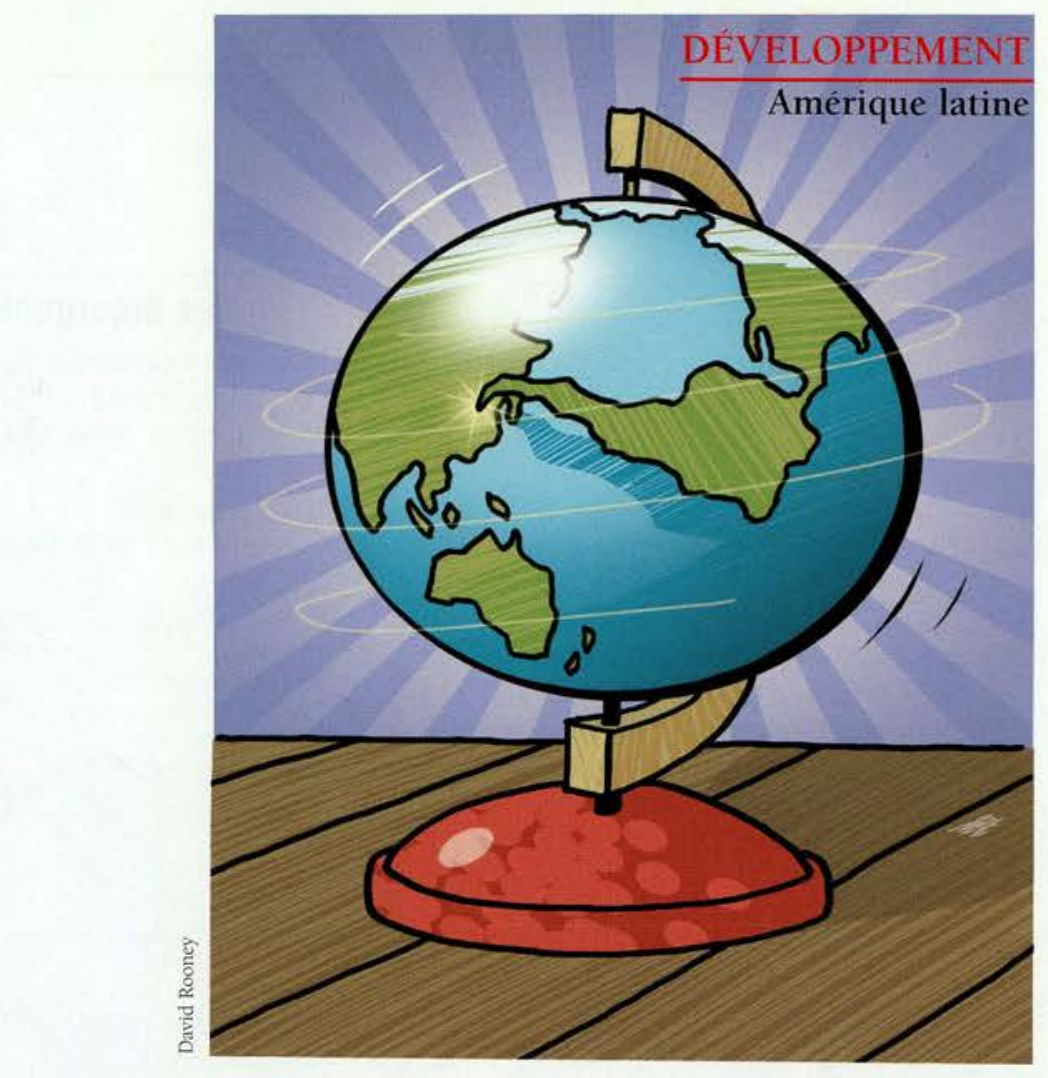

\section{Les marchés émergents comme la Chine, l'Inde et le Brésil sont de plus en plus considérés comme des acteurs centraux sur les marchés mondiaux. Ce "rééquilibrage" peut-il continuer malgré la crise actuelle?}

I ly a 10 ans, face à un ralentissement de l'économie américaine, les économies d'Amérique latine se seraient effondrées comme un jeu de dominos. Aujourd'hui, elles restent relativement solides dans la tourmente financière mondiale, qui met à rude épreuve les États-Unis et d'autres pays de l'OCDE. De nombreux économistes ont même affirmé ces derniers mois que l'Amérique latine avait opéré un « découplage » et se serait affranchie de la domination économique de son voisin d'Amérique du Nord.

Ce n'est certainement pas le cas, comme l'indiquent les dernières Perspectives économiques de l'Amérique latine. La région connaîtra un ralentissement en 2009, dont la gravité dépendra de celui des pays de l'OCDE. Nous assistons cependant à un phénomène plus profond. Une véritable secousse sismique s'est produite. Bien plus qu'un simple découplage entre pays voisins, elle a entraîné un rééquilibrage fondamental dans la répartition des richesses entre les États. Les capitaux se déplacent à travers le monde, et il en va de même pour la richesse, les courants d'échanges et la puissance. Ainsi, alors que la crise financière frappe l'ensemble des marchés financiers, y compris d'Amérique latine, tout porte à croire que des pays en développement autrefois dépendants pourraient non seulement résister à la crise, mais en sortir avec un sentiment de puissance jamais atteint auparavant, en termes relatifs, par rapport aux pays de l'OCDE

La part de l'OCDE dans la production mondiale est en déclin depuis quelques années, et le marché américain des actions (avant la crise) ne représentait qu'un peu plus de $30 \%$ de la capitalisation boursière mondiale, contre $50 \%$ dix ans auparavant. En 2007, la part de l'investissement direct étranger en provenance des pays de l'OCDE a reculé à $85 \%$ alors qu'elle était presque de $100 \%$ en 1970. Signe de ces évolutions, le Mexique, la Corée et la Turquie, trois grands marchés émergents, sont déjà membres de l'OCDE, et d'autres, comme le Chili, Israël ou la Russie, sont engagés dans le processus d'adhésion.

Les mêmes tendances sont perceptibles chez les entreprises. Pour l'Amérique latine, citons ImBev, née de la fusion de brasseurs belge et brésilien. Cette société est déjà une sorte d'OVNI issu de ces nouvelles relations mondiales : inclassable selon les schémas usuels, car autant acteur de marché émergent que des pays riches de l'OCDE, le groupe a récemment acquis Anheuser-Busch, icône des brasseurs nord-américains. Cemex, le géant mexicain du ciment, a toujours son siège à
Monterrey, mais ses centres de recherche économique, financière et stratégique sont en Espagne. Le Brésil en particulier s'affirme comme une puissance commerciale mondiale, présente sur des marchés aussi éloignés que le Moyen-Orient, l'Afrique ou l'Asie du Sud-Est. Des entreprises comme Vale, Petrobras ou Odebrecht sont actives sur les marchés africains tandis qu'Embraer et Marcopolo deviennent des acteurs importants en Chine. Ces multilatinas, qui ont leur siège en Amérique latine, s'inscrivent dans un mouvement lancé par des entreprises indiennes, chinoises, russes et d'Afrique du Sud, entre autres. De fait, n'estil pas ironique que Tata, entreprise indienne, soit désormais propriétaire d'anciens joyaux de l'Empire britannique tels que Corus (autrefois British Steel), Jaguar et Rolls-Royce? Bien plus qu'à un découplage, nous assistons à l'émergence d'un monde beaucoup plus multipolaire.

Tout ceci ne signifie pas que l'Amérique latine est à l'abri de revers sur les marchés extérieurs, surtout aux États-Unis. Le Mexique en particulier : près de $85 \%$ de ses exportations vont aux États-Unis, contre $40 \%$ en moyenne pour l'ensemble de l'Amérique latine. Les exportations mexicaines vers les États-Unis représentaient $27 \%$ de son PIB en 


\section{Amérique latine}

2007, contre $3 \%$ pour le Brésil. Le secteur bancaire peut également faire office de circuit de transmission des chocs : au Mexique, les actifs des banques sont détenus à hauteur de $85 \%$ par des étrangers (parmi lesquels des banques en grande difficulté) alors qu'au Brésil par exemple, ce pourcentage est inférieur à $30 \%$.

Les effets de la crise actuelle ne se limiteront pas au Mexique ou à l'Amérique centrale. À l'instar du peso mexicain, le réal brésilien a subi récemment une dépréciation qui donne la mesure de la vulnérabilité des entreprises d'Amérique latine, dont la dette est libellée en dollars, et de leur exposition aux risques inhérents aux marchés d'instruments dérivés. La réduction de l'effet de levier recherchée par les investisseurs affecte déjà la liquidité dans les économies émergentes, y compris d'Amérique latine. Les envois de fonds par les expatriés en pâtiront également et devraient décliner en termes réels pour la première fois de l'histoire récente: selon les estimations de la Banque interaméricaine de développement, pondérées de l'inflation et des variations des taux de change, la contribution qu'ils apporteront aux revenus des ménages des pays d'Amérique latine et des Caraïbes sera inférieure de $1,7 \%$ à ce qu'elle était en 2007.

Cependant, l'économie du Mexique, du Brésil et de la plupart des pays d'Amérique latine est bien plus dynamique qu'il y a 10 ans, et ils peuvent peut-être supporter la tourmente. Les budgets et les balances des paiements courants sont plus sains, la dette publique extérieure est faible, l'inflation contenue, et la hausse des recettes pétrolières et minières a donné un coup de fouet à l'investissement, qui a progressé de $50 \%$ en 2007. Bien sûr, cet élan retombera quelque peu avec la baisse des cours du pétrole brut dès le dernier trimestre 2008 et au-delà. En outre, l'Amérique latine bénéficie pour la première fois de plus d'un ou deux moteurs exogènes de la croissance (les États-Unis et l'Europe), avec un troisième facteur exogène de croissance majeur : l'Asie.

La véritable inconnue pour 2009 et au-delà n'est donc pas seulement la situation des États-Unis, mais aussi celle la Chine. Si la demande chinoise ne faiblit pas, les exportations de matières premières pourraient être suffisamment résilientes pour empêcher une récession en Amérique latine. Il y a 10 ans à peine, lìdée même que l'Amérique latine puisse échapper à la force d'entraînement des
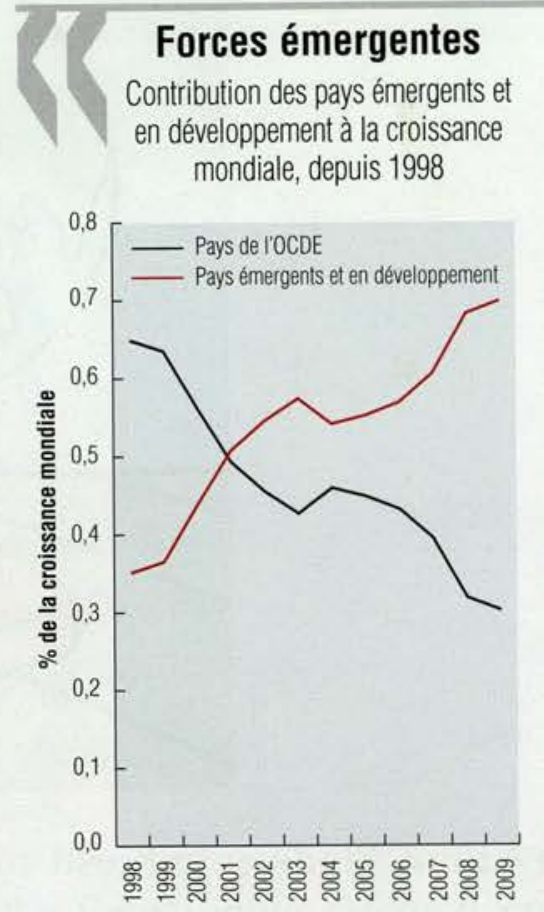

Source : Centre de Développement de l'OCDE, basé sur la World Economic Outlook Database du FMI, avril 2008

États-Unis aurait été immédiatement rejetée. Aujourd'hui, un repli brutal de l'économie en Extrême-Orient pourrait inquiéter l'Amérique latine autant qu'une récession aux États-Unis. Si la croissance en Chine est atteinte par la crise économique et financière que connaissent les pays de l'OCDE - ce qui est loin d'être purement théorique - l'impact sera plus important, surtout sur les marchés de matières premières.

Lun des principaux ingrédients du rééquilibrage des richesses entre les États est le développement des relations Sud-Sud, alors que le centre de gravité de l'économie mondiale se déplace. Les chiffres l'attestent : en 2007, pour la première fois de l'Histoire, les exportations des marchés émergents en direction de la Chine ont dépassé les exportations en direction des États-Unis, et la tendance devrait se poursuivre du fait du tassement de la demande américaine en 2009. En 2006, la Chine s'est retrouvée à son tour pour la première fois davantage tournée vers les économies émergentes que vers les riches pays du G7 : au début des années 2000 , les exportations chinoises en direction des pays du G7 représentaient près de $50 \%$ des exportations chinoises totales ; depuis, cette part est retombée à environ $40 \%$, alors que les exportations en direction des marchés émergents progressent. La moitié des exportations chinoises afflue désormais vers des pays émergents, notamment d'Amérique latine. Et l'inverse est également vrai. Le Chili par exemple exporte déjà vers l'Asie $36 \%$ de sa production totale, soit plus que vers toute autre région du monde, la Chine recevant à elle seule la moitié de ce flux.

La question est donc de savoir comment cette nouvelle Amérique latine va réagir à la récession mondiale imminente. Comme d'autres marchés émergents, elle n'échappera probablement pas aux nuages venus du Nord qui s'amoncellent au-dessus d'elle, mais ses relations avec les marchés asiatiques devraient lui permettre d'éviter un déluge. Il semble probable que des pays comme la Chine, l'Inde et le Brésil vont ressentir les effets de la crise mondiale, mais ils sont à présent plus robustes que par le passé et mieux à même de poursuivre le recentrage économique mondial. Nous ne faisons qu'entrer dans un nouvel ordre mondial, un mundo féliz, où les pays de l'OCDE demeureront des acteurs majeurs, mais où l'Asie et l'Amérique latine auront elles aussi voix au chapitre.

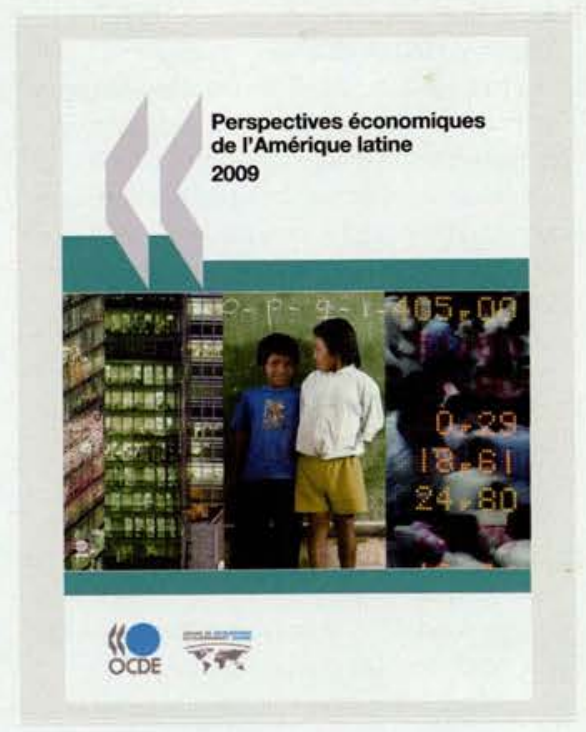

Références

- OCDE (2008), Perspectives économiques de l'Amérique latine 2009, Centre de développement de l'OCDE, Paris Disponibles sur www.oecd.org/librairie

- Santiso, Javier (2005), Amérique latine révolutionnaire, libérale, pragmatique, Éditions Autrement 


\section{Le futur d'Internet ?}

\section{Soyez prêt pour l'Exaflood.}

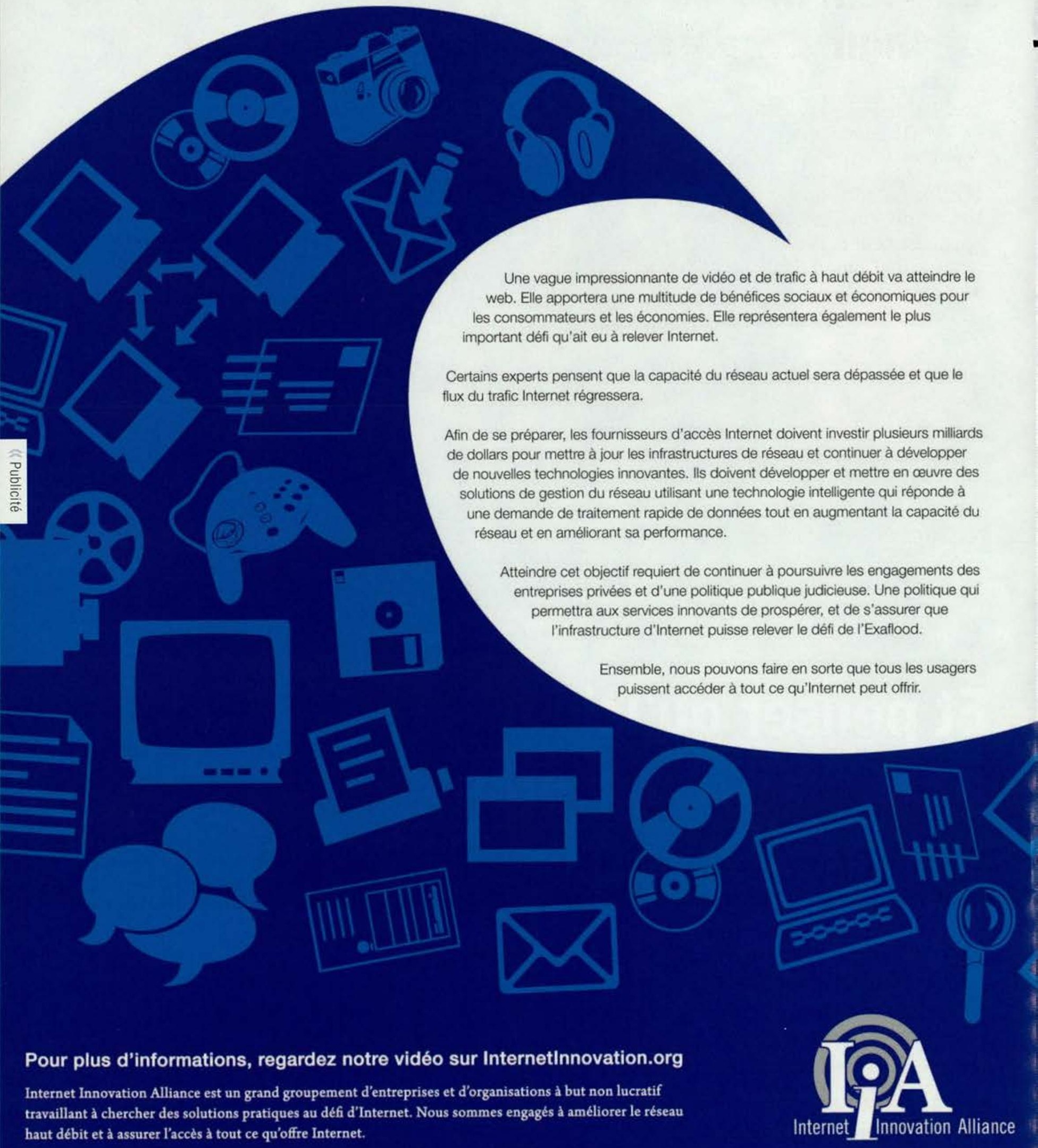




\section{Ouverture, réformes et économie du changment climatique}

\author{
Réunion annuelle du Conseil \\ de l'OCDE au niveau des \\ Ministres, Paris, 4-5 juin 2008
}

Des inquiétudes sur l'économie mondiale apparaissaient déjà lors de la réunion du Conseil de l'OCDE au niveau des Ministres (RCM), en juin dernier.

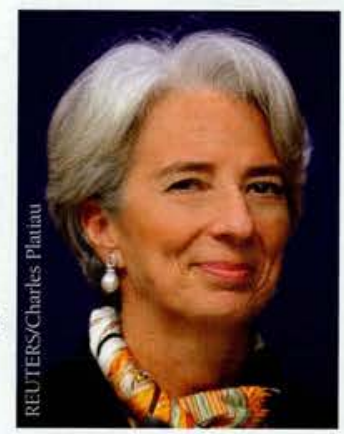

$\mathrm{L}$ a ministre des Finances française, Christine Lagarde (photo), a présidé la Réunion annuelle du Conseil au niveau des Ministres - point d'orgue du calendrier de l'OCDE - et son résumé de la réunion avait des accents quelque peu prémonitoires quant à l'économie, les ministres appelant à la « poursuite d'une coordination étroite des politiques. » Pourtant, l'opinion commune était alors encore relativement optimiste. Malgré les « chocs » qui avaient secoué l'économie mondiale, l'OCDE montrait une * capacité de résistance (...) aux vents contraires " grâce aux * réformes structurelles engagées et aux politiques macroéconomiques judicieuses * de ces dernières années. Mais l'on devait garder un œeil vigilant sur les marchés financiers, où * les conditions actuelles de crédit freinent l'investissement. *

Le Conseil de 2008, suite à « la décision historique de la RCM de 2007 » d'augmenter le nombre d'États membres de l'OCDE, a accueilli pour la première fois cinq pays candidats, le Chili, l'Estonie, Israël, la Fédération de Russie, et cinq pays dits « de l'Engagement renforcé ", le Brésil, l'Inde, l'Indonésie, la Chine et l'Afrique du Sud, pour participer à cet événement.

Les ministres ont félicité le Secrétaire général Angel Gurría pour son dynamisme et son autorité, que reflète le rapport sur les nouvelles orientations stratégiques de l'OCDE, intitulé « Rester pertinent pour faire progresser l'économie mondiale. „ Il fournit à l'OCDE les moyens de répondre aux défis à venir et de s'y adapter. Les ministres ont convenu que «l'économie du changement climatique, les pressions sur les ressources, les inégalités et la pauvreté dans le monde restent aux premiers rangs des priorités de l'OCDE. "

Les ministres ont encouragé l'OCDE à continuer de concevoir l'architecture de la gouvernance mondiale, et ont adopté la Déclaration sur la cohérence des politiques au service du développement, à laquelle l'Estonie et la Slovénie ont adhéré. Il s'agit d'un engagement à dialoguer davantage entre pays partenaires, et un appel à une meilleure coopération internationale pour étendre les bénéfices de la mondialisation, couvrant le commerce, lagriculture, les migrations, l'environnement, les sciences et technologies, de même que l'énergie et la sécurité. Cette déclaration invite l'OCDE à présenter des exemples d'avantages mutuels ou de compromis associés à la cohérence des politiques du développement.
Le changement climatique est l'un des plus grands défis, et tandis que chaque pays doit concevoir sa propre panoplie de mesures, de nombreux ministres ont constaté que les instruments de marché, comme les taxes et les mécanismes de droit d'émissions de carbone, les incitations financières et fiscales, la suppression de subventions, les garanties de prêts et l'élimination des droits de douane sur les biens et services environnementaux, sont essentiels, et doivent être complétés par le recours aux énergies propres ou les dispositifs réglementaires, entre autres.

Les ministres ont souligné l'importance de la coopération internationale, et beaucoup d'entre eux ont mis l'accent sur le principe de « la responsabilité commune mais différenciée et la capacité de chacun (...) pour parvenir à un accord international ambitieux. " * Un cadre international efficace pour l'après-2012 et les politiques nationales correspondantes devront stimuler linnovation » et accélérer la diffusion de technologies vers les pays en développement. Les ministres ont invité l'OCDE à poursuivre ses travaux sur le changement climatique, « en collaboration avec l'AIE et d'autres organisations internationales, »

Concernant le système commercial multilatéral, les ministres ont souligné « la nécessité d'une plus grande ouverture des marchés pour les échanges de biens et de services agricoles et industriels ", d'en améliorer la compréhension par le public, et de bâtir une « argumentation solide en faveur d'une libéralisation supplémentaire des échanges ", que l'OCDE promouvra et nourrira de ses conseils et analyses.

Concernant les fonds souverains, les ministres ont salué les avantages qu'ils apportent. Ils ont adopté la Déclaration de l'OCDE sur les fonds souverains et les politiques des pays d'accueil. Les ministres du Chili, de l'Estonie et de la Slovénie y ont adhéré.

Les ministres ont ensuite discuté de la manière d'engager les réformes et d'obtenir le soutien de leurs concitoyens, et ont demandé à ce que l'OCDE travaille sur ces sujets. Les ministres ont également convenu d'une réforme majeure du financement de l'OCDE afin qu'une base financière solide à long terme lui permette d'atteindre ses priorités, et de " préserver linfluence de l'OCDE ainsi que sa pertinence et son excellence. * $\mathrm{RJC}$

Lisez le résumé complet de la Présidence sur www.oecd.org/mcm2008-fr Pour plus d'informations sur le changement climatique, voir www.oecd.org/env/cc-fr

Sur le commerce, voir www.oecd.org/tad/echange

Sur les fonds souverains, voir www.oecd.org/daf/investissement Sur la Déclaration sur la cohérence des politiques au service du développement, voir www.oecd.org/mcm2008-fr

\section{Sommet du G8}

Le changement climatique a dominé le programme du sommet du G8, du 7 au 9 juillet à Toyako, sur lìle d'Hokkaido au Japon. Le Secrétaire général de l'OCDE Angel Gurría était présent à cette réunion, où se sont rencontrés sept pays membres de l'OCDE (ÉtatsUnis, Japon, Allemagne, Royaume-Uni, France, Italie, Canada) et la Russie, candidate pour l'adhésion à l'OCDE. Ces États ont approuvé un communiqué qui prévoit leur active participation aux pourparlers des Nations unies, avec 200 autres États, sur l'objectif de réduire de moitié au moins les émissions de gaz a effet de serre d'ici à 2050.

Pour plus d'informations sur ce communiqué, voir www.g8summit.go.jp, et sur les relations entre le G8 et l'OCDE, voir www.oecd.org/G8-fr. 


\section{Visite du président des États-Unis}

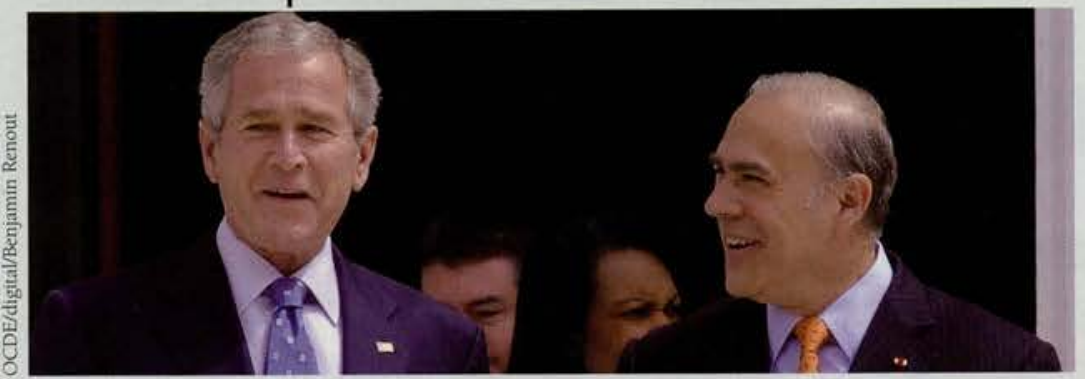

Le Président des États-Unis George W. Bush a été reçu par Angel Gurria, Secrétaire général de l'OCDE, au siège de l'Organisation le 13 juin 2008. M. Bush a prononcé un discours pour la commémoration du $60^{\mathrm{eme}}$ anniversaire du Plan Marshall, dont l'OCDE « conduit [l'esprit] vers un siècle nouveau *. Il a également évoqué l'amitié franco-américaine - « La France fut la première amie des États-Unis * - les relations entre l'Europe et les États-Unis, et des questions plus vastes telles que la sécurité internationale.

Une vidéo et une retranscription de ce discours (en anglais uniquement) sont disponibles sur www.oecd.org

\section{N'oublions pas la planète !}

L es turbulences sur les marchés financiers et le changement

climatique étaient au programme du Forum 2008 de l'OCDE (www.oecd.org/forum2008-fr). Chaque année, le Forum permet aux représentants de la société civile d’influer sur la "Semaine de l'OCDE », et a lieu conjointement à la réunion annuelle des ministres de l'OCDE.

La tempête financière n'a pas entièrement surpris : le président de la Banque centrale européenne, Jean-Claude Trichet, a indiqué que des signes avant-coureurs étaient visibles dès début 2007. Soulignant la nécessité d'améliorer la transparence et l'information, il a appelé à une nouvelle méthodologie pour anticiper les prochaines turbulences. Robert Kuttner, co-rédacteur en chef de The American Prospect, a affirmé que ce quil considérait déjà comme une " crise " remettait en question la notion d'efficience des marchés financiers. Susan George, Présidente du Conseil d'administration du Transnational Institute, a relevé que les fusions entre institutions financières privées avaient fait naître de très grands groupes, qui ont cru bon de réaliser des investissements toujours plus risqués. Or ni les agences de notation ni les autorités de tutelle n'ont tiré la sonnette d'alarme.

Les participants au Forum ont majoritairement convenu que la situation financière ne devait pas être prétexte à retarder l'action publique en matière de changement climatique. Des partenariats solides et une volonté politique forte sont indispensables pour relever ce défi. C'est ce qu'a confirmé la ministre des Affaires économiques suisse, Doris Leuthard, qui a souligné la détermination commune du monde de l'entreprise, des syndicats et de la société civile contre le changement climatique. Mais si le potentiel qu'offre la technologie suscite l'optimisme, les difficultés des chefs d'État à s'accorder sur les mesures à prendre engendrent une certaine frustration.

Toute action véritable est entre les mains des décideurs politiques, a rappelé le Secrétaire général de l'OCDE Angel Gurría, lors d'une session réunissant le Prince Albert II de Monaco, le ministre du Commerce extérieur néo-zélandais Phil Goff et le secrétaire exécutif de la CCNUCC, Yvo de Boer. Les participants ont rappelé que le changement climatique est le problème de tous. Ils ont demandé instamment aux responsables politiques de profiter de l'empressement de l'opinion publique à combattre le changement climatique. Comme l'a démontré le Forum, seuls le dialogue et la coopération peuvent renforcer la mobilisation pour la protection de la planète. John West
Internet stratégique

Réunion ministérielle de l'OCDE sur le futur de l'économie Internet, Séoul, Corée, 17-18 juin 2008

La première réunion ministérielle de l'OCDE au complet en Asie s'est achevée le 18 juin 2008 par une déclaration visant à renforcer la confiance et à préparer lavenir de l'économie Internet. Elle définit une feuille de route pour réactualiser les politiques de communication qui ont fait d'Internet un moteur économique capital, et pour préparer son avenir. En partenariat avec les pays développés et en développement, et avec les organisations internationales, l'OCDE dirigera des travaux visant à améliorer les politiques et à renforcer la coopération dans la lutte contre la cybercriminalité et pour la sécurité sur Internet.

Signe d'une OCDE plus ancrée dans la mondialisation, les pays membres et la Communauté européenne ont été rejoints par des ministres représentant le Chili, l'Égypte, l'Estonie, l'Inde, l'Indonésie, Israël, la Lettonie, le Sénégal et la Slovénie, affirmant leur engagement à travailler ensemble afin de soutenir l'innovation, la concurrence et l'investissement dans les technologies de linformation et des communications. Tous les représentants ont unanimement reconnu la nécessité de travailler en étroite collaboration avec les entreprises, la société civile et les spécialistes techniques afin d'élaborer des politiques capables d'améliorer à la fois l'autonomie et la protection des consommateurs, et d'étendre l'accès à Internet dans le monde entier.

"Étant donné le rôle désormais stratégique de cette infrastructure dans nos économies et dans nos sociétés, nous devrions tous nous engager à développer des mécanismes de gouvernance et des politiques plus efficaces et plus larges », a déclaré le Secrétaire général de l'OCDE Angel Gurría dans son allocution de clôture.

La réunion a été accueillie par le gouvernement coréen, 10 ans après la première réunion ministérielle de lOCDE consacrée au commerce électronique à Ottawa (Canada), alors que des progrès décisifs étaient réalisés dans des domaines comme la fiscalité. Comme l'a souligné M. Gurría : " 10 ans...c'est une éternité à l'échelle d'Internet ». Il s'est engagé à évaluer les progrès réalisés sur la base de la Déclaration de lOCDE d'ici à trois ans.

Pour obtenir le compte rendu complet de la réunion et les discours, voir www.oecd.org/futurinternet. Lire également l'article www.observateurocde.org/seoulinternet2008. 


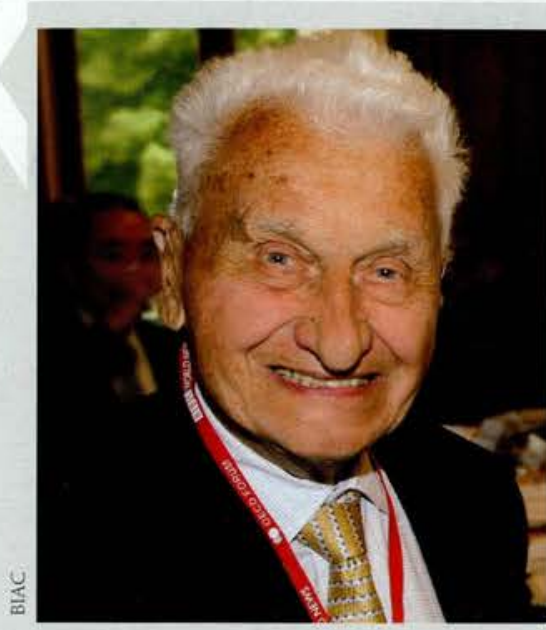

Thomas Bata, propriétaire de l'entreprise multinationale de chaussures du même nom, est décédé à Toronto le $1^{\text {er }}$ septembre, à 93 ans. Lun des pères fondateurs du Comité consultatif économique et industriel auprès de l'OCDE (BIAC) en 1962, M. Bata l'a présidé de 1968 à 1970 et il est demeuré actif dans l'organisation par la suite, notamment en tant que président du Comité des non membres du BIAC, jusqu’à son décès. M. Bata, qui vivait au Canada, est né à Prague le 17 septembre 1914. Issu d'une famille de cordonniers depuis 10 générations, il a dirigé la Bata Shoe Organisation des années 1940 aux années 1980. Après la chute du bloc soviétique, l'entreprise retourna en République tchèque, près de 100 ans après sa création en 1894. Des chefs d'entreprise et dirigeants politiques du monde entier ont exprimé leurs condoléances.

Voir www.biac.org.

\section{Nouveaux ambassadeurs}

11 juillet 2008 - Ulrik Vestergaard Knudsen a pris ses fonctions en tant qu'ambassadeur du Danemark. Il succède à Steffen Smidt.

23 juillet 2008 - Dominic Martin remplace David Lyscom au poste d'ambassadeur du Royaume-Uni. $1^{\text {er }}$ août 2008 - Antonio Armellini devient ambassadeur d'Italie. Il remplace Bruno Cabras.

26 septembre 2008 - Choongsoo Kim succède à Tae-shin Kwon en tant que nouvel ambassadeur de Corée.

\section{Discours récents d'Angel Gurría}

Pour une liste complète des discours et allocutions en français, anglais et autres langues, voir www.oecd.org/discours.

\section{Léconomie mondiale et lOCDE : tirer les leçons de la crise financière \\ $1^{\text {er }}$ octobre 2008 \\ Discours prononcé devant l'Assemblée parlementaire du Conseil de l'Europe. Strasbourg, France.}

The art of making reform happen: Learning from each other

25 septembre 2008

Discours d'ouverture prononcé lors de la réunion annuelle des Hauts responsables des Centre de gouvernements sur « L'Économie politique de la réforme : s'assurer le soutien des parties prenantes ». Mexico, Mexique.

Environnement et changement climatique : libérer le potentiel d'innovation

16 septembre 2008
Discours d'ouverture à l'occasion du Conseil mondial de l'énergie : sommet * Energy Leaders *. Londres, Royaume-Uni.

Water prices for agriculture

12 septembre 2008

Remarques prononcées lors de l'International Advisory Committee of Expo Zaragoza 2008. Saragosse, Espagne.

Offrir à tous un environnement de qualité : bien plus qu'un problème de financement

9 septembre 2008

Remarques prononcées lors de la présentation de l'édition 2008 de Regards sur l'éducation, Centre de conférences de l'OCDE. Paris, France.

$50^{\mathrm{eme}}$ anniversaire du Modèle de convention fiscale de l'OCDE

8 septembre 2008
Remarques prononcées lors de la conférence pour le $50^{\text {ème }}$ anniversaire du Modèle de convention fiscale de l'OCDE, Centre de conférences de l'OCDE. Paris, France.

\section{Aid effectiveness}

4 septembre 2008

Discours d'ouverture prononcé lors du Forum de haut niveau sur l'efficacité de l'aide d'Accra - journée ministérielle. Accra, Ghana.

Leau pour tous : une question de bonne gouvernance - Le point de vue de l'OCDE $1^{\text {er }}$ septembre 2008

Allocution prononcée lors du $13^{\text {ème }}$ Congrès mondial de l'eau. Montpellier, France.

Globalisation: A learning curve

12 août 2008

Réflexions tirées de l'expérience de l'OCDE, exprimées à l'Université de Sydney, Australie.

Léconomie politique de la réforme : mettre en œuvre le changement

3 août 2008

Remarques prononcées lors de la Réunion ministérielle de l'APEC sur la réforme structurelle. Melbourne, Australie.

The global financial crisis: Where to next, and what does it mean for OECD countries?

29 juillet 2008

Discours prononcé à l'Université Victoria et au New Zealand Institute of International Affairs. Wellington, Nouvelle-Zélande.

Lifting productivity: Lessons from the OECD 29 juillet 2008

Discours prononcé devant la Chambre de Commerce de Nouvelle-Zèlande. Wellington, Nouvelle-Zélande.

Indonesia outlook

24 juillet 2008

Discours prononcé à l'occasion de la parution de OECD Economic Assessment of Indonesia (version française à paraître). Djakarta, Indonésie.

South Africa outlook

15 juillet 2008

Discours prononcé à l'occasion de la parution de OECD Economic Assessment of South Africa (version française à paraître). Pretoria, Afrique du Sud.

Challenges in an urban age: Rethinking metropolitan regions in the $O E C D$ and beyond

12 juillet 2008

Discours prononcé lors de la conférence sur les défis urbains, organisée par La Conférence Olivaint. Paris, France. 


\section{Programme des conférences}

Veuillez noter que la plupart des réunions ne sont pas ouvertes au public mais sont mentionnées pour information. Sauf indication contraire, toutes les réunions se tiennent à Paris. Ce document est mis à jour chaque semaine sur le site Internet de l'OCDE : www.oecd.org/media/enbref.

\section{SEPTEMBRE - Temps forts}

2-4 Forum de haut niveau sur l'efficacité de laide, organise par la direction de la Coopération pour le développement. Accra, Ghana.

8-9 Conférence célébrant le 50 eme anniversaire du Modèle de Convention fiscale de l'OCDE

8-10 Enseignement supérieur : qualité, pertinence et impact, conférence organisée par la direction de l'Éducation. Publication de Regards sur l'éducation.

9 Publication des Perspectives des migrations internationales 2008.

17 Améliorer l'efficacité des systèmes de santé : optimiser l'utilisation des ressources, conférence organisée par la direction de l'Emploi, du Travail et des Affaires sociales et la Commission européenne. Bruxelles, Belgique.

23 Food and Fuel Prices, atelier organisé par l'OCDE, le FMI et la Banque mondiale. Washington, États-Unis.

29-30 Latin American Anti-Corruption Conference: Renewed Commitment and Enhanced Co-operation in the Fight against Transnational Bribery, conférence organisée par le gouvernement du Mexique avec la division Anti-corruption de la direction des Affaires financières et des Entreprises. Mexico City, Mexique.

\section{OCTOBRE}

Débat élargi annuel de l'Assemblée parlementaire du Conseil de l'Europe concernant IOCDE et l'économie mondiale. Strasbourg, France.

la direction des Affaires publiques et de la Communication de l'OCDE.

2

Financial Awareness, conférence à haut niveau organisée par la Banque centrale de Hongrie. Publication de l'Examen environnemental de la Hongrie. Budapest, Hongrie.

11-13 Réunion annuelle du FMI et de la Banque mondiale. Washington, D.C., États-Unis.

$50^{\text {eme }}$ anniversaire de l'Agence pour l'énergie nucléaire

Conférence ministérielle Euro-Africaine sur les Migrations et le développement

Publication des Perspectives de l'OCDE de la science, de la technologie et l'industrie, édition 2008

Financial Education, conférence internationale organisée par la direction des Affaires financières et des

Entreprises et la Bank Indonesia.

Jakarta, Indonésie.

La politique des prix des médicaments, symposium à haut niveau organisé par la direction de I'Emploi, du Travail et des Affaires sociales.

Lancement des Perspectives économiques de l'Amérique latine 2009 , organisé par le centre de

Développement de l'OCDE

San Salvador, El Salvador.

30-31 Forum mondial sur les pensions privées, organisé par la direction des Affaires financières et des Entreprises, et l'International Organisation of Pension Supervisors (IOPS). Mombassa, Kenya

\section{NOVEMBRE}

3-4 OECD Policy Dialogue on Aid for Trade, réunion organisée par la direction des Échanges et de l'Agriculture et le comité d'Aide au développement.

3-4 The Measurement of Human Capital, atelier technique organisé par la

Direction des Statistiques et la Fondazione Giovanni Agnelli Turin, Italie.

18-19 Innovation and Sustainable Growth in a Globalised World, conférence OCDE-Banque mondiale

24-26 Table ronde sur le gouvernement d'entreprise en Amérique Latine. Mexico City, Mexique

\section{DÉCEMBRE}

$1-2$

Financement et tarification de l'eau rôles des politiques gouvernementales, du secteur privé et de la société civile. réunion du forum mondial de l'OCDE sur le développement durable

1-2 Careers and Mobility of Doctorate Holders, conférence organisée par la direction de la Science, de la Technologie et de l'Industrie.

Bruxelles, Belgique.

15-16 Visite officielle du Secrétaire général à Ankara, Turquie. Publication de Environmental Performance Review of Turkey.

JANVIER 2009

28-1/2 Forum économique mondial, réunion annuelle. Davos, Suisse
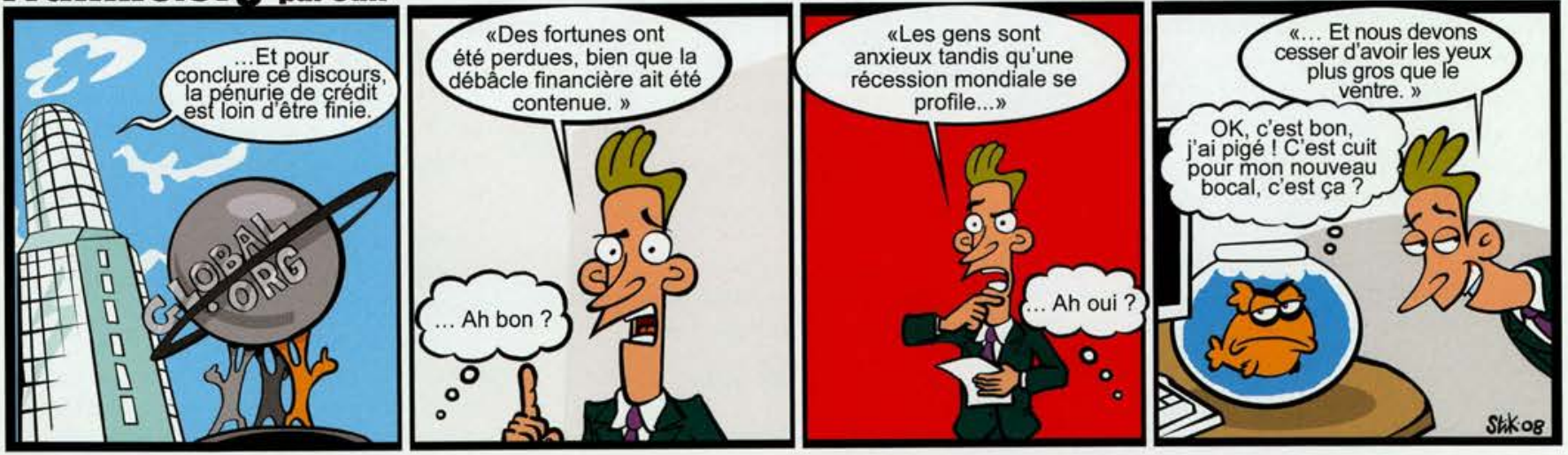


\section{L'école de demain}

Les grandes mutations qui transforment l'éducation

I Géducation est un investissement à long terme, bien que soumis aux constants changements sociaux et économiques, et donc difficile à planifier. Analyser ses tendances actuelles permet d'en prévoir les évolutions, et c'est l'objet de ce rapport. Il examine 26 tendances majeures, comme les évolutions démographiques, économiques, politiques, sociales, ainsi que les innovations technologiques et le changement climatique. Chaque tendance est expliquée et évaluée, puis analysée suivant son impact potentiel sur l'éducation. Prenons les technologies de l'information. Depuis les années 1990 et l'avènement d'Internet, elles font partie intégrante de l'apprentissage, du

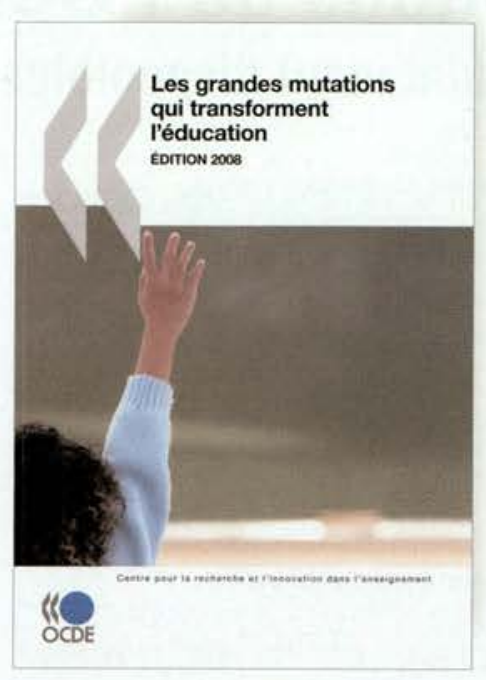

multimédia à l'open source, en passant par les sites wikis et les blogs. L'école forme-t-elle suffisamment les élèves en la matière?

Létude analyse aussi les impacts sociaux tels que le viellissement, qui a un fort impact sur l'enseignement et l'investissement. La natalité est faible dans les pays développés, ce qui laisse présager une baisse des effectifs scolaires, sans pour autant mettre fin à la pénurie globale d'enseignants. Cela affectera les communautés locales et l'économie à une échelle plus large. Le rapport soulève aussi la question de l'adaptation des écoles aux besoins de sociétés vieillissantes.

Certes, une action avisée ne saurait reposer sur la seule analyse des tendances passées. Et il est plus facile de prévoir le nombre d'élèves du primaire dans 10 ans que d'anticiper le prochain bouleversement technologique. Mais Les grandes mutations qui transforment l'éducation n'est pas une boule de cristal. Il offre simplement une série d'outils pour réfléchir davantage et de façon plus ouverte au monde changeant dans lequel l'éducation doit évoluer.

ISBN 9789264046634

\section{Recrutement éthique}

Les personnels de santé dans les pays de l'OECD : comment répondre à la crise imminente?

A lors que le monde en développement a un besoin urgent de millions de professionnels de santé pour les seuls soins de base, beaucoup de médecins quittent les pays pauvres. Comment alors expliquer le manque criant de médecins et d'infirmières dans les pays riches, s'interroge ce rapport de l'OCDE. Rien qu'aux États-Unis, plus de 250000

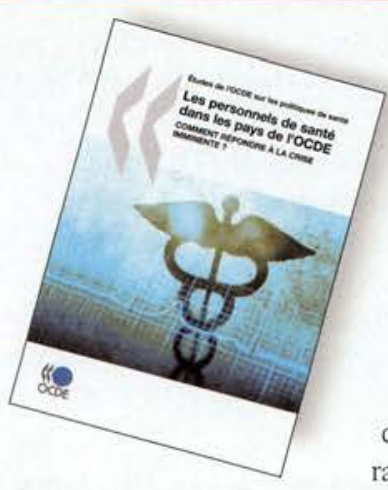

On peut aussi se pencher sur la situation des professinonnels de santé existants : salaires et lieux de travail, départs en retraite différés, et primes à la productivité, par exemple en liant l'augmentation des salaires aux performances ou en investissant dans les technologies de l'information.

Il y a ensuite la délicate question du recrutement de professionnels étrangers. D'ores et déjà, selon le rapport, près des trois quarts des médecins et deux tiers des infirmiers nés à l'étranger sont originaires professionnels de santé publics supplémentaires seront nécessaires ces 10 prochaines années.

Publié en collaboration avec l'OMS, ce rapport rend compte d'un projet de deux ans sur les interactions entre baisse des effectifs de santé et migrations internationales croissantes. Il s'intéresse à la demande mondiale de professionnels de santé, marquée par une concurrence féroce entre pays recruteurs. Et la pénurie devrait encore s'aggraver.

Comment les pays de l'OCDE pourront-ils faire face à cette demande? La réponse la plus efficace est bien sûr de former plus de personnel, mais cela ne suffira pas. Malgré une augmentation des étudiants dans le secteurs de la santé ces 10 dernières années, les pays industrialisés comptaient moins de diplômés en 2005 qu'en 1985.

de pays non membres de l'OCDE. LOMS prévient : la pénurie de personnel médical qualifié dans les pays pauvres menace les Objectifs de développement du millénaire tels que la réduction du VIH et de la malaria et l'amélioration de la santé des femmes et des soins contraceptifs. Selon l'Oxfam, il y a un médecin pour 100000 personnes dans les pays les plus pauvres du monde, contre 3 pour 100 dans les pays de l'OCDE.

Les personnels de santé dans les pays de l'OCDE souligne que les individus ont le droit de chercher des opportunités partout dans le monde, mais appelle à des codes de conduites internationaux sur le recrutement, l'accueil d'étudiants étrangers en médecine bénéfique pour les deux pays, et le renforcement des systèmes de santé dans les pays en développement.

ISBN 9789264050433 


\section{Nouvelles publications de I'OCDE}

\section{Maintenant disponibles via www.SourceOCDE.org}

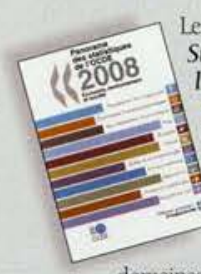

Le Panorama des Statistiques 2008 de l'OCDE est une publication statistique annuelle très complete de TOOCDE. Plus de 100 indicateurs couvrent un tres grand nombre de

domaines, avec cette année pour thème spécial la productivité. Chaque indicateur est présenté sur deux pages comprenant une définition, une évaluation des tendances à long terme, une bibliographie et des tableaux et graphiques qui illustrent les principaux enseignements à tirer des données. Statlink dirige le lecteur, pour chaque tableau, vers une page web où les données correspondantes son disponibles en format Excel@

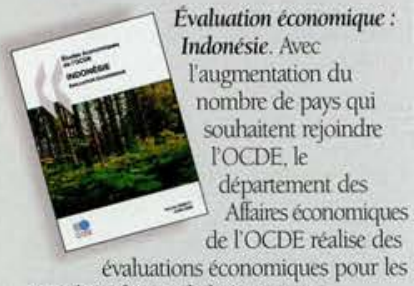
pays bénéficiant de l'engagement renforcé. Deux de ces évaluations, portant respectivement sur l'Indonésie et sur lAfrique du Sud, viennent d'être publiées.

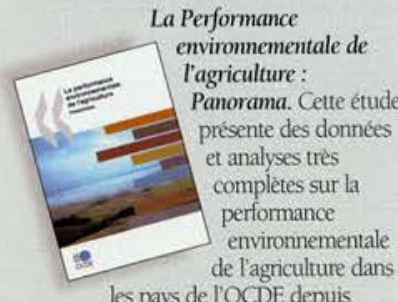
les pays de l'OCDE depuis 1990, notamment sur les sols, leau, Iair et la biodiversité, en passant en revue les faits récents intervenus dans les 30 pays membres.

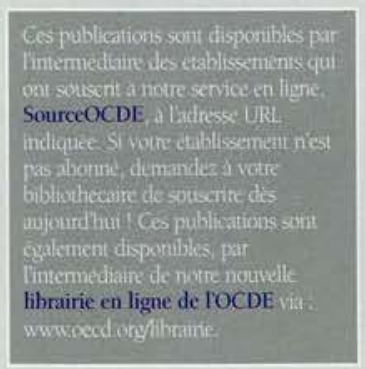

\section{ÉCONOMIE GÉNÉRALE}

Panorama des statistiques de l'OCDE 2008 : Économie, environnement et société 25-juil-2008, 300 pages, $€ 35 \$ 50 £ 25 \quad ¥ 4800$ www.SourceOCDE.org/9789264040557 Librairie en ligne : www.oecd.org/bookshop?9789264040557

Études économiques de l'OCDE : Allemagne

À paraître, 210 pages, $€ 52 \$ 72 £ 37 \quad ¥ 7800$ www.SourceOCDE.org/9789264043497 Librairie en ligne www.oecd.org/bookshop?9789264043497

Études économiques de l'OCDE : Canada 4-juil-2008, 188 pages, $€ 52 \quad \$ 72 \quad £ 37 \quad ¥ 7800$

www.SourceOCDE.org/9789264043954 Librairie en ligne

www.oecd.org/bookshop?9789264043954

Études économiques de l'OCDE :

Évaluation économique : Indonésie A paraitre, 148 pages, $€ 52 \quad \$ 72 £ 37 \quad ¥ 7800$ www.SourceOCDE.org/9789264049000 Librairie en ligne www.oecd.org/bookshop?9789264049000 4

Études économiques de l'OCDE : Japon À paraître, 168 pages, $€ 52 \quad \$ 72 \quad £ 37 \quad ¥ 7800$ www.SourceOCDE.org/9789264043084 Librairie en ligne www.oecd.org/bookshop?9789264043084

Études économiques de l'OCDE :

Évaluation économique : Afrique du Sud A paraitre, 161 pages, $€ 52 \quad \$ 72 \quad £ 37 ¥ 7800$ www.SourceOCDE.org/9789264047938 Librairie en ligne

www.oecd.org/bookshop?9789264047938

Études économiques de l'OCDE : Turquie A paraitre, 156 pages, $€ 52 \quad \$ 72 £ 37 ¥ 7800$ www.SourceOCDE.org/9789264046351
Librairie en ligne :

www.oecd.org/bookshop?9789264046351

\section{SANTÉ}

Les personnels de santé dans les pays de l'OCDE : Comment répondre à la crise imminente ?

13-oct-2008, 95 pages, $€ 24 \$ 29 £ 17 \quad ¥ 3300$ www.SourceOCDE.org/9789264050778 Librairie en ligne www.oecd.org/bookshop?9789264050778

\section{AGRICULTURE}

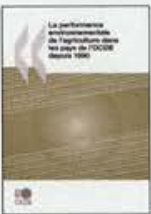

\section{La performance} environnementale de l'agriculture dans les pays de l'OCDE depuis 1990 29-août-2008, 660 pages, $€ 90 \quad \$ 126 \quad £ 64 \quad ¥ 12500$

www.SourceOCDE.org/9789264040939 Librairie en ligne :

www.oecd.org/bookshop?9789264040939

Perspectives agricoles de l'OCDE et de la FAO 2008-2017

3-sep-2008, 256 pages, $€ 80 \$ 124 £ 57 ¥ 11100$ www.SourceOCDE.org/9789264045927 Librairie en ligne : www.oecd.org/bookshop?9789264045927

Les politiques agricoles des pays de l'OCDE: Panorama 2008

15-sep-2008, 250 pages, $€ 24 \$ 32 £ 17 ¥ 3300$ www.SourceOCDE.org/9789264044654 Librairie en ligne : www.oecd.org/bookshop?9789264044654

\section{DÉVELOPPEMENT}

Perspectives économiques en Afrique 2007/2008 21-mai-2008, 727 pages, $€ 80 \quad \$ 124 £ 57 ¥ 11100$ www.SourceOCDE.org/9789264046436 Librairie en ligne www.oecd.org/bookshop?9789264046436 


\section{EMPLOI}

Perspectives de l'emploi de l'OCDE 2008

29-août-2008, 408 pages, $€ 80 \quad \$ 124 £ 57 \quad ¥ 11100$ www.SourceOCDE.org/9789264046344 Librairie en ligne :

www.oecd.org/bookshop?9789264046344

Jobs for Youth/Des emplois pour les jeunes : Canada

20-juin-2008, 191 pages, €29 \$44£20 ¥4000

www.SourceOECD.org/9789264046702

Librairie en ligne :

www.oecd.org/bookshop?9789264046702

Jobs for Youth/Des emplois pour les jeunes : United Kingdom

18-juil-2008, 169 pages, $€ 29 \$ 44 £ 20 ¥ 4000$

www.SourceOECD.org/9789264046467

Librairie en ligne :

www.oecd.org/bookshop?9789264046467

\section{ENERGIE}

Energy Technology Perspectives 2008

8-juil-2008, 650 pages, $€ 80 \$ 124 £ 57 ¥ 11100$

www.SourceOECD.org/9789264041431

Librairie en ligne :

www.oecd.org/bookshop?9789264041431

Disponible en anglais uniquement

Energy Policies of IEA Countries: Japan

19-juin-2008, 220 pages, $€ 75 \$ 105 £ 54 \quad ¥ 10400$

www.SourceOECD.org/9789264043350

Librairie en ligne :

www.oecd.org/bookshop/9789264043350

Disponible en anglais uniquement

$\mathrm{CO}_{2}$ Capture and Storage: A Key Carbon

Abatement Option

oct-2008, 400 pages, $€ 100 \$ 140 £ 72 \quad ¥ 13900$

SourceOECD:

www.SourceOECD.org/9789264041400

Librairie en ligne :

www.oecd.org/bookshop?9789264041400

Disponible en anglais uniquement

\section{ÉNERGIE NUCLÉAIRE}

Uranium 2007 : Ressources, production et demande

À paraittre, 444 pages, $€ 120 \$ 186$ f86 ¥16 600

www.SourceOCDE.org/9789264047709
Librairie en ligne :

www.oecd.org/bookshop?9789264047709

Disponible en anglais uniquement

Données sur l'énergie nucléaire 2008

25-juil-2008, 120 pages, $€ 35 \$ 53 £ 27 ¥ 5600$

SourceOECD:

www.SourceOECD.org/9789264047969

Librairie en ligne :

www.oecd.org/bookshop?9789264047969

Disponible en anglais uniquement

\section{ENVIRONNEMENT}

Aspects économiques de l'adaptation au changement climatique

20-juin-2008, 157 pages, $€ 30 \$ 46 £ 21 \quad ¥ 4100$

www.SourceOCDE.org/9789264046863

Librairie en ligne :

www.oecd.org/bookshop?9789264046863

Measuring Sustainable Production

10-avr-2008, 130 pages, $€ 35 \$ 49 £ 25 ¥ 4800$

www.SourceOECD.org/9789264044128

Librairie en ligne :

www.oecd.org/bookshop/9789264044128

Disponible en anglais uniquement

\section{FINANCE ET INVESTISSEMENT / ASSURANCE ET PENSIONS}

OECD Journal: Financial Market Trends No. 94, May 2008

2-juil-2008, 238 pages,

Abonnement 2008: $€ 270 \$ 361 \quad £ 183 \quad ¥ 44800$

www.SourceOECD.org/19952864

Librairie en ligne :

www.oecd.org/bookshop?19952805

International Investment Law: Understanding Concepts and Tracking Innovations

4-avr-2008, 344 pages, €95 \$133 £68 ¥13 200

www.SourceOECD.org/9789264042025

Librairie en ligne :

www.oecd.org/bookshop?9789264042025

Disponible en anglais uniquement

Corruption : Glossaire des normes pénales internationales

1-mai-2008, 104 pages, $€ 24 \$ 29 £ 17 ¥ 3300$

www.SourceOCDE.org/9789264044029

Librairie en ligne

www.oecd.org/bookshop?9789264044029

\begin{abstract}
Selon l'édition 2008 des
Perspectives de l'emploi de l'OCDE, la

discrimination sur le

marché du travail reste

un problème lancinant

dans les pays de

1OCDE. Les femmes

ont $20 \%$ moins de

chances d'exercer un emplo

rémunéré que les hommes, et

perçoivent un salaire inférieur de $17 \%$

en moyenne. Les pratiques

discriminatoires sur le marché du travail

expliquent au moins $30 \%$ de l'écan de

salaires et $8 \%$ de l'écart de taux

d'emploi. Cette publication propose des

solutions pour y remédier.
\end{abstract}

Les jeunes qui quittent

l'école sans

qualifications ont du

mal a trouver un

emploi et à se lancer

sur le marché du

travail, ce qui peut

les pénaliser

durablement dans

leur vie. Cette série de

rapports Jobs for Youth/Des emplois

pour les jeunes consacrés aux emplois

pour les jeunes dans les pays de

IOCDE préconise des solutions

pratiques pour remédier à ce problème.

Ce numéro de la

publication semestrielle

de l'OCDE Financial

Market Trends vient a

point nommé puisqu'i

est consacré à la crise

financière actuelle et

contient des articles

sur la crise des

crédits hypothécaires a risque,

les systèmes d'assurance-dépóts et de

garantie financière, ainsi que les fonds

souverains, autant de questions qui sont

au cour de lactualité.

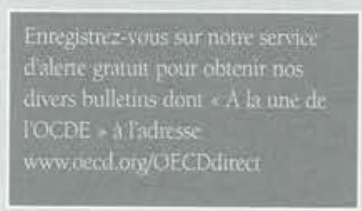




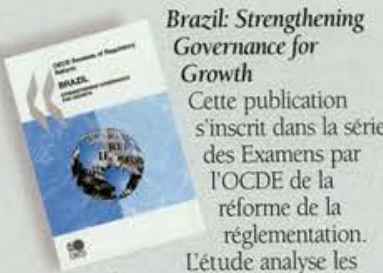

défis que pose le renforcement de la gouvernance réglementaire au Brésil afin de soutenir la croissance économique, en mettant en place les cadres réglementaires adéquats pour les principaux secteurs d'infrastructure. Au Brésil, le débat sur l'économie de marché est aujourd'hui entré dans une nouvelle phase, et porte sur les questions plus larges de la qualité de la réglementation et de la réduction du risque réglementaire. Lamélionation de la situation macroéconomique et les progres accomplis par les organismes de réglementation sectoriels ont porté leurs fruits, tandis que la societé participe davantage à l'amélioration du cadre réglementaire, avec une implication plus forte des consommateurs. Néanmoins, le Brésil doit encore renforcer ses capacités à produire une réglementation de qualité, accroitre la transparence et la responsabilité au sein du système afin d'améliorer la performance de la réglementation.

Disponible en anglais uniquement

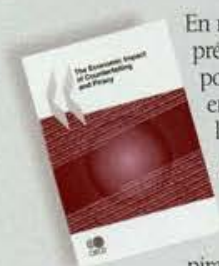

En réponse aux préoccupations des pouvoirs publics et des entreprises, lOCDE a lancé en 2005 un projet visant à évaluer limporrance et lincidence de la contrefaçon et du piratage. The Economic

Impact of Counterfeiting and Privacy présente les résultats de ce projet en se concentrant sur six secteurs l'audiovisuel, lautomobile, les composants électriques, les produits alimentaires et les boissons, les produits pharmaceutiques et le tabac.

Disponible en anglais uniquement

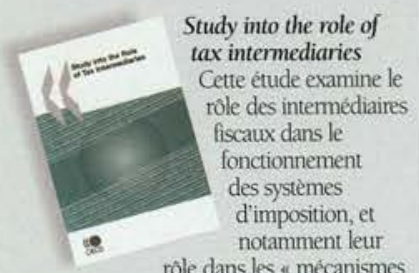

rôle dans les « mécanismes

inacceptables de réduction de

limposition *. En outre, ce rapport

répertonie les stratégies mises en ceuvre

afin de renforcer la relation entre ces

intermédiaires et les administrations

fiscales.

Disponible en anglais uniquement

\section{GOUVERNANCE}

Brazil: Strengthening Governance for Growth 6-juin-2008, 333 pages, $€ 45 \$ 63 \quad £ 32 \quad ¥ 6200$ www.SourceOECD.org/9789264042933 Librairie en ligne :

www.oecd.org/bookshop?9789264042933

Disponible en anglais uniquement

\section{4}

OECD Public Management Reviews: Ireland 6-juin-2008, 377 pages, $€ 60 \quad \$ 84 \quad £ 43 ¥ 8300$ www.SourceOECD.org/9789264043251 Librairie en ligne : www.oecd.org/bookshop?9789264043251

Disponible en anglais uniquement

Supprimer les obstacles à l'accès des PME aux marchés internationaux

A paraitre, 227 pages, $€ 45 \$ 58 £ 32 ¥ 6200$

www.SourceOCDE.org/9789264040250

Librairie en ligne :

www.oecd.org/bookshop?9789264040250

\section{INDUSTRIE}

Staying Competitive in the Global Economy:

Compendium of Studies on Global Value Chains 19-juin-2008, 252 pages, $€ 50 \quad \$ 77 £ 36 \quad ¥ 6900$ www.SourceOECD.org/9789264046306

Librairie en ligne

www.oecd.org/bookshop?9789264046306

Disponible en anglais uniquement

\section{SCIENCE ET TECHNOLOGIE}

Remaking the Movies: Digital Content and Evolution of the Film and Video Industries 15 -mai-2008, 135 pages, $€ 30 \$ 46 £ 21 ¥ 4100$ www.SourceOECD.org/9789264043299

Librairie en ligne :

www.oecd.org/bookshop?9789264043299

Disponible en anglais uniquement

The Economic Impact of Counterfeiting and Piracy

8-juil-2008, 399 pages, $€ 80 \$ \$ 124 £ 57 \quad ¥ 11100$

www.SourceOECD.org/9789264045514

Librairie en ligne

www.oecd.org/bookshop?9789264045514

Disponible en anglais uniquement

\section{TRANSPORTS}

Pétrole et transports : La fin des carburants à prix abordable ?

6-juin-2008, 232 pages, $€ 75 \$ 116$ £54 ¥10 400

www.SourceOCDE.org/9789282102510

Librairie en ligne

www.oecd.org/bookshop?9789282102510

Évolution des transports : 1970-2006

17 -juin-2008, 80 pages, $€ 24 \$ 37 £ 17 ¥ 3300$

www.SourceOCDE.org/9789282112649

Librairie en ligne

www.oecd.org/bookshop?9789282112649
BASES DE DONNÉES MISES À JOUR RÉCEMMENT

Principaux indicateurs économiques www.SourceOCDE.org/16081234

Statistiques mensuelles du commerce international

www.SourceOCDE.org/16081226

Comptes nationaux

www.SourceOCDE.org/16081188

Statistiques du commerce international par produit

www.SourceOCDE.org/16081218

\section{A PARAITTRE}

Études économiques de l'OCDE 2008 : Norvège et Luxembourg

Politiques de la biodiversité : Impacts socioéconomiques, enjeux et stratégies d'action des pouvoirs publics

Les partenariats public-privé : Partager les risques et optimiser les ressources

Stockage définitif des déchets de haute activité : Calendrier de mise en œuvre

Disponible en anglais uniquement :

Business for Development 2008: Promoting Commercial Agriculture in Africa

Multifunctionality in Agriculture: Evaluating the degree of jointness, policy implications

Deploying Renewables: Principles for Effective Policies

OECD Rural Policy Reviews: Netherlands

\section{DERNIÈRES SYNTHEESES}

Publications gratuites en ligne sur www.oecd.org/publications/syntheses

Études économiques de l'OCDE : Allemagne, Canada, Finlande, Irlande, Japon, Luxembourg Norvège, Pologne, Portugal, République tchèque, Turquie ; Évaluations économiques de l'Afrique du sud et de l'Indonésie

Agriculture : améliorer la cohérence des politiques au service du développement

Le futur de l'économie Internet

Mettre fin aux discriminations en matière d'emploi

Limpact social de linvestissement direct étranger

Le droit et la politique de la concurrence en Ukraine

Evvaluer la qualité de la réglementation Budget et performances : guide de l'utilisateur Faire des échanges un vecteur de développement

Évaluer la qualité de la réglementation 


\section{Sélection sur la fiscalité}

\section{CONVENTIONS ET PRINCIPES}

Modèle de convention fiscale concernant le revenu et la fortune: Version abrégée, Juillet 2008 À paraitre, 450 pages, $€ 60 \$ 92 £ 46 ¥ 9600$ www.SourceOCDE.org/9789264048201 Librairie en ligne :

www.oecd.org/bookshop?9789264048201

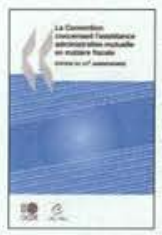

La Convention concernant l'assistance administrative mutuelle en matière fiscale : Édition du 20 ème anniversaire 23-avr-2008, 139 pages, $€ 24 \$ 29 £ 17 ¥ 3300$ wwwSourceOCDE.org/9789264041059

Librairie en ligne :

www.oecd.org/bookshop?9789264041059

Principes applicables en matière de prix de transfert à l'intention des entreprises multinationales et des administrations fiscales : Édition de poche

18-juin-2001, 284 pages, $€ 52 \quad \$ 68 £ 32 ¥ 4900$ www.SourceOCDE.org/9789264286283

Librairie en ligne :

www.oecd.org/bookshop?9789264286283

\section{ANALYSE FISCALE}

Study into the Role of Tax Intermediaries 18-mar-2008, 92 pages, $€ 24 \$ 29 £ 17 ¥ 3300$ www.SourceOECD.org/9789264041790 Librairie en ligne :

www.oecd.org/bookshop?9789264041790

Disponible en anglais uniquement

Effets de la fiscalité sur l'investissement direct étranger : Données récentes et analyse des politiques

À paraître, 201 pages, $€ 50 \quad \$ 70 £ 36 ¥ 6900$

www.SourceOCDE.org/9789264038394

Librairie en ligne:

www.oecd.org/bookshop?9789264038394

Réforme fondamentale de l'impôt sur les bénéfices des sociétés

À paraître, 194 pages, $€ 45 \$ 63 £ 32 ¥ 6200$

www.SourceOCDE.org/9789264038134

Librairie en ligne :

www.oecd.org/bookshop? 9789264038134
Coopération fiscale 2007 : Vers l'établissement de règles du jeu équitables : Évaluation par le Forum mondial sur la fiscalité

4-août-2008, 231 pages, $€ 60, \$ 78, £ 43, ¥ 8300$

www.sourceocde.org/9789264039049

Librairie en ligne :

www.oecd.org/bookshop?9789264039049

Encourager l'épargne grâce à des comptes à régime fiscal préférentiel

A paraitre, 150 pages, $€ 30 \$ 40 £ 21 ¥ 4100$

www.SourceOCDE.org/9789264031371

Librairie en ligne :

www.oecd.org/bookshop?9789264031371

L'imposition des gains en capital des personnes physiques : Enjeux et méthodes

24-sep-2008, 206 pages, $€ 40 \$ 54 £ 28 \quad ¥ 5500$

www.SourceOCDE.org/9789264029514

Librairie en ligne :

www.oecd.org/bookshop?9789264029514

\section{STATISTIQUES SUR LA FISCALITÉ}

Les impôts sur les salaires 2006-2007

Étude spéciale : Réformes fiscales et pressions fiscales 2000-2006

23-avr-2008, 510 pages,

$€ 120 \$ 168$ f86 ¥16 600

www.SourceOCDE.org/9789264042124

Librairie en ligne :

www.oecd.org/bookshop?9789264042124

Statistiques des recettes publiques 1965-2006

24-oct-2007, 345 pages,

$€ 120 \$ 156$ £86 ¥16 600

www.SourceOECD.org/9789264038349

Librairie en ligne :

www.oecd.org/bookshop?9789264038349

Consumption Tax Trends: VAT/GST and Excise Rates, Trends and Administration Issues, 2006 Edition

16-juin-2006, 121 pages, $€ 40 \$ 50 £ 27 ¥ 5500$

www.SourceOECD.org/9789264014176

Librairie en ligne :

www.oecd.org/bookshop?9789264014176

Disponible en anglais uniquement

\section{À LA UNE}

Les travaux de lOCDE dans le domaine de la fiscalité ont toujours été un volet important des activités d'ensemble de l'Organisation, contribuant ainsi à établir des normes pour la communauté fiscale internationale. Par exemple le Modèle de Convention fiscale de l'OCDE constitue depuis longtemps le fondement des conventions fiscales adoptées par les pays, et les Principes applicables en matière de prix de transfert de 1995 ont largement inspiré la législation fiscale des pays de lOCDE et d'un nombre croissant d'économies non membres. Le centre de Politique et d'administration fiscales de l'OCDE constitue le point de convergence des travaux de l'Organisation dans

le domaine fiscal. Le centre

examine tous les aspects de la fiscalité autres que la politique budgétaire générale. Ses activités englobent les questions fiscales nationales et internationales, les impôts directs et indirects, la politique et l'administration fiscales. Les publications statistiques du centre fournissent des comparaisons annuelles des niveaux et des structures dimposition dans les pays membres.

Le Modèle de
Convention
fiscale de
l'OCDE fête
son $50^{\mathrm{e} e}$ e
anniversaire ! A
cette occasion,
l'OCDE publie
une nouvelle
version abrégée
contenant les mises a jour
approuvées en juillet 2008 (version
francaise à paraître). Les mises à
jour des versions électronique et
sous forme de feuillets mobiles
seront bientôt annoncées.




\section{Nemo-technique}

Dictionnaire multilingue des poissons et produits de la pêche

$\mathrm{V}$ ous êtes dans un restaurant européen et souhaitez manger du saumon. Vous commanderez sans hésiter du salmone en Italie, du salmao au Portugal, ou encore du solomós en Grèce. Et un Allemand (lachs) commandera sans peine du laks en Norvège, du lax en Suède ou du lox dans un restaurant yiddish. Mais confronté aux termes yeono (coréen), som balı̆g (turc), sake mau-rui (japonais) ou losos (croate), un dictionnaire des poissons lui serait bien utile.

Bien sûr, avec plus de 360 pages, la 5ème édition du Dictionnaire multilingue des poissons et produits de pêches de l'OCDE, parue récemment, n'est pas un guide de poche. C'est un outil indispensable sur les marchés internationaux, destiné à promouvoir et faciliter les échanges de poissons et produits de pêche, en fournissant une liste complète des produits commercialisés dans le monde.

Le dictionnaire commence avec alpricken, "petite anguille vidée, frite et conservée dans de l'huile comestible ", fabriquée en Allemagne et se termine avec le poisson d'eau douce européeen zanthe, également connu sous le nom de vimpa en Finlande, strandslabbi en Islande et certa en Pologne.
On apprend également que yakiboshi est le nom donné par les Japonnais aux poissons " séchés après avoir été bouillis ou grillés (...) vidés et fixés sur des pousses de bambou ; (...) Yakiboshi est habituellement suivi du nom du poisson employé. Ainsi, yakiboshi

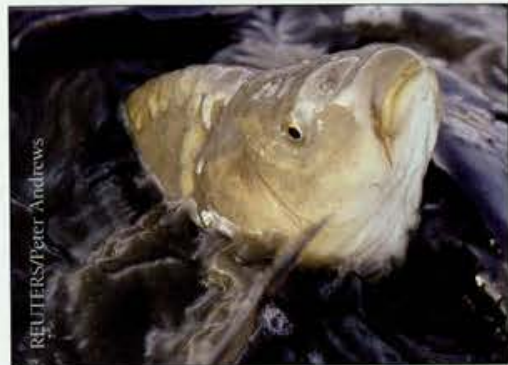

Rappelez-moi votre nom ? ayu est fait à base du poisson d'eau douce ayu, yakiboshi iwashi est fait lui à partir de sardine ou d'anchois. *

Si les noms de poissons differrent entre les pays et les régions, plusieurs termes peuvent aussi exister dans une même langue. Les termes pomfret/butterfish et pickerel/pike désignent le même poisson en Europe et en Amérique du Nord, tout comme perch/sea et bream/porgy. Par exemple, le modeste loup français, catfish au Royaume-Uni, y est aussi désigné rock turbot, rock salmon, sea cat, sea wolf, sand scar ou swine. Rockfish est néanmoins le terme recommandé pour le commerce.

Le coréen a été ajouté à cette édition, qui fournit aussi un index dans les 21 langues utilisées, ainsi qu'un index des noms scientifiques.

ISBN 9789264039896

\section{BON DE COMMANDE}

Abonnez-vous à LObservateur de l'OCDE Tarif spécial pour deux ans disponible sur www.observateurocde.org/abonnement.html

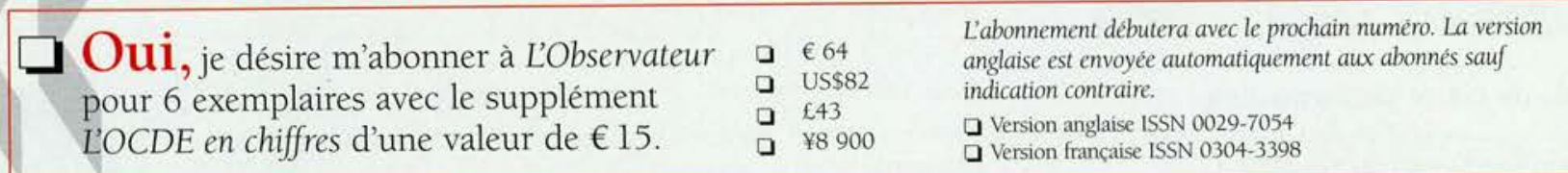

Commandez vos publications en ligne: www.ocdelibrairie.org, ou demandez les nouvelles publications qui vous intéressent dans cette section a l'une des adresses ci-dessous. Où effectuer la livraison ?

Nom

Organisation

Profession

Adresse,

Code postal

Ville

Règlement

$\square$ Chèque/Mandat postal ci-joint (à l'ordre de lOCDE)

口 Veuillez débiter ma carte de crédit VISAMMasterCard/American Express

TOTAL A PAYER

$\mathrm{N}^{\circ}$ de carte

Date d'expiration

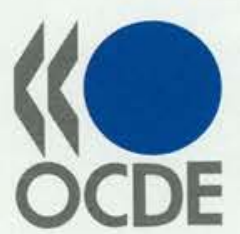

Pour les États-Unis

Turpin Distribution

The Bleachery

143 West Street, New Milford

Connecticut 06776 USA

Tel: (1) 8004566323

Tel: (1) 8004566323

Fax: (1)

oecdna@turpin-distribution.com
Pays

Téléphone.

Fax

E-mail

Date
Pour le reste du monde

Turpin Distribution Services Ltd

Stratton Business Park

Pegasus Drive, Biggleswade

Bedfordshire SG18 8QB, UK

Tel: (44) 1767604960

Fax: (44) 1767604640

E-mail:

oecdrow@extenza-turpin.com 

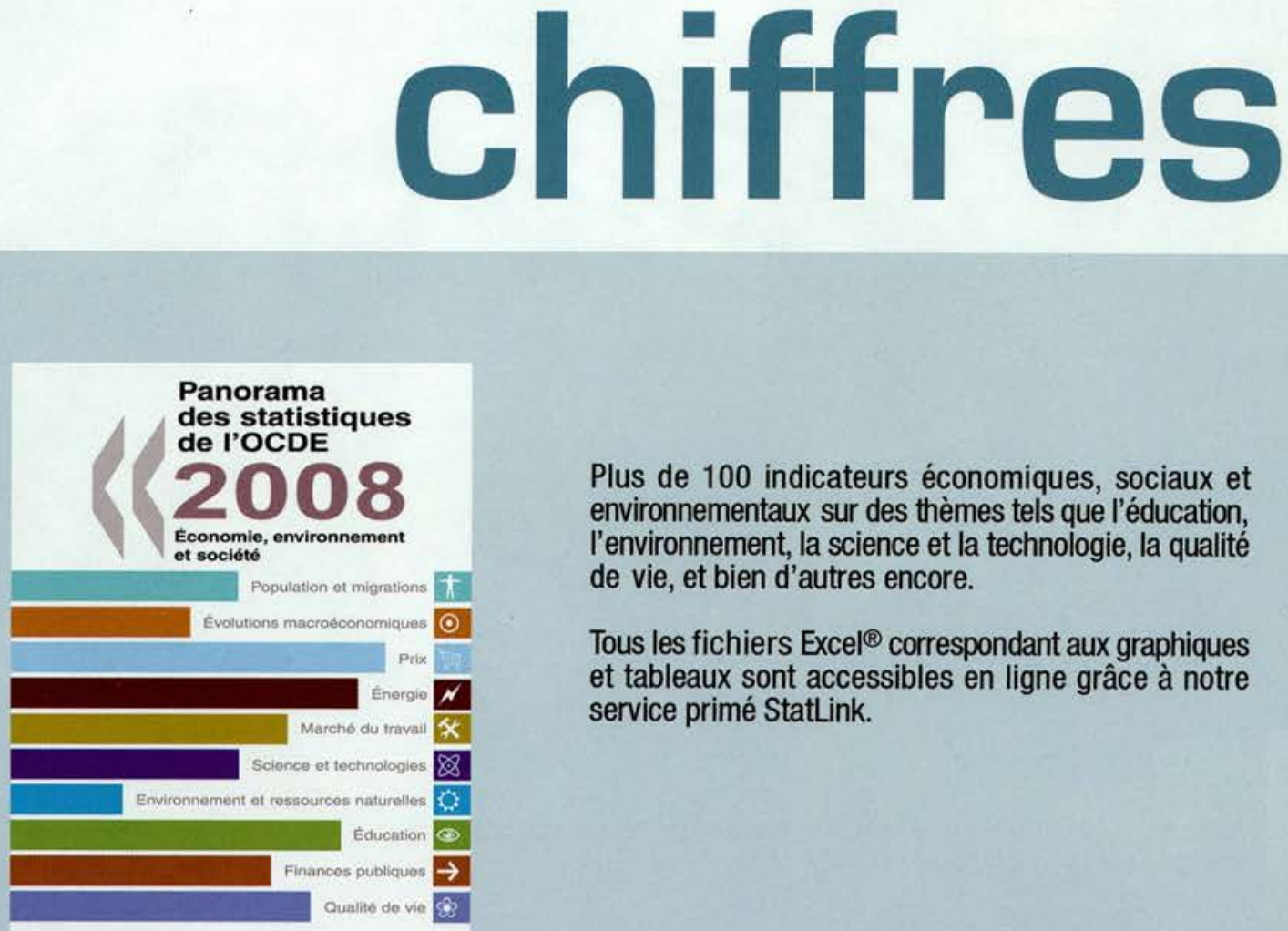

Plus de 100 indicateurs économiques, sociaux et environnementaux sur des thèmes tels que l'éducation, l'environnement, la science et la technologie, la qualité de vie, et bien d'autres encore.

Tous les fichiers Excel ${ }^{\circledR}$ correspondant aux graphiques et tableaux sont accessibles en ligne grâce à notre service primé StatLink.

\section{« Essentiel »}

\section{Choice magazine}

«Idéal pour les étudiants en économie »

\section{L'Expansion}

«Les données sont accompagnées d'analyses explicatives et de graphiques faciles à comprendre, qui permettent d'établir des comparaisons claires entre pays. ”

Publi News

\section{PANORAMA DES STATISTIOUES DE L'OCDE}

POUR PLUS D'INFORMATION : www.oecd.org/publications/panoramastats Www.www.oecd.org/enchiffres COMMANDEZ VOTRE EXEMPLAIRE

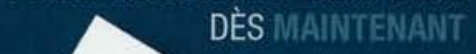

\section{Et aussi, L'OCDE en chiffres 2007}

Depuis 1988

Publié en français et en anglais observer@oecd.org

www.oecd.org/enchiffres

Prix: $15 € 20$ USD $10 £ 2000 ¥$

Offert pour un abonnement à L'Observateur de l'OCDE :

ISSN 03043398 ; sales@oecd.org

Disponible sur www.oecd.org/librairie
Format de poche! 


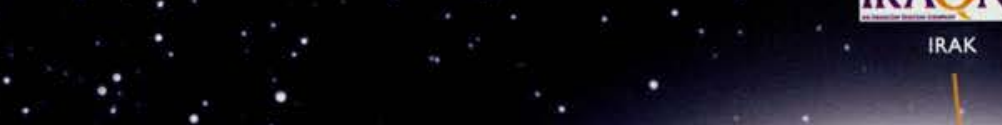

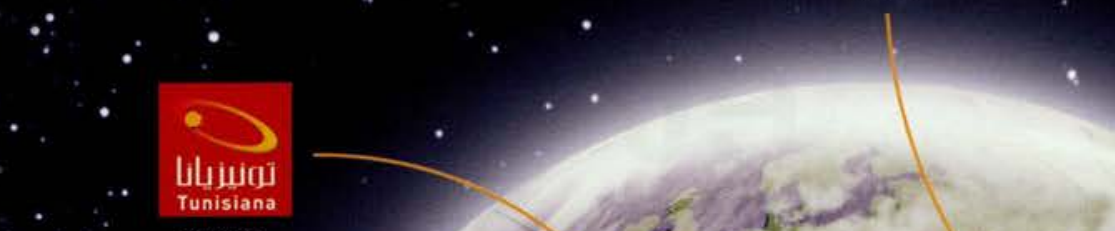

Tunisian

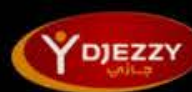

ALGÉRIE

愈

Aujourd'hui, Orascom Telecom est présent dans sept pays et permet à 51 millions de personnes de faire entendre et de partager leurs espoirs, leurs craintes, leurs ambitions et leurs sentiments. Chaque jour, notre grande famille de plus de 20000 employés s'assure que ces voix soient entendues partout dans le monde.

Pour les millions de personnes qui n'ont pas encore cette chance, nous arrivons. 


\section{Santé économique?}

$\mathrm{L}^{\prime}$ industrie pharmaceutique occupe une place importante dans léconomie de la zone OCDE, comme en témoignent les dépenses élevées en produits pharmaceutiques. Elles ont en effet atteint 569 milliards de dollars en 2005 (patients hospitalisés non compris).

Tandis que la France et l'Espagne ont été les plus gros consommateurs de produits pharmaceutiques par habitant en volume, les États-Unis ont réalise les plus grosses dépenses, avec 235 milliards de dollars, soit plus de $40 \%$ du total de lOCDE; ils sont suivis du Japon avec 71 milliards de dollars. La France a dépensé quant à elle 39 milliards de dollars, et l'Espagne 21 milliards.

Depuis les années 1990, la croissance moyenne des dépenses pharmaceutiques était de 5,6\% par an, un rythme bien supérieur à celui des dépenses totales de santé sur la même période, à 4,2\% par an, tandis que la croissance annuelle du PIB était de $3 \%$.

Ramenées au nombre d'habitants, ce sont les Etats-Unis qui ont connu les plus grosses dépenses, à 792 dollars par habitant, mais de nombreux pays de l'OCDE ont un niveau de dépenses comparable, autour de 400-600

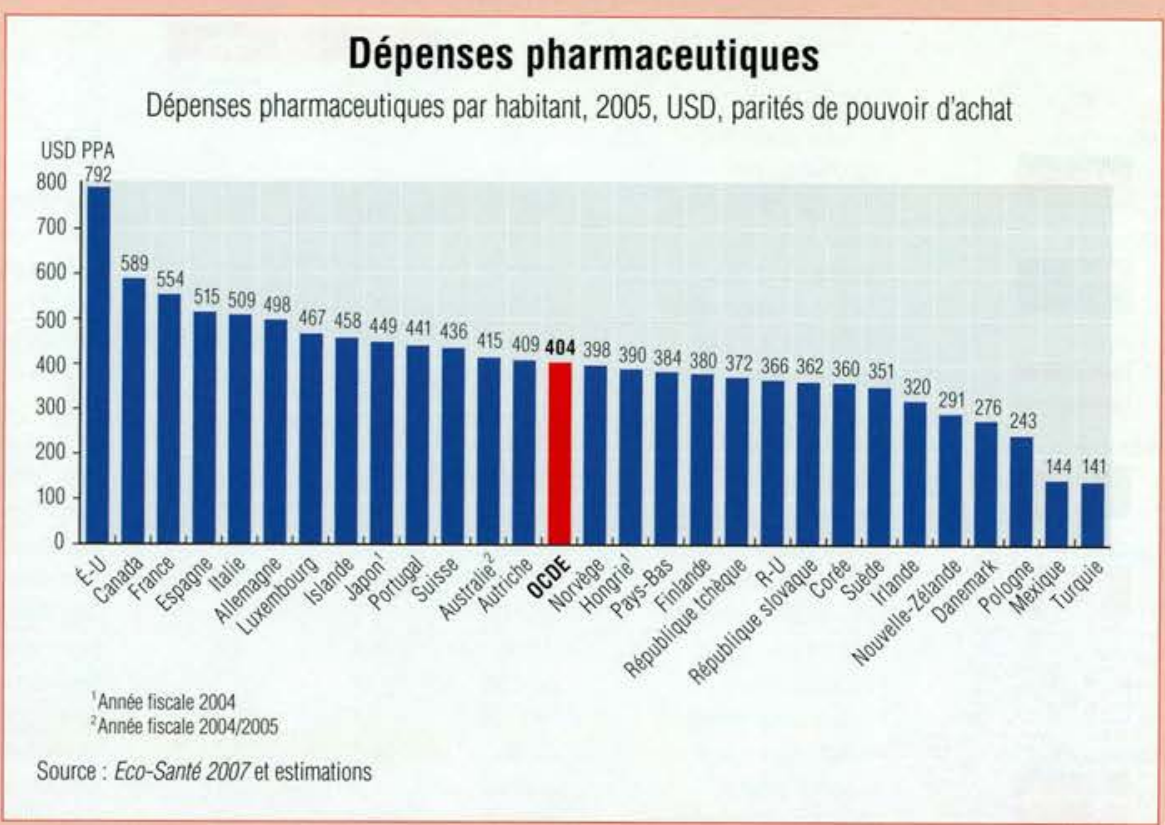

dollars par habitant. Cela dit, au Mexique, ce chiffre était de 144 dollars, soit seulement $18 \%$ du niveau américain, et 100 dollars de moins qu'en Pologne. Le chiffre de 141 dollars en Turquie a été calculé sur la base des prix des produits manufacturés, qui peut conduire à sous-estimer la dépense finale.

Ces chiffres proviennent d'un nouveau rapport de l'OCDE, qui compare les niveaux des prix pour évaluer comment les politiques de prix pharmaceutiques et de remboursement ont contribué à atteindre les objectifs de santé, comprenant disponibilité, accessibilité et innovation.

Les prix des médicaments sur un marché global : Politiques et enjeux sera prochainement disponible sur www.oecd.org/librairie

\section{Hausse des prix}

L' inflation des prix à la consommation s'est accrue dans de nombreux pays pour la première fois depuis plusieurs années. Selon L'OCDE en chiffres 2008 , nouvellement paru, lindice des prix à la consommation énergétique a suivi de près celui des prix à la consommation autre qu'énergétique et alimentaire pendant une vingtaine d'années, mais a bondi beaucoup plus nettement depuis 2003. Lindice des prix du fuel, de l'électricité et du carburant a bondi de $68 \%$ de mi-2003 à mi-2008, contre $32 \%$ sur les cinq années avant fin 1992, et $24 \%$ de 1998 à 2002. (Le prix des marchandises a néanmoins diminué depuis aout 2008.)

La hausse des prix à la consommation est restée modeste dans la zone OCDE prise dans son ensemble. La hausse mensuelle moyenne des prix a ralenti par rapport au pic d'environ $0,5 \%$ par mois en 1987-92, à 0,3\% en 19982003 , et à $0,2 \%$ dans la période ayant précédé 2006. De fait, selon LOCDE en chiffres, depuis 2000 , il y a eu 20 mois pendant lesquels les prix n'ont pas du tout augmenté ! Mais la hausse globale des prix a atteint $0,6 \%$ au printemps 2008.

Mi-2008, linflation moyenne dans l'OCDE a atteint $4,4 \%$, le Japon en ayant le moins pâti, avec $2 \%$ de hausse annuelle de l'indice des prix à la consommation, contrairement à l'Islande, avec $12 \%$ de hausse pour le même mois.

LOCDE en chiffres, édition spéciale 20 ème anniversaire, est gratuite pour les abonnés à LObservateur de l'OCDE. Il peut être commandé séparément sur www.oecd.org/librairie.

\section{Inflation}

Indices des prix à la consommation juillet $2008 ; 2000=100$

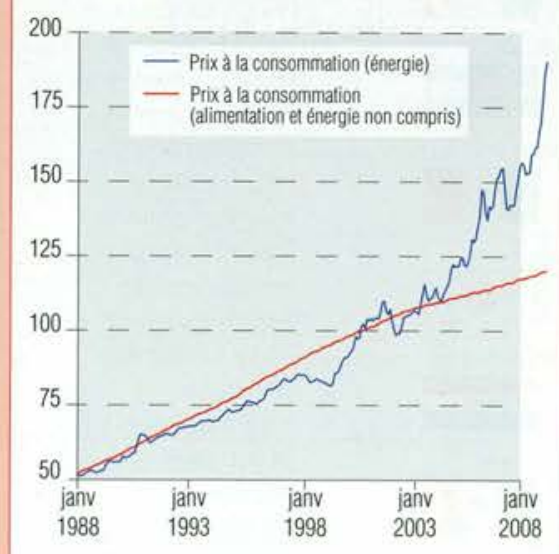

Source : L'OCDE en chiffres 2008

StatLink anss http://dx.doi.org/10.1787/468585546260 


\section{Indicateurs}

\begin{tabular}{|c|c|c|c|c|c|c|c|c|}
\hline & & & \multicolumn{2}{|c|}{ Variation (\%) par rapport a : } & & & \multicolumn{2}{|c|}{ Niveau: } \\
\hline & & & $\begin{array}{c}\text { période } \\
\text { précédente }\end{array}$ & $\begin{array}{c}\text { année } \\
\text { précédente }\end{array}$ & & & $\begin{array}{c}\text { valeur } \\
\text { courante }\end{array}$ & $\begin{array}{l}\text { mème période } \\
\text { année précedente }\end{array}$ \\
\hline \multirow[t]{3}{*}{ Allemagne } & Produit intérieur brut & T208 & $-0,5$ & 1,7 & Balance courante & T2 08 & 71,01 & 62,30 \\
\hline & Indicateur avancé & août 08 & $-2,0$ & $-7,6$ & Taux de chômage & août 08 & 7,20 & 8,30 \\
\hline & Prix à la consommation & août 08 & $-0,3$ & 3,1 & Taux d'intérêt & & $\cdot$ & $*$ \\
\hline \multirow{3}{*}{ Australie } & Produit intérieur brut & T208 & 0,3 & 2,7 & Balance courante & T2 08 & $-12,05$ & $-13,61$ \\
\hline & Indicateur avancé & août 08 & 0,0 & $-3,4$ & Taux de chômage & août 08 & 4,10 & 4,30 \\
\hline & Prix à la consommation & $\mathrm{T} 208$ & 1,5 & 4,5 & Taux d'intérêt & août 08 & 7,31 & 6,75 \\
\hline \multirow[t]{3}{*}{ Autriche } & Produit intérieur brut & T208 & 0,4 & 2,2 & Balance courante & T2 08 & 3,02 & 2,95 \\
\hline & Indicateur avancé & août 08 & $-0,9$ & $-6,6$ & Taux de chômage & août 08 & 3,30 & 4,70 \\
\hline & Prix à la consommation & août 08 & $-0,2$ & 3,7 & Taux d'intérêt & & * & . \\
\hline \multirow[t]{3}{*}{ Belgique } & Produit intérieur brut & T2 08 & 0,2 & 1,9 & Balance courante & T2 08 & $-10,85$ & 1,41 \\
\hline & Indicateur avancé & août 08 & $-1,3$ & $-5,3$ & Taux de chômage & août 08 & 6,60 & 7,30 \\
\hline & Prix à la consommation & sept. 08 & 0,2 & 5,5 & Taux d'intérêt & & 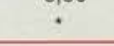 & $\cdot$ \\
\hline \multirow[t]{3}{*}{ Canada } & Produit intérieur brut & $\mathrm{T} 208$ & 0,1 & 0,7 & Balance courante & T2 08 & 6,69 & 6,49 \\
\hline & Indicateur avancé & août 08 & $-1,5$ & $-4,7$ & Taux de chômage & août 08 & 6,10 & 6,00 \\
\hline & Prix à la consommation & août 08 & $-0,2$ & 3,5 & Taux d'intérêt & sept. 08 & 3,29 & 5,11 \\
\hline \multirow[t]{3}{*}{ Corée } & Produit intérieur brut & T2 08 & 0,8 & 4,8 & Balance courante & août 08 & $-4,82$ & 1,75 \\
\hline & Indicateur avancé & août 08 & 0,8 & 1,0 & Taux de chômage & août 08 & 3,20 & 3,20 \\
\hline & Prix à la consommation & sept. 08 & 0,1 & 5,1 & Taux d'intérêt & sept. 08 & 5,79 & 5,34 \\
\hline \multirow[t]{3}{*}{ Danemark } & Produit intérieur brut & T2 08 & 0,4 & 1,0 & Balance courant & T2 08 & 1,57 & 1,40 \\
\hline & Indicateur avancé & août 08 & $-1,9$ & $-10,1$ & Taux de chômage & août 08 & 2,90 & 3,80 \\
\hline & Prix à la consommation & août 08 & 0,2 & 4,3 & Taux d'intérêt & sept. 08 & 5,03 & 4,60 \\
\hline \multirow[t]{3}{*}{ Espagne } & Produit intérieur brut & T2 08 & 0,1 & 1,8 & Balance courante & juill. 08 & $-10,13$ & $-12,67$ \\
\hline & Indicateur avancé & août 08 & 0,2 & $-7,0$ & Taux de chômage & août 08 & 11,30 & 8,30 \\
\hline & Prix à la consommation & août 08 & $-0,2$ & 4,9 & Taux d'intérêt & & $\cdot$ & . \\
\hline \multirow{3}{*}{ 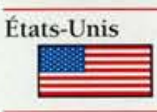 } & Produit intérieur brut & T2 08 & 0,7 & 2,1 & Balance courante & T2 08 & $-183,15$ & $-194,09$ \\
\hline & Indicateur avancé & août 08 & $-0,5$ & $-5,3$ & Taux de chômage & sept. 08 & 6,10 & 4,70 \\
\hline & Prix à la consommation & août 08 & $-0,4$ & 5,4 & Taux d'intérêt & août 08 & 2,79 & 5,49 \\
\hline \multirow[t]{3}{*}{ Finlande } & Produit intérieur brut & T2 08 & 0,8 & 2,4 & Balance courante & juin 08 & 1,79 & 0,92 \\
\hline & Indicateur avancé & août 08 & $-0,5$ & $-4,1$ & Taux de chômage & août 08 & 6,30 & 6,80 \\
\hline & Prix à la consommation & août 08 & 0,4 & 4,7 & Taux d'intérêt & & $\cdot$ & $\cdot$ \\
\hline \multirow[t]{3}{*}{ France } & Produit intérieur brut & T2 08 & $-0,3$ & 1,1 & Balance courante & juill. 08 & $-6,03$ & $-2,60$ \\
\hline & Indicateur avancé & août 08 & $-0,8$ & $-5,6$ & Taux de chômage & août 08 & 8,00 & 8,20 \\
\hline & Prix à la consommation & août 08 & 0,0 & 3,2 & Taux d'intérêt & & $\cdot$ & $\cdot$ \\
\hline & Produit intérieur brut & T2 08 & 0,8 & 3,5 & Balance courante & juill. 08 & $-4,70$ & $-4,12$ \\
\hline F & Indicateur avancé & août 08 & $-0,5$ & $-4,4$ & Taux de chômage & juin 08 & 7,50 & 8,40 \\
\hline & Prix à la consommation & sept. 08 & 2,0 & 4,6 & Taux d'intérêt & & $\cdot$ & ${ }^{\star}$ \\
\hline Hong & Produit intérieur brut & T208 & 0,6 & 1,7 & Balance courante & T2 08 & $-2,64$ & $-1,83$ \\
\hline & Indicateur avancé & août 08 & $-1,0$ & $-1,6$ & Taux de chômage & août 08 & 7,90 & 7,40 \\
\hline & Prix à la consommation & août 08 & $-0,3$ & 6,5 & Taux d'intérêt & sept. 08 & 8,62 & 7,44 \\
\hline Irlande & Produit intérieur brut & T2 08 & $-0,5$ & $-0,7$ & Balance courante & T2 08 & $-3,43$ & $-2,36$ \\
\hline & Indicateur avancé & avr. 08 & $-1,2$ & $-13,1$ & Taux de chômage & août 08 & 6,20 & 4,50 \\
\hline & Prix à la consommation & août 08 & 0,5 & 4,3 & Taux d'intérêt & & $\cdot$ & $\cdot$ \\
\hline Islande & Produit intérieur brut & T2 08 & 4,9 & 4,9 & Balance courante & T2 08 & $-1,79$ & $-0,87$ \\
\hline & Indicateur avancé & & .. & .. & Taux de chômage & août 08 & 1,30 & 0,90 \\
\hline & Prix à la consommation & août 08 & 1,2 & 14,5 & Taux d'intérêt & fév. 08 & 19,00 & 16,52 \\
\hline Italie & Produit intérieur brut & T208 & $-0,3$ & $-0,1$ & Balance courante & avr. 08 & $-4,31$ & $-4,84$ \\
\hline & Indicateur avancé & août 08 & $-0,8$ & $-5,9$ & Taux de chômage & juin 08 & 6,80 & 6,00 \\
\hline & Prix à la consommation & sept. 08 & $-0,3$ & 3,8 & Taux d'intérêt & & . & $\cdot$ \\
\hline Japon & Produit intérieur brut & T2 08 & $-0,7$ & 0,8 & Balance courante & juill. 08 & 14,56 & 15,40 \\
\hline & Indicateur avancé & août 08 & $-0,9$ & $-2,8$ & Taux de chômage & août 08 & 4,10 & 3,80 \\
\hline & Prix à la consommation & août 08 & 0,3 & 2,1 & Taux d'intérêt & août 08 & 0,75 & 0,74 \\
\hline Luxembourg & Produit intérieur brut & $\mathrm{T} 108$ & 1,3 & 2,5 & Balance courante & T2 08 & 1,07 & 0,96 \\
\hline & Indicateur avancé & août 08 & $-3,2$ & $-12,6$ & Taux de chômage & août 08 & 4,20 & 4,10 \\
\hline & Prix à la consommation & sept. 08 & 0,1 & 4,0 & Taux d'intérêt & & $\cdot$ & $*$ \\
\hline Mexique & Produit intérieur brut & T208 & 0,2 & 2,1 & Balance courante & T2 08 & $-3,24$ & $-2,63$ \\
\hline & Indicateur avancé & juill. 08 & 2,3 & 3,1 & Taux de chômage & août 08 & 3,80 & 3,60 \\
\hline & Prix à la consommation & août 08 & 0,6 & 5,6 & Taux d'intérêt & sept. 08 & 8,32 & 7,36 \\
\hline Norvège & Produit intérieur brut & T2 08 & 0,6 & 3,3 & Balance courante & T208 & 24,69 & 13,41 \\
\hline ঘ亡 & Indicateur avancé & août 08 & $-0,1$ & $-5,2$ & Taux de chômage & juill. 08 & 2,40 & 2,50 \\
\hline 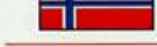 & Prix à la consommation & août 08 & 0,1 & 4,5 & Taux d'intérêt & sept. 08 & 6,82 & 5,51 \\
\hline
\end{tabular}




\begin{tabular}{|c|c|c|c|c|c|c|c|c|}
\hline & & & \multicolumn{2}{|c|}{ Variation (\%) par rapport a : } & & & \multicolumn{2}{|c|}{ Niveau: } \\
\hline & & & $\begin{array}{c}\text { période } \\
\text { précedente }\end{array}$ & $\begin{array}{c}\text { année } \\
\text { précédente }\end{array}$ & & & $\begin{array}{c}\text { valeur } \\
\text { courante }\end{array}$ & $\begin{array}{l}\text { mème période } \\
\text { année préédente }\end{array}$ \\
\hline \multirow{3}{*}{ Nouvelle-Zélande } & Produit intérieur brut & T2 08 & $-0,5$ & $-0,3$ & Balance courante & T2 08 & $-3,59$ & $-2,73$ \\
\hline & Indicateur avancé & août 08 & 1,5 & $-2,7$ & Taux de chômage & T2 08 & 3,90 & 3,60 \\
\hline & Prix à la consommation & $\mathrm{T} 208$ & 1,6 & 4,0 & Taux d'intérêt & sept. 08 & 7,95 & 8,81 \\
\hline \multirow[t]{3}{*}{ Pays-Bas } & Produit intérieur brut & T2 08 & 0,1 & 3,0 & Balance courante & T2 08 & 15,88 & 13,26 \\
\hline & Indicateur avancé & août 08 & $-0,9$ & $-4,1$ & Taux de chômage & août 08 & 2,60 & 3,10 \\
\hline & Prix à la consommation & sept. 08 & 0,4 & 3,1 & Taux d'intérêt & & . & $\cdot$ \\
\hline \multirow{3}{*}{ Pologne } & Produit intérieur brut & T208 & 1,5 & 6,1 & Balance courante & juill. 08 & $-1,82$ & $-1,61$ \\
\hline & Indicateur avancé & août 08 & $-1,2$ & $-10,6$ & Taux de chômage & août 08 & 6,70 & 9,20 \\
\hline & Prix à la consommation & août 08 & $-0,4$ & 4,8 & Taux d'intẻrêt & sept. 08 & 6,63 & 5,01 \\
\hline \multirow[t]{3}{*}{ Portugal } & Produit intérieur brut & T208 & 0,3 & 0,7 & Balance courante & juin 08 & $-2,59$ & $-1,60$ \\
\hline & Indicateur avancé & août 08 & $-0,3$ & $-5,3$ & Taux de chômage & août 08 & 7,50 & 8,10 \\
\hline & Prix à la consommation & août 08 & $-0,5$ & 3,0 & Taux d'intérêt & & $\cdot$ & $\cdot$ \\
\hline \multirow{3}{*}{ République slovaque } & Produit intérieur brut & T2 08 & 1,9 & 8,0 & Balance courante & T2 08 & $-2,34$ & $-1,04$ \\
\hline & Indicateur avancé & août 08 & 0,5 & $-1,7$ & Taux de chômage & août 08 & 9,90 & 11,20 \\
\hline & Prix à la consommation & août 08 & 0,2 & 5,0 & Taux d'intérêt & août 08 & 4,03 & 4,07 \\
\hline \multirow{3}{*}{ République tchèque } & Produit intérieur brut & T2 08 & 0,9 & 4,6 & Balance courante & T2 08 & $-2,67$ & $-0,83$ \\
\hline & Indicateur avancé & août 08 & $-0,8$ & $-3,0$ & Taux de chômage & août 08 & 4,30 & 5,10 \\
\hline & Prix à la consommation & août 08 & $-0,1$ & 6,4 & Taux d'intérêt & sept. 08 & 3,81 & 3,46 \\
\hline \multirow{3}{*}{ Royaume-Uni } & Produit intérieur brut & T2 08 & 0,0 & 1,5 & Balance courante & T208 & $-21,59$ & $-24,65$ \\
\hline & Indicateur avancé & août 08 & $-1,1$ & $-6,1$ & Taux de chômage & juin 08 & 5,40 & 5,30 \\
\hline & Prix à la consommation & août 08 & 0,6 & 4,7 & Taux d'intérêt & sept. 08 & 5,87 & 6,58 \\
\hline \multirow[t]{3}{*}{ Suède } & Produit intérieur brut & T2 08 & 0,0 & 0,9 & Balance courante & T208 & 7.66 & 8,39 \\
\hline & Indicateur avancé & août 08 & 0,4 & $-7,3$ & Taux de chômage & août 08 & 5,80 & 5,90 \\
\hline & Prix à la consommation & sept. 08 & 1.0 & 4,4 & Taux d'intérêt & sept. 08 & 4,49 & 3,62 \\
\hline \multirow[t]{3}{*}{ Suisse } & Produit intérieur brut & T208 & 0,4 & 2.4 & Balance courante & T2 08 & 11,25 & 17,97 \\
\hline & Indicateur avancé & août 08 & $-1,2$ & $-6,1$ & Taux de chômage & T2 08 & 3,50 & 3,70 \\
\hline & Prix à la consommation & sept. 08 & 0,1 & 2,9 & Taux d'intérêt & sept. 08 & 2,96 & 2,79 \\
\hline \multirow{3}{*}{$\begin{array}{l}\text { Turquie } \\
\qquad C^{*}\end{array}$} & Produit intérieur brut & T208 & $-2,4$ & 2,1 & Balance courante & T208 & $-12,91$ & $-8,22$ \\
\hline & Indicateur avancé & août 08 & $-0,9$ & $-5,8$ & Taux de chômage & juin 08 & 9,00 & 8,80 \\
\hline & Prix à la consommation & sept. 08 & 0,5 & 11,1 & Taux d'intérêt & avr. 08 & 16,65 & 17,86 \\
\hline \multirow{3}{*}{ Zone euro } & Produit intérieur brut & T4 07 & 0,4 & 2,2 & Balance courante & juill. 08 & $-2,68$ & 6,50 \\
\hline & Indicateur avancé & août 08 & $-1,0$ & $-6,4$ & Taux de chômage & août 08 & 7,50 & 7,40 \\
\hline & Prix à la consommation & août 08 & $-0,1$ & 3,8 & Taux d'intérêt & sept. 08 & 5,02 & 4,74 \\
\hline \multirow[t]{3}{*}{ Russie $^{1}$} & Produit intérieur brut & $\mathrm{T} 108$ & 1,0 & 8,7 & Balance courante & $\mathrm{T} 108$ & 34,63 & 19,33 \\
\hline & Indicateur avancé & août 08 & $-2,3$ & $-0,4$ & Taux de chômage & & 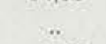 & .. \\
\hline & Prix à la consommation & août 08 & 0,3 & 15,0 & Taux d'intérêt & juill. 08 & 7.73 & 6,26 \\
\hline \multirow[t]{3}{*}{ Brésil $^{2}$} & Produit intérieur brut & T2 08 & 1,6 & 6,2 & Balance courante & $\mathrm{T} 108$ & $-8,88$ & 1,97 \\
\hline & Indicateur avancé & août 08 & 1,0 & 3,4 & Taux de chômage & & .. & .. \\
\hline & Prix à la consommation & août 08 & 0,3 & 6,2 & Taux d'intérêt & & .. &. \\
\hline \multirow{3}{*}{$\begin{array}{r}\text { Chine }^{2} \\
\star \\
\star\end{array}$} & Produit intérieur brut & & &.. & Balance courante & & .. & .. \\
\hline & Indicateur avancé & août 08 & $-0,7$ & $-3,1$ & Taux de chômage & & .. & .. \\
\hline & Prix à la consommation & & & .. & Taux d'intérêt & juill. 08 & 4,47 & 3,14 \\
\hline \multirow[t]{3}{*}{ Inde $^{2}$} & Produit intérieur brut & T2 08 & 0,5 & 8,1 & Balance courante & T1 08 & $-7,16$ & $-1,68$ \\
\hline & Indicateur avancé & juill. 08 & $-1,2$ & $-7,1$ & Taux de chômage & & .. & .. \\
\hline & Prix à la consommation & août 08 & 1,4 & 9,0 & Taux d'intérêt & & &.. \\
\hline \multirow[t]{3}{*}{ Indonésie $^{2}$} & Produit intérieur brut & $\mathrm{T} 108$ & 1,4 & 6,3 & Balance courante & T1 08 & 2,65 & 2,48 \\
\hline & Indicateur avancé & août 08 & $-1,5$ & 3,8 & Taux de chômage & &. & .. \\
\hline & Prix à la consommation & sept. 08 & 1,0 & 11,9 & Taux d'intérêt & août 08 & 8,40 & 7,51 \\
\hline Afrique du Sud ${ }^{2}$ & Produit intérieur brut & T2 08 & 1,2 & 4,2 & Balance courante & T1 08 & $-5,99$ & $-4,30$ \\
\hline & Indicateur avancé & août 08 & $-1,7$ & $-11,6$ & Taux de chômage & & .. &.. \\
\hline & Prix à la consommation & août 08 & 0,7 & 13,7 & Taux d'intérêt & août 08 & 11,37 & 9,13 \\
\hline
\end{tabular}

Définitions et notes :

Produit intérieur brut : Séries en volume ; corrigées des variations saisonnières. Indicateur avancé : Indice composite, basé sur différents indicateurs de l'activité économique qui signale les mouvements cycliques de ta production industrielle de six à neuf mois en avance. Indice des prix à la consommation : Mesure les variations dan e temps des prix de vente au détail d'un panier constant de hiens et cenvices. Balance courante : Millards de dollars E-U. - corigées des vatiations sasonn chômage standardisés ; définitions nationales pour l'Islande, le Mexique et la Turouie ; corrigées des variations saisonnières sauf pour la Turquie. Taux d'intérêt : Taux à trois mois, "voir zone euro.

$\therefore=$ données non disponibles.

'Candidat à l'adhésion à l'OCDE

2Programme d'engagement renforce

Source : Principaux indicateurs èconomiques, octobre 2008. 


\section{Retour du pic fiscal?}

T e Danemark demeure le pays de l'OCDE où la fiscalité est la plus lourde, suivi de la Suède, tandis qu'elle est la plus basse au Mexique et en Turquie, selon les dernières Statistiques des recettes publiques. Au Danemark, le taux d'imposition par rapport au PIB s'est élevé à $48,9 \%$ en 2007 , contre $23,7 \%$ en Turquie.

Dans l'ensemble, le taux de fiscalité moyen dans les 30 pays membres de l'OCDE - soit les recettes fiscales par rapport au PIB - est proche de son pic historique de $36 \%$ en 2000 . En 2006 , le rapport fiscalité/PIB est passé à $35,9 \%$, un point de pourcentage de plus qu'en 2005.

Les derniers chiffres indiquent une augmentation continue des recettes issues de la fiscalité des entreprises, ayant atteint une moyenne de 3,9\% du PIB en 2006, contre $3,7 \%$ en 2005 et $3,6 \%$ en 2000 . Selon l'OCDE, cette hausse devrait être enrayée du fait du

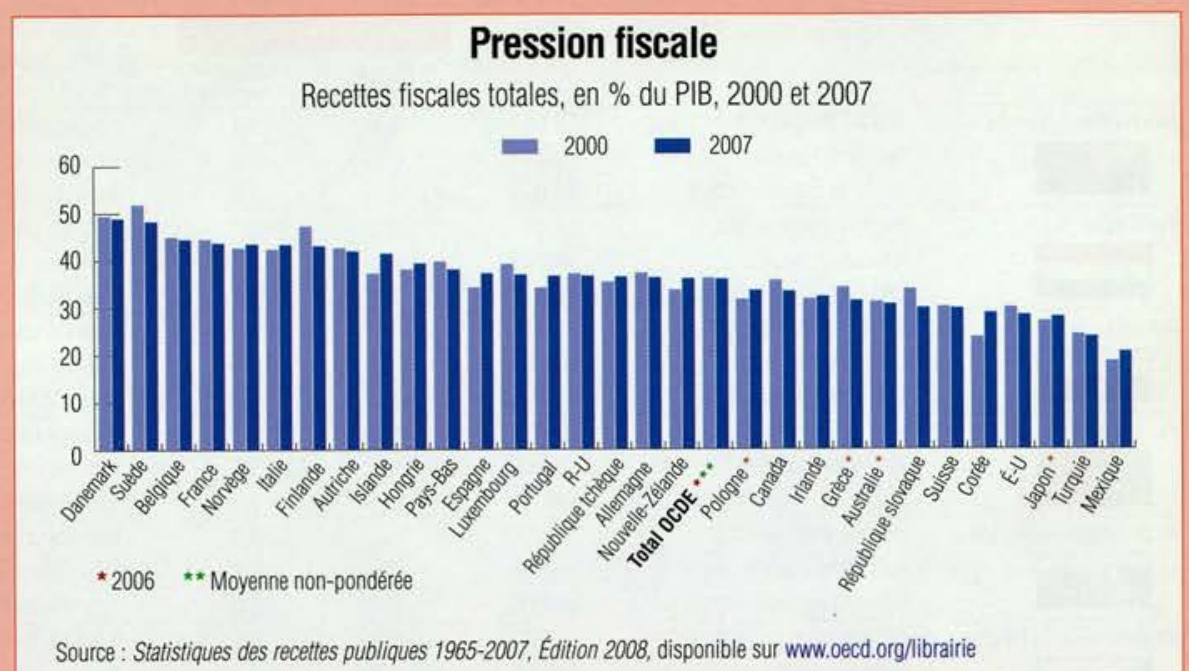

ralentissement économique, et certains pays revoient déjà à la baisse leurs prévisions de recettes fiscales issues du secteur financier.

En 2007, la fiscalité a augmenté dans 11 des 26 pays pour lesquels les chiffres provisoires sont disponibles, et a diminué dans 13 autres. La Hongrie a connu la plus forte hausse annuelle, passant de $37,1 \%$ en 2006 à $39,3 \%$ en 2007 , et la plus importante baisse a eu lieu aux Pays-Bas, d'un niveau estimé à $39,3 \%$ à $38 \%$.

\section{Demande de migrants peu qualifiés}

$\mathrm{T}$ andis que les pays de l'OCDE se concurrencent pour attirer des immigrants hautement qualifiés, les Perspectives des migrations internationales 2008 indiquent que les employeurs ont de plus en plus recours à des salariés peu qualifiés. Dans 21 pays de l'OCDE, en moyenne $1 / 5^{\text {eme }}$ des salariés peu qualifiés sont nés à l'étranger, tandis que la moyenne de l'UE à 25 est de $14,1 \%$.

Le Luxembourg connait la plus forte proportion de travailleurs nés à l'étranger, lesquels représentent plus de la moitié ( $52 \%$ ) de la main-d'œuvre peu qualifiée. La Suisse et les États-Unis suivent, avec respectivement $43 \%$ et $38,7 \%$. Les immigrants représentent plus d'un quart de la main-d'œuvre peu qualifiée en Allemagne et en Autriche.

Dans presque tous les pays étudiés, la proportion d'immigrants parmi la main-d'œuvre peu qualifiée a augmenté depuis 1995, même

\section{Tendance à la hausse}

\% de personnes nées à l'étranger parmi les salariés peu qualifiés, 1995-2006

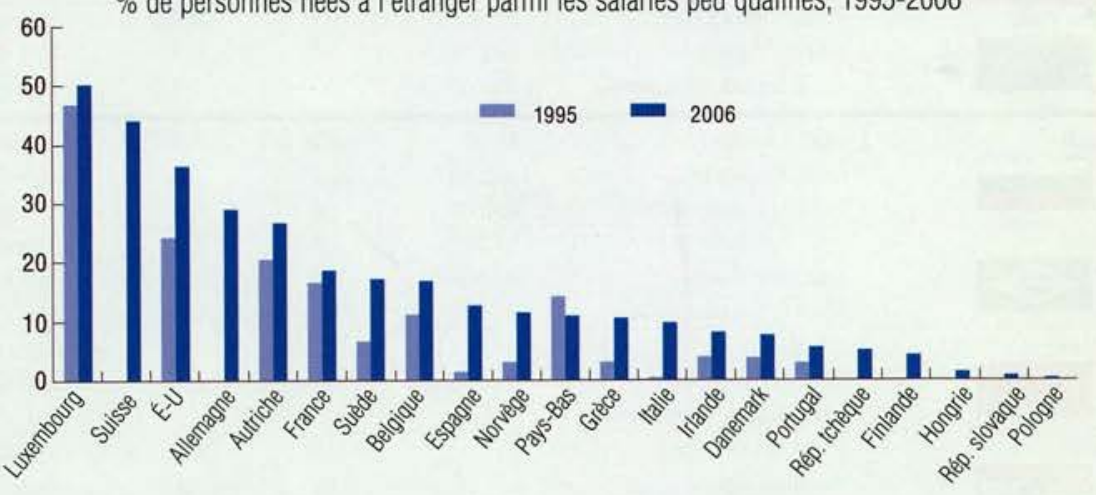

Source : Perspectives des migrations internationales, SOPEMI 2008 StatLink mansa http://dx.doi.org/10.1787/436305130626

dans les pays limitant l'entrée d'immigrants peu qualifiés. En Espagne, leur proportion a été multipliée par six depuis 1995, atteignant $12,4 \%$ en 2006. La Grèce et la Norvège ont également connu d'importantes augmentations, et comptent désormais plus de $10 \%$ de main-d'œuvre peu qualifiée née à l'étranger.

Selon les auteurs du rapport, des secteurs tels que les métiers de l'alimentation, la pêche et lagriculture, les soins aux personnes et l'aide à domicile, ainsi que la construction et les transports, ont particulièrement recours aux immigrés peu qualifiés. D'autre part, les métiers peu qualifiés devraient augmenter au cours des 10 prochaines années, en partie du fait du vieillissement de la main-d'œuvre, selon le rapport.

Commander Perspectives des migrations internationales 2008 sur www.oecd.org/librairie, ISBN 978-92-64-04569-9 


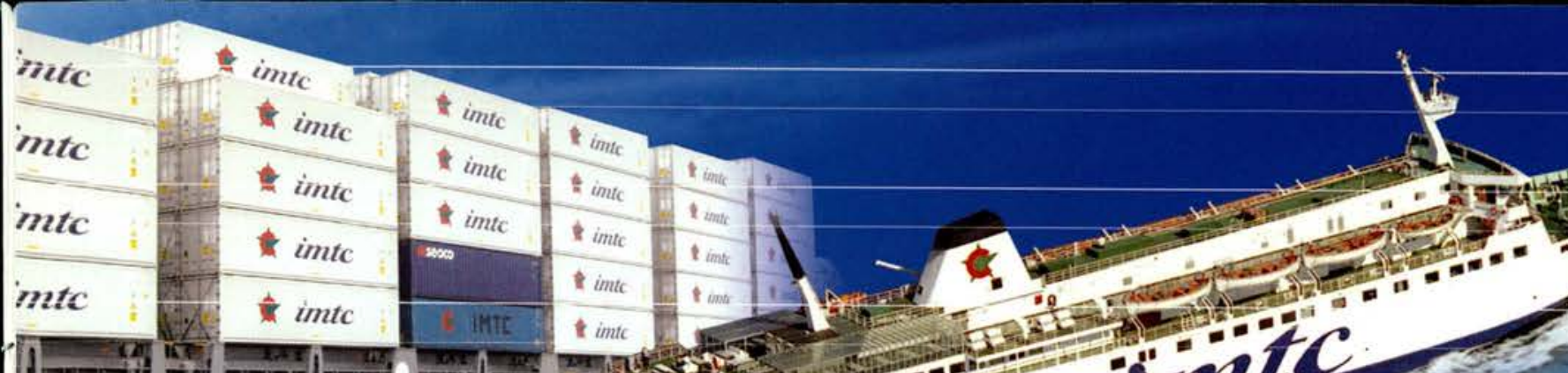

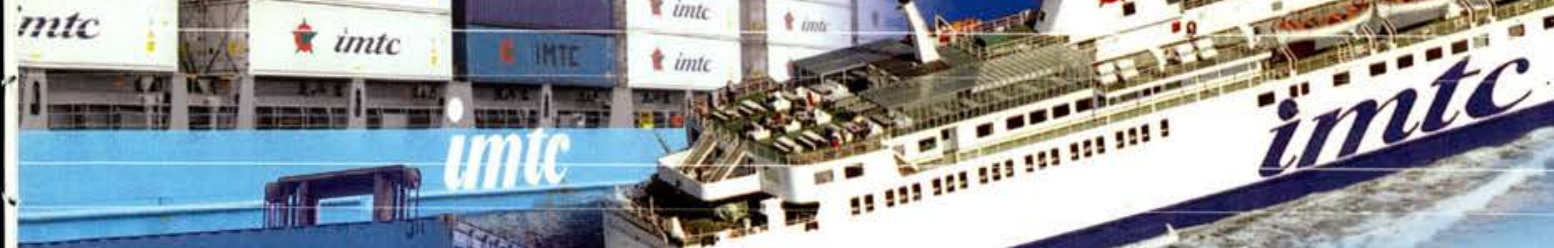

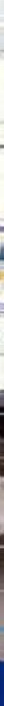

\section{IMTC Group}

20 ans de proximité

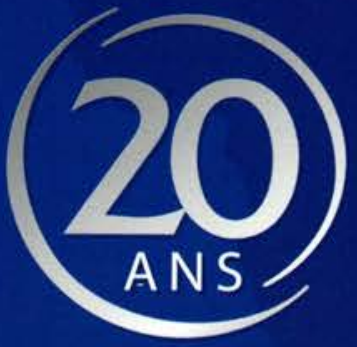




\section{Réduction des émissions de carbonne.}

Les nouvelles tecticacite énergétique. Haute performance. Le climat est favorable aux trains.

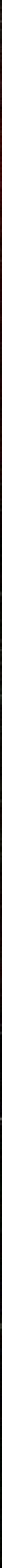

